\title{
LONG-TERM SUPPLY CURVES FOR GEOTHERMAL ENERGY - THE IMPACTS OF TECHNOLOGY
}

L. L. Fassbender

C.H. Bloomster

January 1980

Prepared for

the U.S. Department of Energy under Contract EY-76-C-06-1830

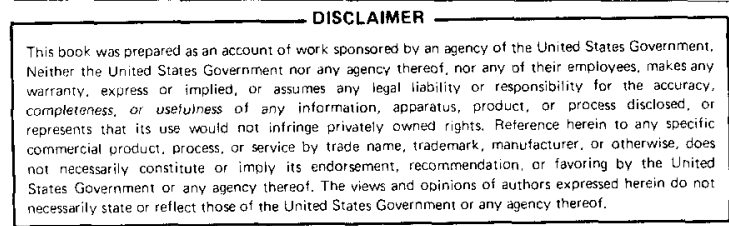

Pacific Northwest Laboratory Richland, Washington 99352 


\section{DISCLAIMER}

This report was prepared as an account of work sponsored by an agency of the United States Government. Neither the United States Government nor any agency Thereof, nor any of their employees, makes any warranty, express or implied, or assumes any legal liability or responsibility for the accuracy, completeness, or usefulness of any information, apparatus, product, or process disclosed, or represents that its use would not infringe privately owned rights. Reference herein to any specific commercial product, process, or service by trade name, trademark, manufacturer, or otherwise does not necessarily constitute or imply its endorsement, recommendation, or favoring by the United States Government or any agency thereof. The views and opinions of authors expressed herein do not necessarily state or reflect those of the United States Government or any agency thereof. 
SUMMARY

INTRODUCTION

FIGURES

TABLES

NEAR-TERM SUPPLY CURVE

LONG-TERM SUPPLY CURVES .

SURFACE EXPLORATION TECHNOLOGY

10

DRILLING AND COMPLETIONS TECHNOLOGY . . . . . . . . . . . . . . . . . . 14

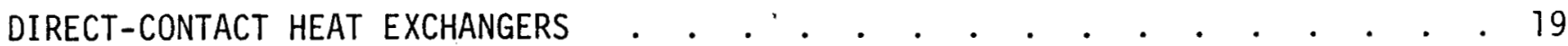

DOWNHOLE PUMPS . . . . . . . . . . . . . . . . . . . . . . 24

FLUTED-TUBE CONDENSERS . . . . . . . . . . . . . . . . . . . . . . . . . 29

RESERVOIR ENGINEERING - RESERVOIR VERIFICATION . . . • . • . . . . . . . 33

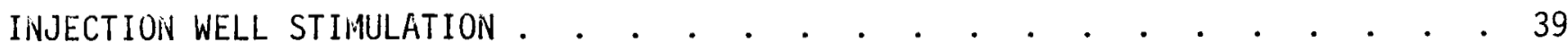

POLYGER COINCRETE . . . . . . . . . . . . . . . . . . . . . . . . . 47

SAINPLING AND MONITORING INSTRUMENTATION AND CONTROL EQUIPMENT . . • . . . . 52

GEOTHERIAL WELL CEMENTS . . . . . . . . . . . . . . . . . . . . 58

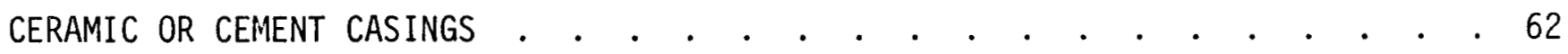

COMBINED IMPACTS OF ALL PROGRAMS . . . . . . . . . . . . . . . . . . . . 66

STEAM CYCLE TECHNOLOGIES . . . . . . . . . . . . . . . . . . . . . 73

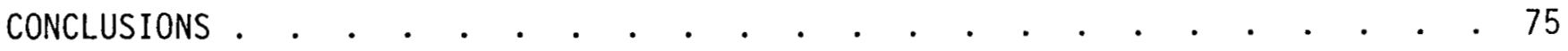

ACKNOWLEDGMENTS . . . . . . . . . . . . . . . . . . . . . 76

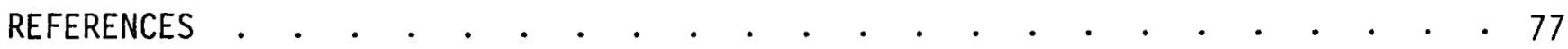




\section{SUMMARY}

Through a combination of significant technological advances currently being pursued by DOE, most of the identified hydrothermal resources could become competitive with conventional energy sources for electric power production by 1985 . More specifically, about 4,500 MWe centuries (equivalent to 15,000 MWe for 30 years) may be competitive with oil by 1985; about 2,800 MWe centuries (or 9,300 MWe for 30 years) may be competitive with nuclear and coal.

This report presents near-term and long-term supply curves for electric applications of geothermal energy. It is a sequel to a previous report $(1)$ where we first developed the near-term supply curve. We used the GEOCOST model ${ }^{(2)}$ to determine the present and future energy production costs for the high-temperature and intermediatetemperature hydrothermal resources identified by the U.S.G.S. in Circular $790^{(3)}$.

The long-term supply curves illustrate the potential shifts in the near-term supply curve which would result from certain technology improvements currently being pursued under DOE funding. Programs with the most significant potential impacts are those which result in large reductions in drilling cost, those which lead to development of commercial high capacity downhole pumps, and those which lead to large increases in the plant capacity factor. Curves were drawn to show the impacts of individual technology improvements and also to show the cumulative impacts of combinations of technological advances expected to be achieved by 1982 and 1985 . Successful completion of all the programs which we evaluated would result in a cumulative cost reduction of $\$ 90$ billion (not discounted) in electrical generating costs from the identified hydrothermal resources. 
INTRODUCTION

The purpose of this report is to develop long-term supply curves for electrical applications of geothermal energy through determining the impacts of new technology on the production cost and availability of geothermal resources. In a previous report $(1)$ we developed the near-term supply curve based on current state-ofthe-art technology. Our approach here is to quantify the technical objectives of the R\&D programs funded by the Division of Geothermal Energy (DGE), and then to determine the impacts of successful completion of these programs on the near-term supply curve. The results are applied to evaluating the effectiveness of the RaD programs, singly and in combination, in increasing the commercial potential of geothermal energy.

To derive the supply curves, we used the GEOCOST model ${ }^{(2)}$, which simulates the production of electricity from geothermal resources. GEOCOST has the advantages of providing internal consistency for comparative analysis of resources and technologies and of requiring all the assumptions used in the analysis to be made explicit.

The sensitivity of the cost of electricity production from hydrothermal resources to resource characteristics and other factors was described in a previous report ${ }^{(4)}$. The potential market penetration and accompanying savings in electrical generating costs using hydrothermal resources were estimated in an earlier report ${ }^{(5)}$.

Although we applied the analyses to only the identified hydrothermal resources, the technology improvements would also apply to undiscovered resources with similar characteristics. Besides the hydrothermal resources, many of the technology improvements would also apply to other geothermal resources, such as hot dry rock and geopressure, but these resources are outside the scope of this report. Some of the technology improvements would also apply to non-electric applications of hydrothermal resources, but these are also outside the scope of this report. 


\section{FIGURES}

1 Near-Term Supply Curve for Electric Applications of Hydrothermal

Resources

2 Near-Term Supply Curve for Electric Applications of Hydrothermal

3 Comparison of Near-Term Supply Curves Based on Circulars 790 and 726

Resources

4 Supply Curve for Surface Exploration Technology Program with Suc-

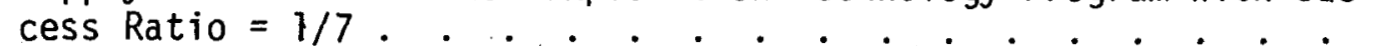

5 Supply Curve for Surface Exploration Technology Program with Success Ratio $=1 / 2$. . . . . . . . . . . . . . . . . . . . 12

6 Supply Curves for Surface Exploration Technology Program . . . . . 13

7 Supply Curve for Drilling and Completions Technology Program

(Base Case) . . . . . . . . . . . . . . .

8 Supply Curve for Drilling and Completions Technology Program (1982 Case)

9 Supply Curve for Drilling and Completions Technology Program (1985 Case)

10 Supply Curves for Drilling and Completions Technology Program . . . . 18

11 Supply Curve for Direct-Contact Heat Exchanger Program (Conventional She11-and-Tube Exchangers) . . . . . . . . .

12 Supply Curve for Direct-Contact Heat Exchanger Program (DirectContact Exchangers) • . . . . . . . . . . . . . . . . 22

13 Supply Curves for Direct-Contact Heat Exchanger Program . . . . . . 23

14 Supply Curve for Downhole Pump Program (Conventional Pumps) . . . . 26

15 Supply Curve for Downhole Pump Program (Advanced Pumps) . . . . . . 27

16 Supply Curves for Downhole Pump Program . . . . . . . . . . . 28

17 Supply Curve for Fluted-Tube Condenser Program (Conventional Condensers) . . . . . . . . . . . . . . . . . . . . 30

18 Supply Curve for Fluted-Tube Condenser Program (Fluted-Tube Condensers)

19 Supply Curves for Fluted-Tube Condenser Program . . . . . . . . 32 
20 Reservoir Engineering Program Objectives . . . . . . . . . . . 34

21 Supply Curve for Reservoir Engineering Program (Base Case) . . . . . 35

22 Supply Curve for Reservoir Engineering Program (1985 Case) . . . . . 36

23 Supply Curve for Reservoir Engineering Program (2000 Case) . . . . . 37

24 Supply Curve for Reservoir Engineering Program . . . . . . . . . 38

25 Supply Curve for Injection Well Stimulation Program (3-Year

Injection Well Life). . . . . . . . . . . . . . . . . . 41

26 Supply Curve for Injection Well Stimulation Program (4.5-Year

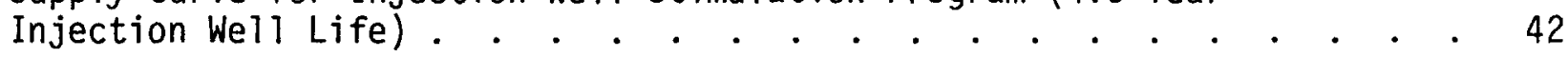

27 Supply Curves for Injection Well Stimulation Program . . . . . . . 43

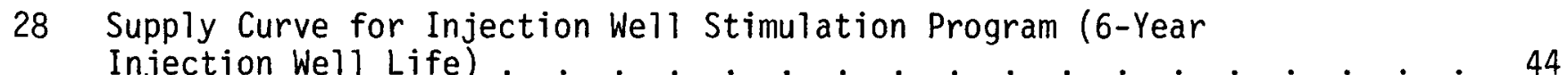

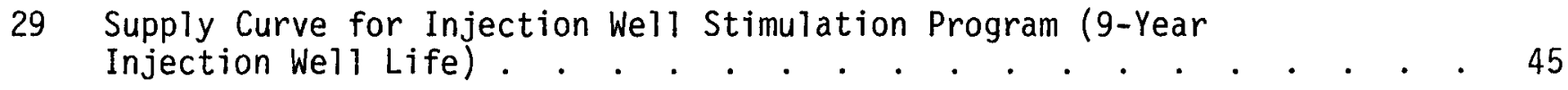

30 Supply Curves for Injection Well Stimulation Program . . . . . . . 46

31 Supply Curve for Polymer Concrete Program (Reference Case) . . . . . 49

32 Supply Curve for Polymer Concrete Program (Polymer Concrete) . . . . 50

33 Supply Curves for Polymer Concrete Program . . . . . . . . . . 51

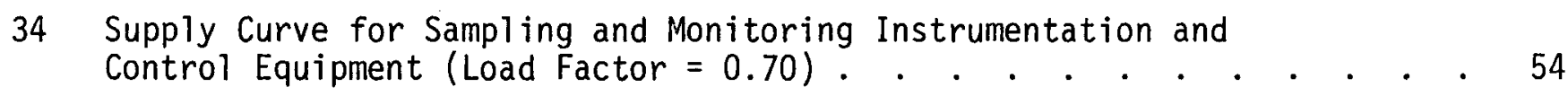

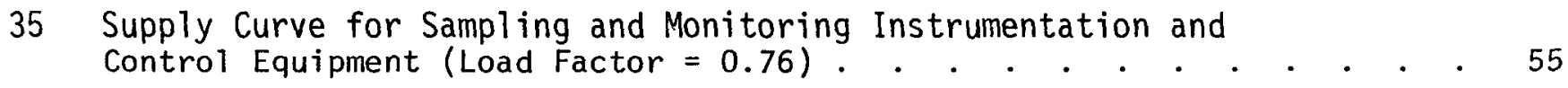

36 Supply Curve for Sampling and Monitoring Instrumentation and Control Equipment (Load Factor $=0.78$ ). . . . . . . . . . . . 56

37 Supply Curves for Sampling and Monitoring Instrumentation and Control Equipment . . . . . . . . . . . . . . . . . . 57

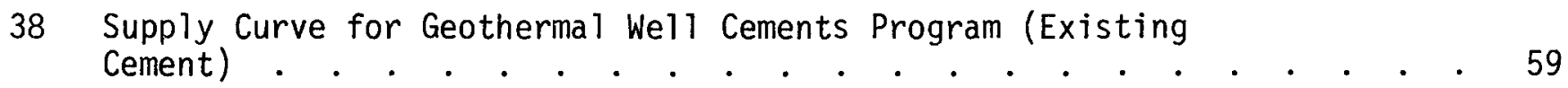

39 Supply Curve for Geothermal Well Cements Program (New Cement) . . . . 60

40 Supply Curves for Geothermal Well Cements Program .. . . . . . . . 61

41 Supply Curve for Ceramic or Cement Casings Program (Stee)

Casing . . . . . . . . . . . . . . . . . . . 63 
42 Supply Curve for Ceramic or Cement Casings Program (Ceramic or

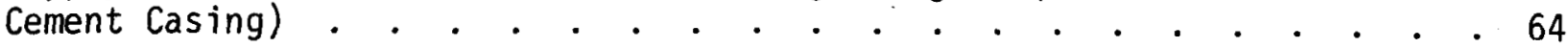

43 Supply Curves for Ceramic or Cement Casings Program . . . . . • . . 65

44 Near-Term Supply Curve for Electric Applications of Hydrothermal Resources . . . . . . . . . . . . . . . . . . . . . 68

45 Supply Curve for Combined Impacts of All Programs (1982) . . . . . . 69

46 Supply Curve for Combined Impacts of All Programs (1985) . . . . . . 70

47 Supply Curves for Combined Impacts of A11 Programs . • . . • . • . • 71 


\section{TABLES}

1 High-Temperature Hydrothermal Reservoirs . . . . . . . . . . 3a

2 Intermediate-Temperature Hydrothermal Reservoirs . . . . . . . . $3 c$

3 DGE Programs . . . . . . . . . . . . . . . . . . . . . . . 9

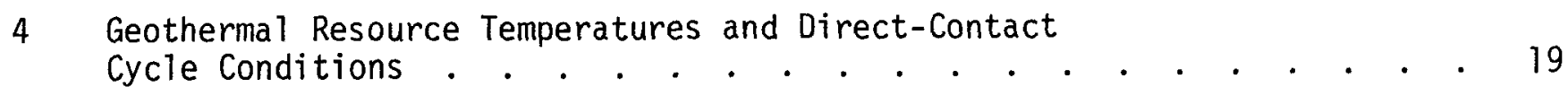

5 Timing for Technology Improvements . . . . . . . . . . . . . 67

6 Wellhead Separator Temperatures and Steam Contents . . . . . . . . 73

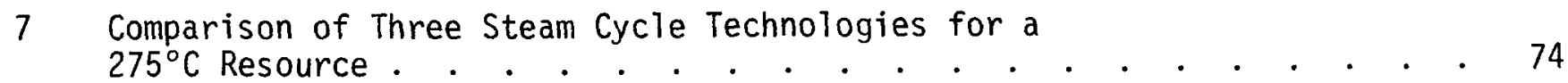

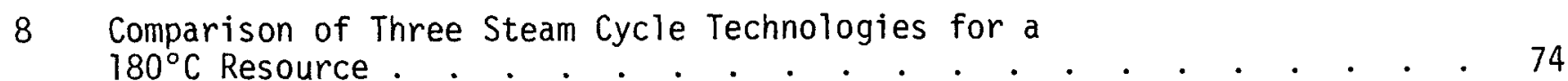




\section{DISCLAIMER}

Portions of this document may be illegible in electronic image products. Images are produced from the best available original document. 


\section{NEAR-TERM SUPPLY CURVE}

We derived the near-term supply curve (Figure 1) for electrical applications of hydrothermal resources based on USGS resource assessment data. Each step in the curve is composed of one or more geothermal resources identified by the USGS, as indicated for several of the steps on Figure 1. Both high-temperature and intermediate-temperature resources were included up to an arbitrary cost ceiling of $100 \mathrm{mills} / \mathrm{kWh}$. For the near-term we excluded the high-temperature hydrothermal resources in Alaska, the Salton Sea, and the National Parks. The technology implicit in this curve is discussed below. Figure 2 shows the smooth curve which we have drawn to represent the step function shown in Figure 1. Figure 2 will serve as the reference curve to illustrate the shifts which would be caused by potential technology improvements. It is easier to visualize shifts in cost or quantity if the supply curves are smooth rather than step functions. The step function appearance of Figure 1 is caused by the existence of "blocks" of geothermal resources with identical subsurface temperatures and reservoir depths. For example, the 500-MWecenturies block in the lower-left corner represents the dry steam resource at The Geysers, which yields the lowest cost of power of all the hydrothermal resources. Resource quality decreases as you move up and to the right on these curves, and thus, the cost of power increases.

The supply curve is based on resource assessment work done by the USGS ${ }^{(3)}$. Table 1 shows the characteristics of the identified high-temperature hydrothermal resources. The USGS estimated the subsurface temperature, the reservoir thickness, and the heat content of each reservoir. They also assumed a $25 \%$ recovery of the stored heat at the surface and an electrical conversion efficiency of $8 \%$ or $10 \%$, depending on temperature, to estimate the electrical potential of each reservoir. We combined the individual reservoirs into the temperature/thickness categories shown in Table 1 for the purpose of deriving supply curves. Temperature strongly influences production costs. Thickness is a measure of the average drilling depth, which influences the cost of wells.

Tahle ? shows the characteristics of the identified intermediate-temperature hydrothermal resources. The USGS also estimated the subsurface temperature, reservoir thickness, and heat content of each of these reservoirs. The USGS made no estimates of electrical potential for the intermediate-temperature reservoirs since they were assumed to be attractive for direct heating uses only. However, we also 


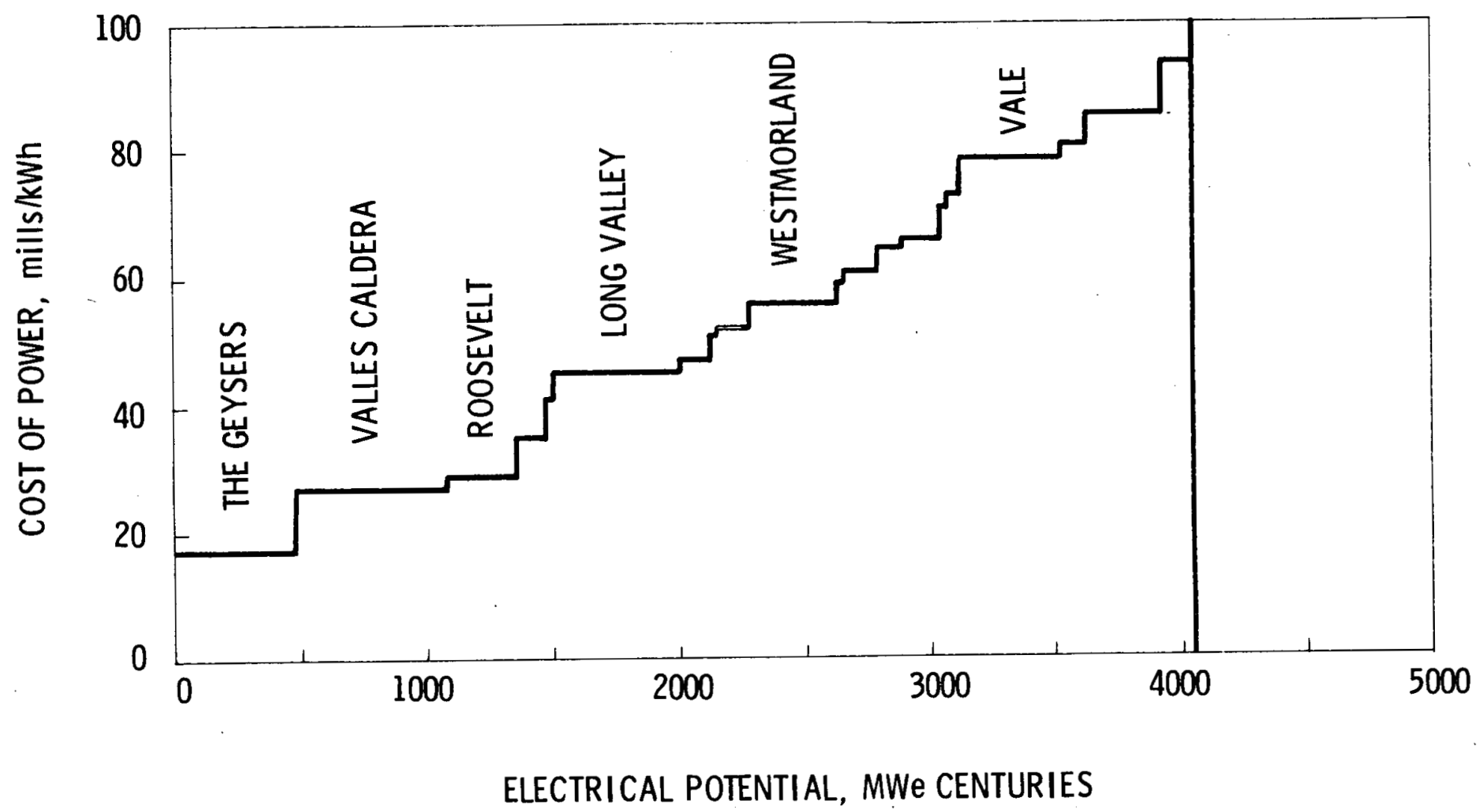

FIGURE 1. Near-Term Supply Curve for Electric Applications of Hydrothermal Resources 


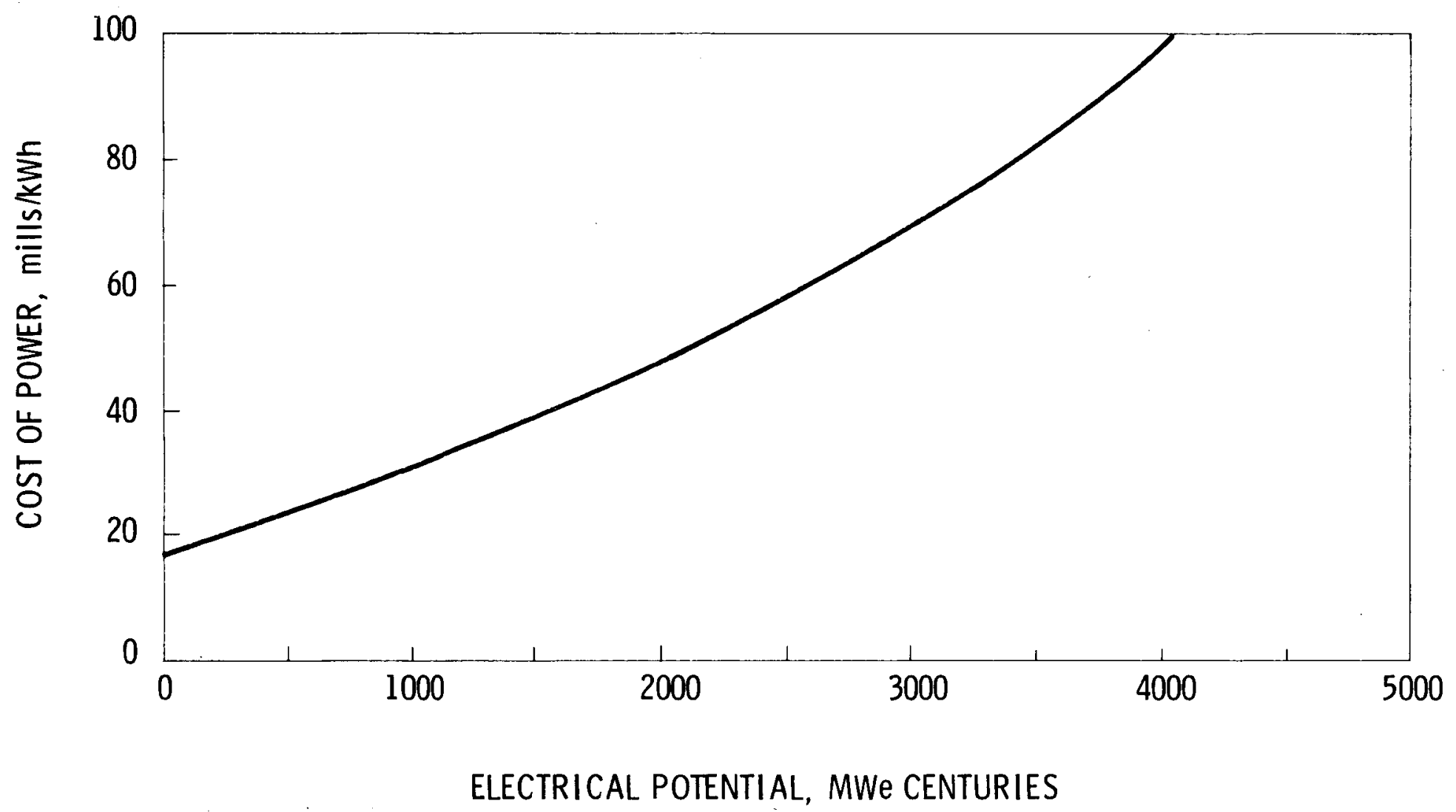

FIGURE 2. Near-Term Supply Curve for Electric Applications of Hydrothermal Resources 
TABLE 1. High-Temperature Hydrothermal Reservoirs $(a)$

\begin{tabular}{ccc}
$\begin{array}{c}\text { Subsurface } \\
\begin{array}{c}\text { Temperature, } \\
{ }^{\circ} \mathrm{C}\end{array}\end{array}$ & $\begin{array}{c}\text { Reservoir } \\
\text { Thickness, } \\
\text { km }\end{array}$ & $\begin{array}{c}\text { Heat } \\
\text { (b) } \\
\text { Content, } \\
\text { 18 }^{18} \text { Calories }\end{array}$ \\
\cline { 2 - 3 } 275 & 2.0 & 20.780 \\
275 & 1.5 & 1.914 \\
265 & 2.0 & 7.643 \\
255 & 1.5 & 5.256 \\
230 & 2.0 & 1.123 \\
230 & 1.5 & 6.450 \\
225 & 2.0 & 18.634 \\
220 & 2.0 & 5.973 \\
220 & 1.5 & 6.928 \\
215 & 2.0 & 1.075 \\
215 & 1.5 & 16.441 \\
205 & 2.0 & 1.553 \\
200 & 2.7 & 3.440 \\
190 & 2.0 & 1.329 \\
190 & 1.5 & 10.081 \\
180 & 2.0 & 4.243 \\
180 & 1.5 & 1.699 \\
175 & 2.0 & 7.406 \\
175 & 1.5 & 1.027 \\
170 & 2.0 & 4.874 \\
165 & 1.5 & 6.422 \\
160 & 2.5 & 7.000 \\
160 & 1.5 & 1.885 \\
155 & 2.5 & 3.751 \\
155 & 2.0 & 11.349 \\
& & 158.276 \\
& &
\end{tabular}

(a) Exciuding National Parks, Alaska, The Geysers, and the Salton Sea.

(b) Above $15^{\circ} \mathrm{C}$ 
TABLE 1. Continued

\begin{tabular}{|c|c|c|c|}
\hline & $\begin{array}{c}\text { Subsurface } \\
\text { Temperature, } \\
{ }^{\circ} \mathrm{C} \\
\end{array}$ & $\begin{array}{c}\text { Reservoir } \\
\text { Thickness, } \\
\mathrm{km}\end{array}$ & $\begin{array}{l}\text { Heat }(a) \\
\text { Content, } \\
10^{18} \text { Calories }\end{array}$ \\
\hline \multirow[t]{3}{*}{ Alaska } & 210 & 2.0 & 1.314 \\
\hline & 165 & 2.0 & 0.320 \\
\hline & 160 & 1.5 & $\frac{0.315}{1.949}$ \\
\hline The Geysers & 237 & 2.0 & 23.885 \\
\hline The Salton Sea & 325 & 2.0 & 23.168 \\
\hline \multirow[t]{3}{*}{ National Parks (b) } & 265 & 2.5 & 296.169 \\
\hline & 235 & 1.0 & 10.032 \\
\hline & 225 & 1.3 & $\frac{1.099}{307.300}$ \\
\hline
\end{tabular}

(a) Above $15^{\circ} \mathrm{C}$

(b) Includes Yellowstone and Mt. Lassen National Parks, both of which are permanently withdrawn from exploitation. 
TABLE 2. Intermediate-Temperature Hydrothermal Reservoirs (a)

\begin{tabular}{cc}
$\begin{array}{c}\text { Subsurface } \\
\begin{array}{c}\text { Temperature, } \\
{ }^{\circ} \mathrm{C}\end{array}\end{array}$ & $\begin{array}{c}\text { Reservoir } \\
\text { Thickness, } \\
\mathrm{km}\end{array}$ \\
\cline { 2 - 2 } 150 & 2.0 \\
150 & 1.5 \\
145 & 2.0 \\
145 & 1.5 \\
140 & 1.5 \\
135 & 1.5 \\
130 & 1.5 \\
125 & 2.0 \\
125 & 1.5 \\
120 & 1.5 \\
115 & 1.5 \\
110 & 2.0 \\
110 & 1.5 \\
105 & 1.5 \\
100 & 1.5 \\
95 & 1.5 \\
&
\end{tabular}

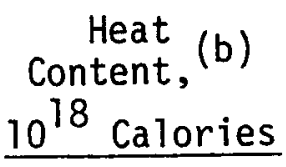

18.873

3.393

1.051

1.685

2.254

1.464

6.279

2.047

3.355

3.230

4.902

7.435

2.241

111.507

6.859

3.545

$\overline{180.120}$

(a) Excluding National Parks and Alaska.

(b) Above $15^{\circ} \mathrm{C}$ 
TABLE 2. Continued

\begin{tabular}{|c|c|c|c|}
\hline & $\begin{array}{c}\text { Subsurface } \\
\text { Temperature, } \\
{ }^{\circ} \mathrm{C}\end{array}$ & $\begin{array}{c}\text { Reservoir } \\
\text { Thickness, } \\
\mathrm{km}\end{array}$ & $\begin{array}{c}\text { Heat }(a) \\
\text { Content, } \\
10^{18} \text { Calories } \\
\end{array}$ \\
\hline \multirow[t]{12}{*}{ Alaska } & 145 & 1.5 & 0.277 \\
\hline & 140 & 1.5 & 0.803 \\
\hline & 135 & 1.5 & 0.260 \\
\hline & 130 & 1.5 & 1.232 \\
\hline & 125 & 1.5 & 0.719 \\
\hline & 120 & 1.5 & 0.222 \\
\hline & 115 & 1.5 & 0.865 \\
\hline & 110 & 1.5 & 0.201 \\
\hline & 105 & 1.5 & 0.385 \\
\hline & 100 & 1.5 & 0.184 \\
\hline & 95 & 1.5 & 0.170 \\
\hline & 90 & 1.5 & $\frac{0.327}{5.645}$ \\
\hline National Parks (b) & 125 & 1.5 & 0.239 \\
\hline
\end{tabular}

\footnotetext{
(a) Above $15^{\circ} \mathrm{C}$

(b) Mount Rainier National Park, which has been permanently withdrawn from exploitation.
} 
categorized these reservoirs into temperature/thickness categories and assumed that with sufficient technology advances, these resources could also be used for electric power production. We combined the high and intermediate-temperature reservoirs to provide the resource base used to derive the supply curves.

In deriving the supply curves we also assumed a $25 \%$ recovery of the stored heat at the surface, but we calculated the electrical conversion efficiency independently for each temperature category using the GEOCOST model and its simulation of the power cycle based on the thermodynamic properties of the geothermal fluid. This results in some differences in the electrical potential, but has the advantage in subsequent analyses of introducing the sensitivity needed to future changes in electrical conversion efficiency resulting from technology improvements.

We define near-term technology to consist of both steam and binary cycles operating at a $70 \%$ power plant load factor. Binary cycle plants apply to resources with subsurface temperatures of $175^{\circ} \mathrm{C}$ or less. Steam cycle plants apply to all resources with temperatures greater than $175^{\circ} \mathrm{C}$. The steam cycle uses flashing in the well bore and steam separation at the wellhead. The binary cycle uses isobutane as the working fluid. For the binary cycle, the well is driven by conventional downhole pumps which suppress flashing in the well bore. Conventional downhole pumps are assumed to possess the following characteristics:

$\begin{array}{ll}\text { Maximum Temperature Limit } & 360^{\circ} \mathrm{F}\left(180^{\circ} \mathrm{C}\right) \\ \text { Maximum Depth } & 1000 \mathrm{ft}(0.3 \mathrm{~km}) \\ \text { Maximum Flow Rate } & 880 \mathrm{GPM}(440,000 \mathrm{lb} / \mathrm{hr}) \\ \text { Life } & 9 \text { Months } \\ \text { Efficiency } & 60 \% \\ \text { Cost } & \$ 125,000\end{array}$

The supply curve is based on 1979 cost estimates. The supply curve was obtained by graphing the energy production costs calculated using the GEOCOST model, and is intended to represent current state-of-the-art technology. For comparison, under similar financial assumptions the cost of electricity from new nuclear and coal power plants coming on line in 1979 is in the range of $25-30 \mathrm{mills} / \mathrm{kWh}$, while the cost of electricity from new oil-fired power plants is in the range of $50-60 \mathrm{mi} 11 \mathrm{~s} / \mathrm{kWh}$.

Figures 1 and 2 are based on the USGS resource assessment data in Circular $790^{(3)}$. In a previous report ${ }^{(1)}$, we derived the near-term supply curve based on data in Circular $726^{(6)}$. There are some major differences between Circulars 790 and 726 , mostly due to decreases in the estimates of reservoir areas and subsurface temperatures. The biggest difference is the decrease in estimated heat content of the 
Bruneau-Grand View resource from $263 \times 10^{18}$ calories to $107 \times 10^{18}$ calories. Figure 3 shows the impact of the Circular 790 reassessment on the near-term supply curve. Based on Circular 790, there are about 4,050 Whe centuries of identified electrical potential available at or below a power cost of $100 \mathrm{mills} / \mathrm{kWh}$; based on Circular 726, there were about 8,850 MWe centuries. For the supply curves in this report, we used the Circular 790 data.

It is important to emphasize that the supply curves are based on the identified resources only. The discovery of new resources is expected to add substantially to the resource base. 


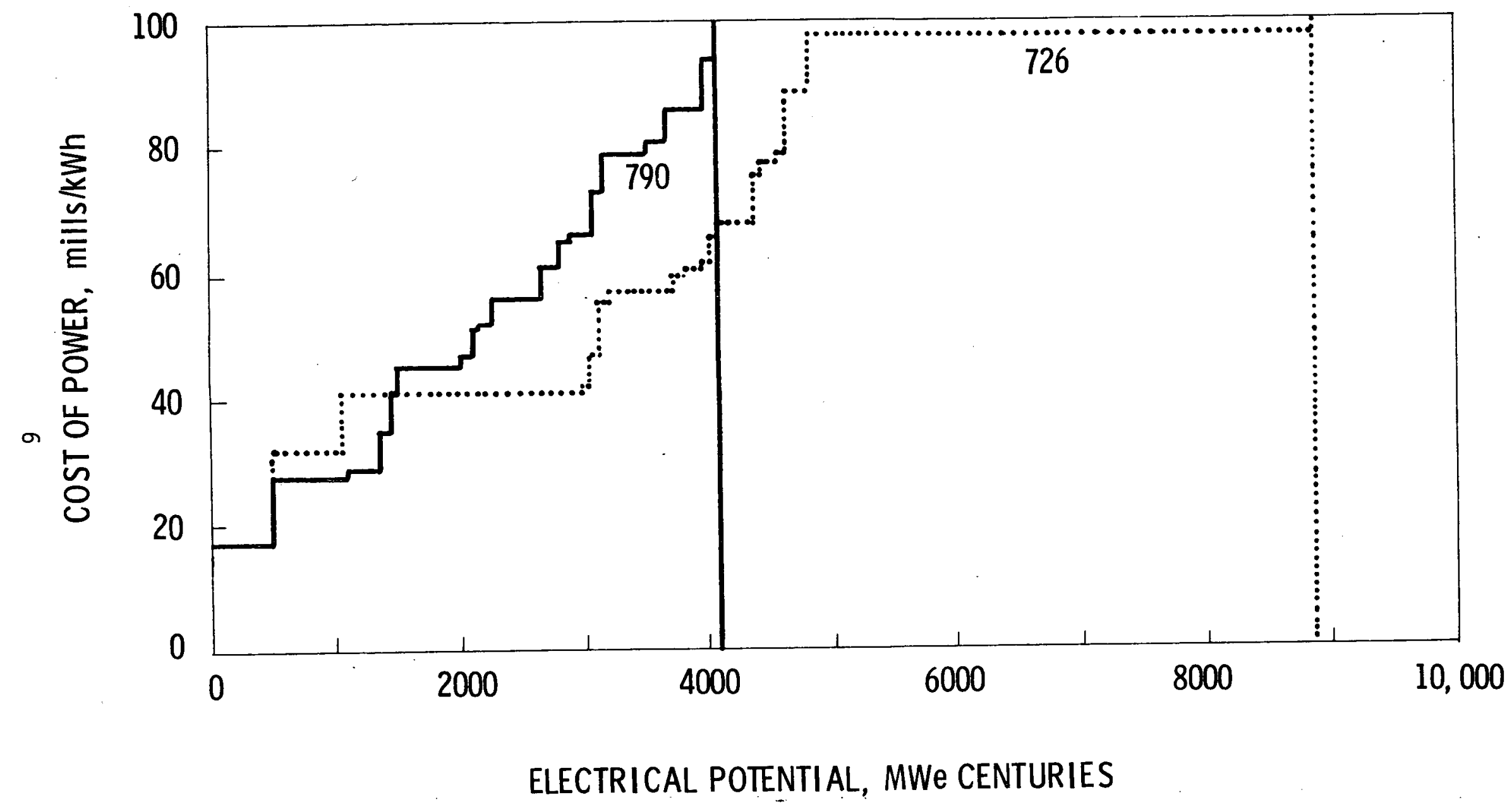

FIGURE 3. Comparison of Near-Term Supply Curves Based on Circulars 790 and 726 


\section{LONG-TERM SUPPLY CURVES}

The long-term supply curves were derived by determining the impacts of specific technology improvements on the near-term supply curve. The first step in the analysis was to conduct interviews with the DGE program managers. These interviews resulted in discussions of the R\&D programs listed in Table 3 . We requested that each program manager define the quantitative objectives of his programs.

In general, the objectives of the $R \& D$ programs were to improve the commercial potential of geothermal resources in one or more ways: (1) reduce costs, (2) increase supply, (3) reduce uncertainty, or (4) accelerate commercial use of the resource. For those programs with objectives to reduce costs or increase supply, we then determined the potential impacts of successful completion of the programs on the cost and supply of geothermal energy. This was done using the GEOCOST program through modeling the effect of successful completion of each program in terms of changes in the production function and changes in the costs of the factors of production. The impact of the programs was to shift the supply curve toward lower costs and increased supply.

Several of the listed programs, however, were not included in our analysis since they had no direct impact on production cost or supply. These were programs with objectives to reduce uncertainty or accelerate commercial use. The long-term supply curves were derived under the assumptions that the resource characteristics were known (i.e., temperature, depth, and favorable fluid composition) and that the conversion technology was feasible. Those programs which reduced uncertainty, therefore, would have no effect on the supply curves since the time dimension of the supply curves pertains only to the commercial availability of the resources under the specified levels of technology.

Once commercial availability is indicated, the process of commercialization requires additional time for technology transfer, the reduction of risk and uncertainty, and the demonstration of technical and economic feasibility. The time requirements for this commercialization process are outside the scope of this study. Although outside the scope of this study, programs which reduce uncertainty are important to commercialization since they fulfill objectives which are necessary prerequisites to commercialization; that is, some programs provide information of a go/no-go nature and others reduce risk and uncertainty and thereby facilitate the commercialization process. 
Programs which reduce uncertainties were of three types: (1) those which provide new data (e.g., basic research), (2) those which provide more accurate or precise data (e.g., better measurement tools), and (3) those which demonstrate technical or commercial feasibility of a technology or resource.

The programs which have direct impact on the long-term supply curves will now be discussed individually. We will then combine the impacts of all of these programs in order to evaluate the effectiveness of successful completion of these programs on the commercial availability of the hydrothermal resources. 
TABLE 3. DGE Programs

- GEOTHERMAL LOG INTERPRETATION

- SURFACE EXPLORATION TECHNOLOGY

- ROCK PROPERTIES

- DRILLING AND COMPLETIONS TECHNOLOGY

- LOGGING INSTRUMENTATION DEVELOPMENT

- HOT DRY ROCK

- $\mathrm{H}_{2} \mathrm{~S}$

- SUBSIDENCE

- WASTE DISPOSAL

- DIRECT-CONTACT HEAT EXCHANGERS

- DOWNHOLE PUMPS

- RESERVOIR stimulation

- FLUTED-TUBE CONDENSERS

- OPTIMIZATION OF CONDENSING AND HEAT-REJECTION SYSTEMS FOR BINARY PLANTS

- WELLHEAD GENERATORS

- RESERVOIR ENGINEERING

- DEVELOPMENT OF INTEGRATED SYSTEMS

- INJECTION WELL STIMULATION

- SOLID WASTE DISPOSAL

- SITE-SPECIFIC WATER PURIFICATION

- SAMPLING AND MONITORING INSTRUMENTATION AND CONTROL EQUIPMENT

- geOTHERMAL WELL CEMENTS

- COMPUTER MODELING AND GEOCHEMISTRY

- materials

- pOLYMER CONCRETE

- CERAMic OR CEMENT CASINGS

- MT. HOOD

- RAFT RIVER 5 MWe binary PLANT

- EAST MESA GEOTHERMAL COMPONENT TEST FACILITY

- NILAND GEOTHERMAL LOOP EXPERIMENTAL FACILITY

- VAlles caldera 50 mWe demonstration PLANT

- HAWAII WELLHEAD GENERATOR

- GEOPRESSURED 
PROGRAM: $\quad$ SURFACE EXPLORATION TECHNOLOGY

OBJECTIVE: The objective of this program is to decrease the number of dry exploration wells that are drilled. We assumed that the current success ratio for exploration wells is $1 / 7$. That is, for every seven exploration wells that are drilled, only one is successful enough to warrant field development drilling nearby. Then, to represent the possible results of this program, we assumed that the success ratio for exploration wells increased to $1 / 2$.

RESULTS: $\quad$ Figures 4 and 5 show the supply curves for geothermal electrical potential which we generated with the GEOCOST model, based on successful completion of this program. Figure 4 represents the current situation (success ratio $=1 / 7$ ) and Figure 5 represents achievement of the objective of reducing the number of dry exploration wells (success ratio $=1 / 2)$. In Figure 6 , we have plotted smooth curves to represent the two cases previously shown as step functions. The horizontal or vertical distance between the curves shows the quantity or cost difference due to successful achievement of the objective. As Figure 6 indicates, the impact of increasing the success ratio for exploration wells from $1 / 7$ to $1 / 2$ would be to lower the cost of power for all resources by about $1-2 \mathrm{mills} / \mathrm{kWh}$. Assuming that the entire 4,050 MWe centuries of geothermal electrical potential shown in Figure 6 is developed, a $1.5 \mathrm{mill} / \mathrm{kWh}$ reduction in cost of power amounts to a savings of $\$ 3.73$ billion (not discounted).*

* We can obtain a rough estimate of the present value of this savings by dividing by 10. The present value of the potential future savings can only be obtained through a market penetration analysis, which is outside the scope of this report. 


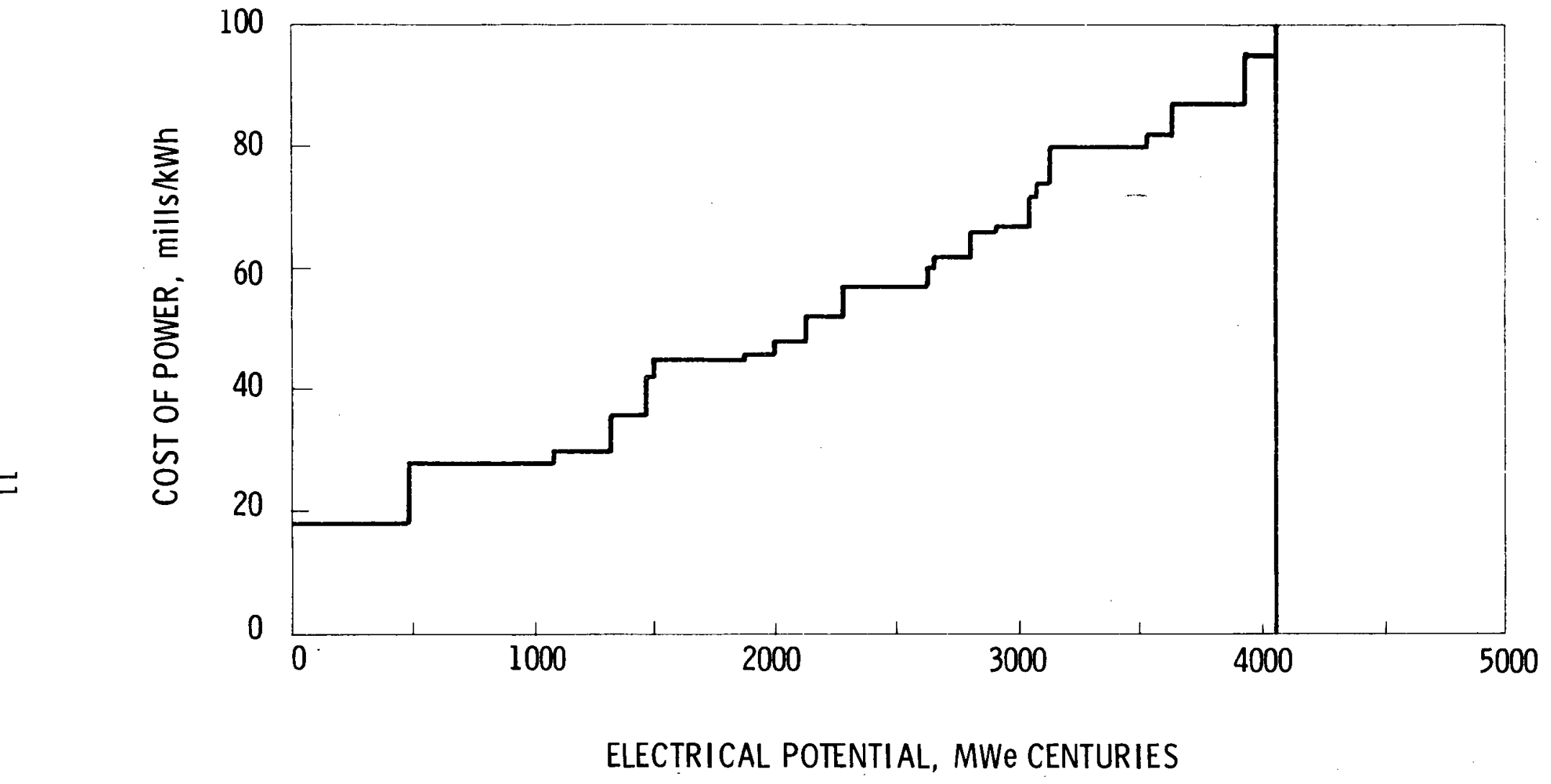

FIGURE 4. Supply Curve for Surface Exploration Technology Program with Success Ratio $=1 / 7$ 


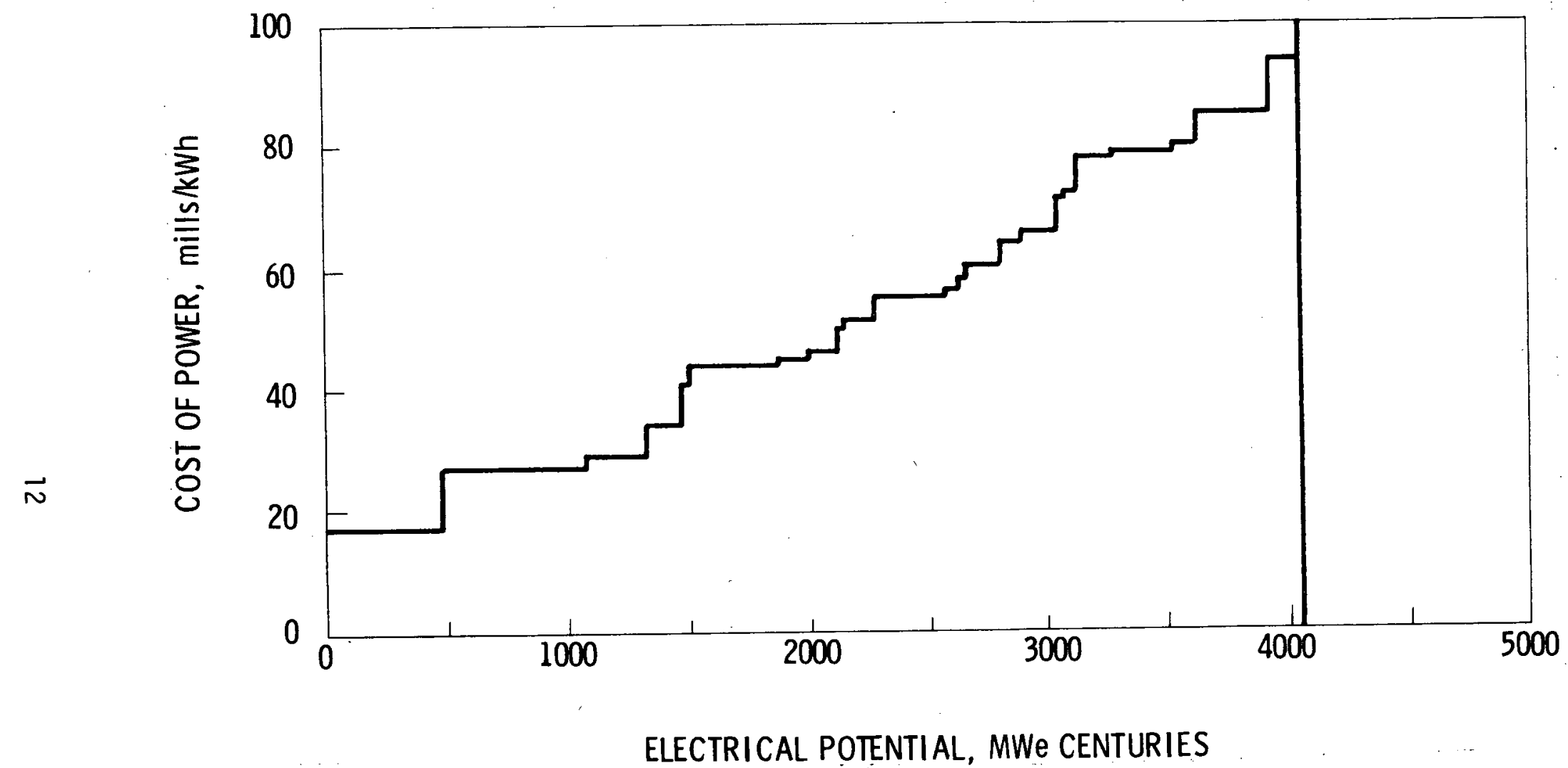

FIGURE 5. Supply Curve for Surface Exploration Technology Program with Success Ratio $=1 / 2$ 


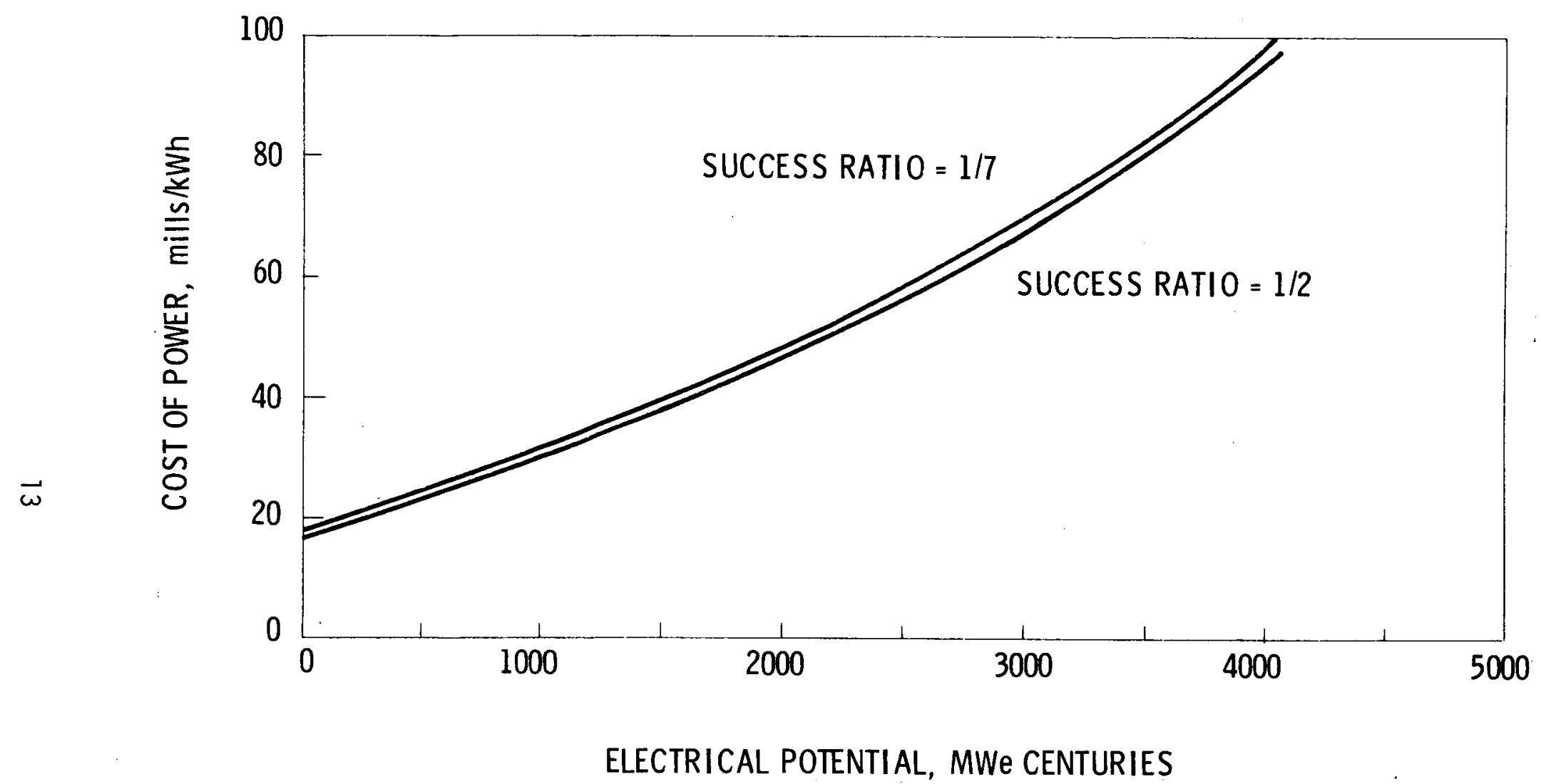

FIGURE 6. Supply Curves for Surface Exploration Technology Program 
PROGRAM: DRILLING AND COMPLETIONS TECHNOLOGY

OBJECTIVES: (1) To reduce the cost of a geothermal well by $25 \%$ by the end of 1982.

(2) To reach $50 \%$ reduction in well cost by 1985 or 1986 .

RESULTS: $\quad$ Figures 7,8 , and 9 show the supply curves for geothermal electrical potential. The base case represents the current situation, while the 1982 and 1985 cases represent achievements of the 1982 and 1985 objectives stated above. In Figure 10, we have plotted smooth curves to represent the three cases previously shown as step functions. We assumed that the $25 \%$ and $50 \%$ drilling cost reductions applied to the total drilling costs. However, tangible and intangible drilling costs are treated differently for tax purposes. The supply curves could change somewhat depending on whether the actual cost reductions apply to tangible or intangible costs. Assuming that the entire 4,050 MWe centuries of geothermal electrical potential shown in Figure 10 is developed, an average cost reduction of $6.5 \mathrm{mills} / \mathrm{kWh}$ by 1982 amounts to a savings of $\$ 16.14$ billion (not discounted). An average cost reduction of $12.5 \mathrm{mills} / \mathrm{kWh}$ by 1985 amounts to a savings of $\$ 31.04$ bi1lion (not discounted). 


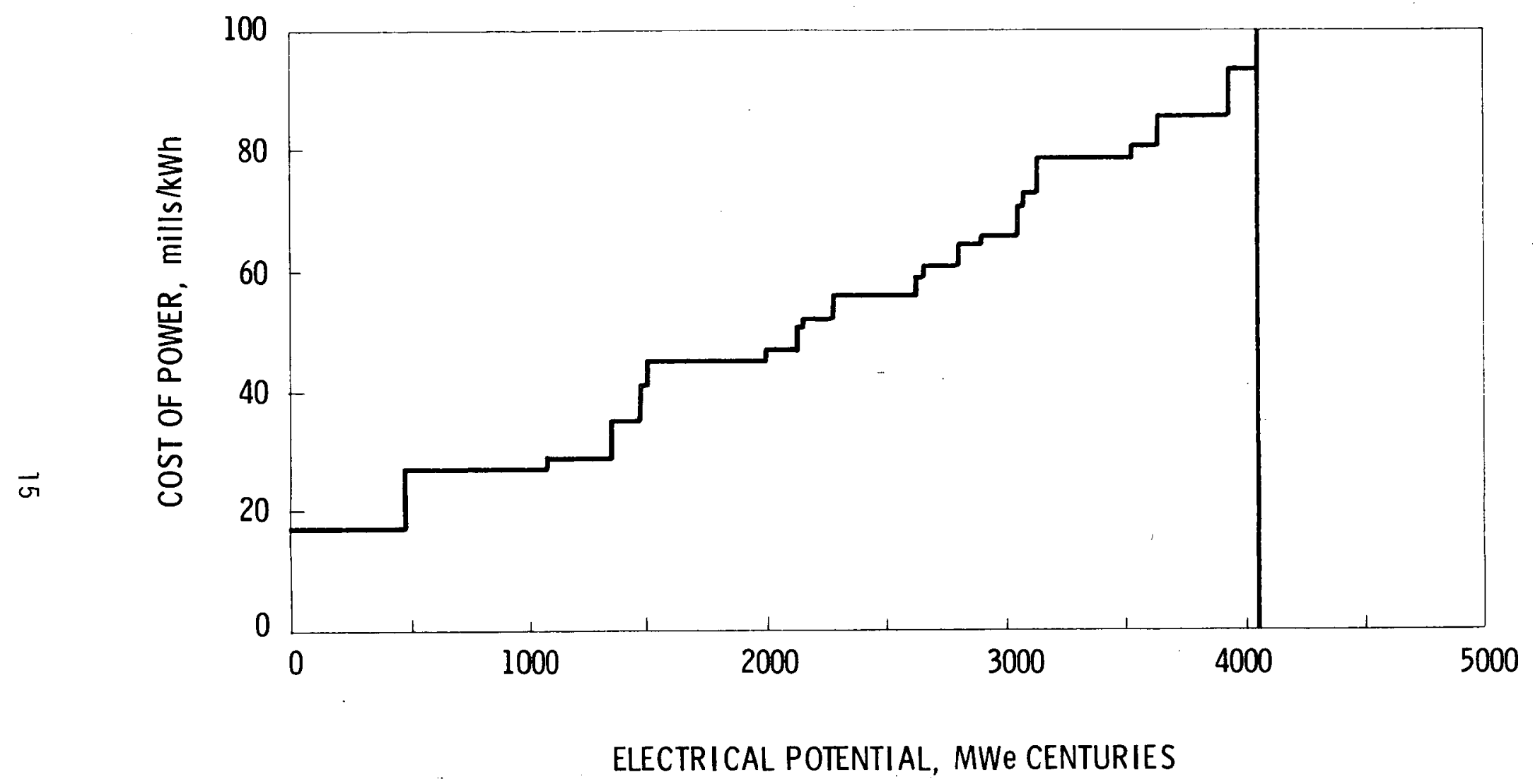

FIGURE 7. Supply Curve for Drilling and Completions Technology Program (Base Case) 


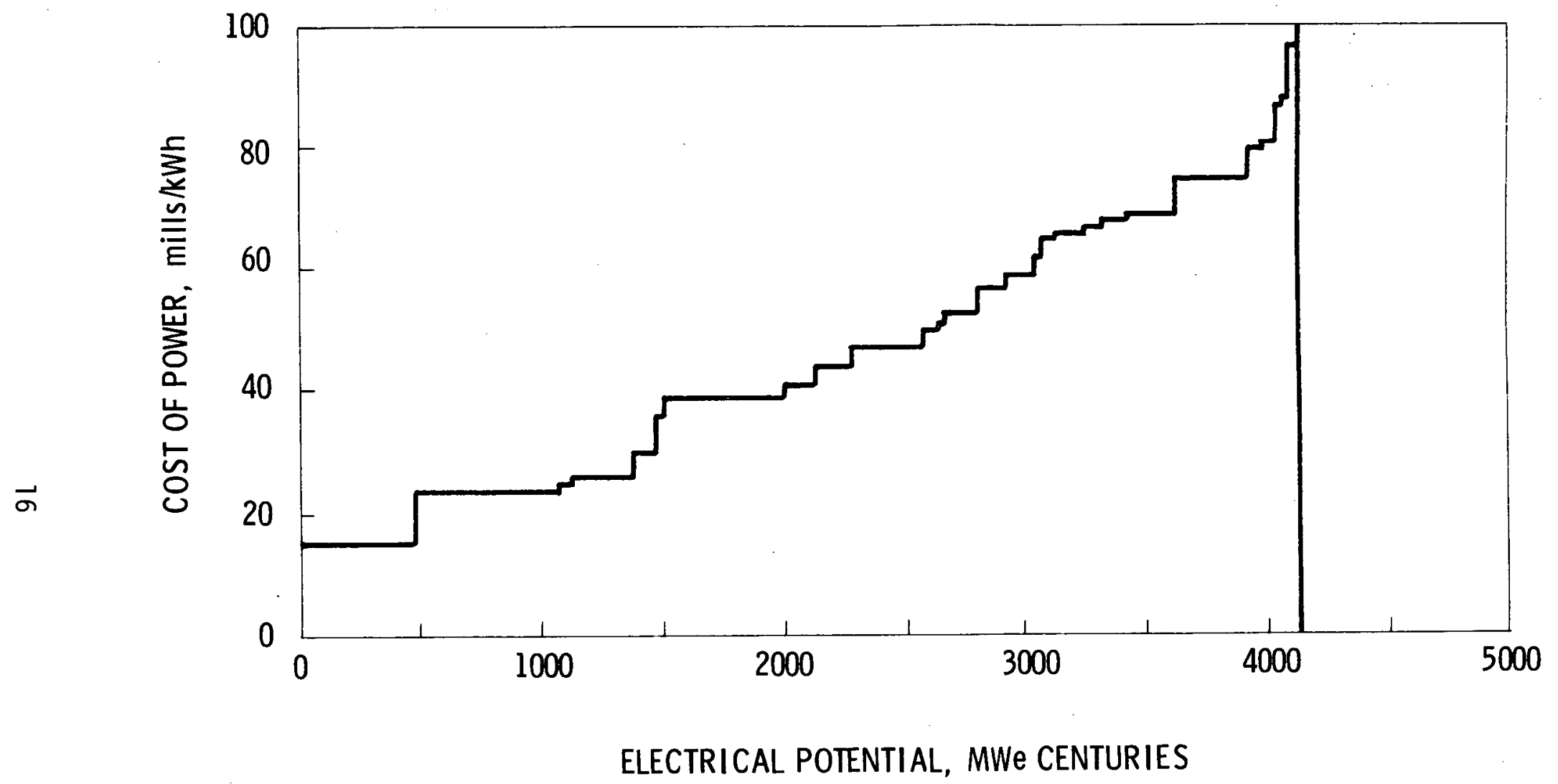

FIGURE 8. Supply Curve for Drilling and Completions Technology Program (1982 Case) 


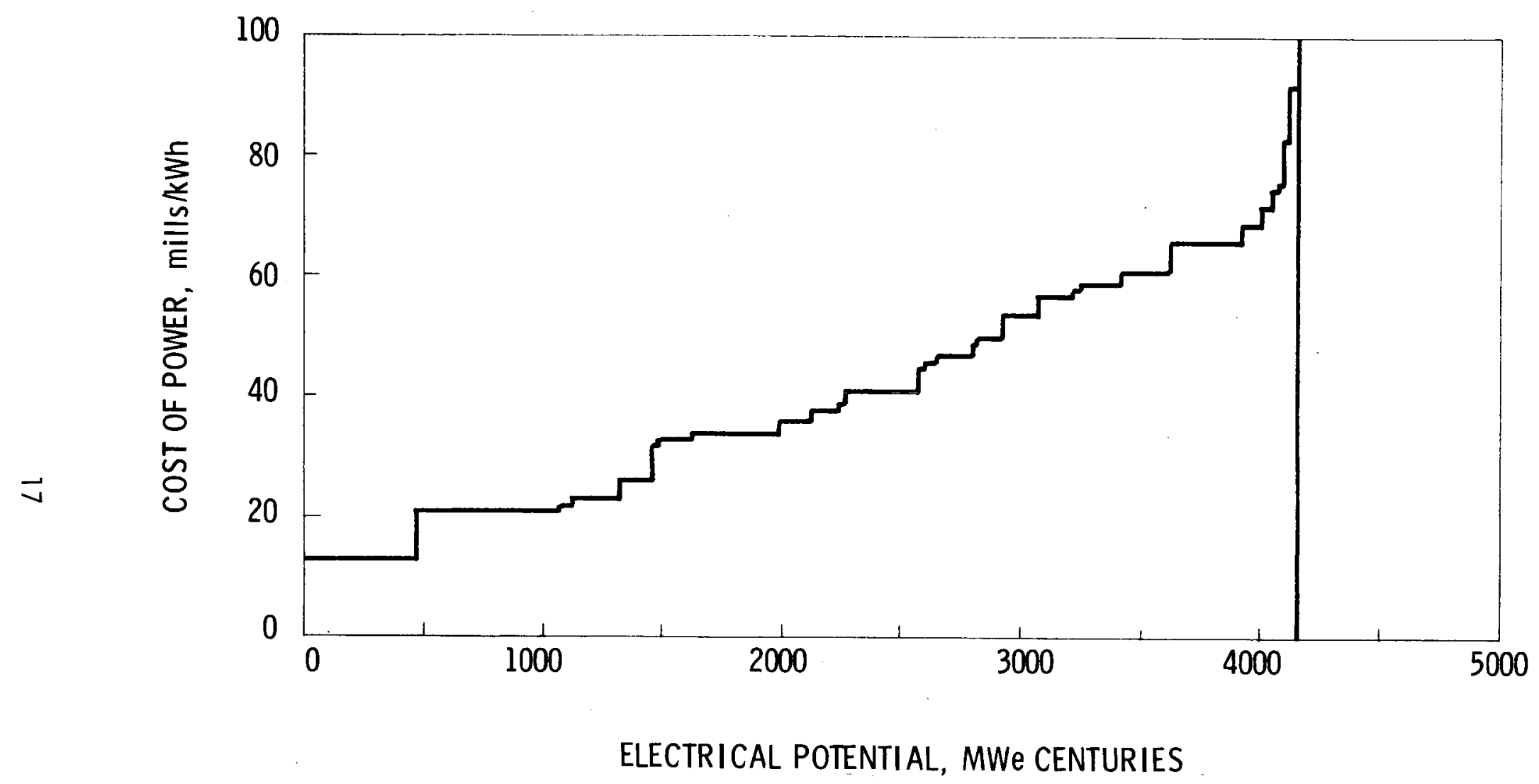

FIGURE 9. Supply Curve for Drilling and Completions Technology Program (1985 Case) 


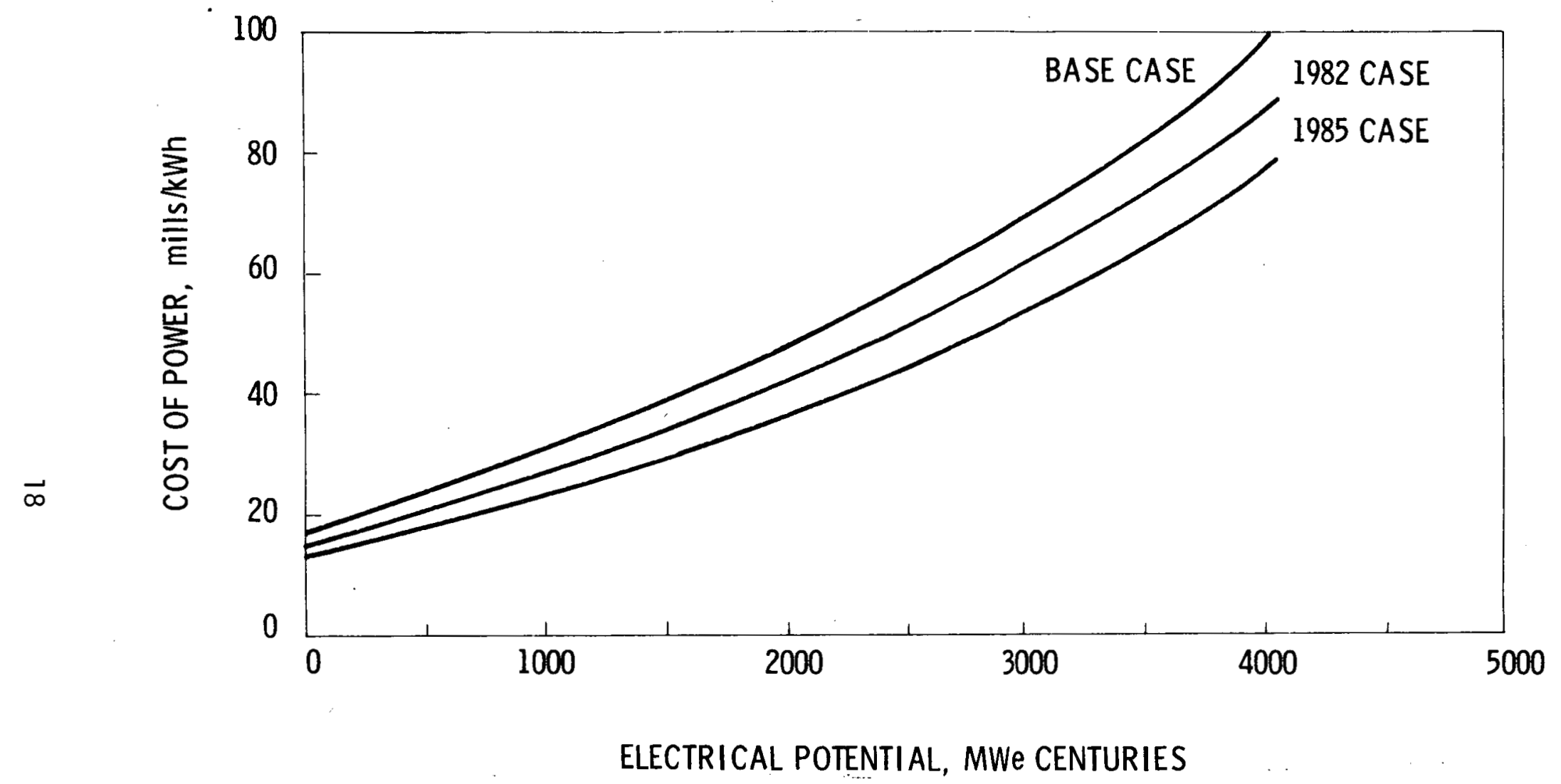

FIGURE 10. Supply Curves for Drilling and Completions Technology Program 
PROGRAM:

OBJECTIVE: To develop and use direct-contact heat exchangers in a binary power cycle.

Table 4 shows the geothermal resource temperatures and cycle conditions that were used to model the direct-contact exchanger. We used isobutane as the working fluid, a $5^{\circ} \mathrm{F}$ pinch point, and a subcritical cycle. ATso, we used the DGE assumption that the capital cost of a direct-contact exchanger is $20 \%$ of the capital cost of a conventional shell-and-tube exchanger. We decided to use a $30^{\circ} \mathrm{F}$ approach and a minimal amount of superheat based on the results of a sensitivity analysis of the effects of approach temperature and turbine inlet pressure on the cost of power.

TABLE 4. Geothermal Resource Temperatures and Direct-Contact Cycle Conditions

\begin{tabular}{ccccc}
$\begin{array}{c}\text { Geothermal } \\
\text { Resource } \\
\text { Temperature, } \\
\text { Tem } \\
{ }^{\circ} \mathrm{C}\end{array}$ & $\begin{array}{c}\text { Exchanger } \\
\text { Approach } \\
\text { Temperature, } \\
{ }^{\circ} \mathrm{F}\end{array}$ & $\begin{array}{c}\text { Turbine } \\
\text { Inlet } \\
\text { Temperature, } \\
{ }^{\circ} \mathrm{F}\end{array}$ & $\begin{array}{c}\text { Turbine } \\
\text { Inlet } \\
\text { Pressure, } \\
\text { PSIA }\end{array}$ \\
\cline { 1 - 2 } 175 & 347 & 30 & 317 & 480 \\
170 & 338 & 30 & 308 & 480 \\
165 & 329 & 30 & 299 & 480 \\
160 & 320 & 30 & 290 & 480 \\
155 & 311 & 30 & 287 & 480 \\
150 & 302 & 30 & 272 & 480 \\
145 & 293 & 30 & 263 & 460
\end{tabular}

RESULTS: $\quad$ Figure 11 represents the current state-of-the-art technology, which in this case means using conventional shell-and-tube exchangers. Figure 12 represents achievement of the objective of developing and using direct-contact heat exchangers. In Figure 13 we have plotted smooth curves to represent the two cases previously shown as step functions. It appears that use of a direct-contact cycle has the potential to lower the cost of power by up to $? 4 \mathrm{mills} / \mathrm{kWh}$. However, it should be noted that these curves do not include the incremental costs of any additional pieces of equipment needed in a direct-contact cycle that are not used in a conventional scheme. Assuming that the entire 2,200 MWe 
centuries of geothermal binary electrical potential shown in Figure 13 is developed, an average cost reduction of $7 \mathrm{mills} / \mathrm{kWh}$ amounts to a savings of $\$ 9.44$ billion (not discounted).

There is no impact on the lower end of the supply curve since this portion of the curve represents the higher-temperature resources that are exploited with the steam cycle. The portion of the curve between 2,100 MWe centuries and 4,300 MWe centuries is assumed to be exploited with the binary cycle. This portion amounts to 2,200 MWe centuries as mentioned before. 


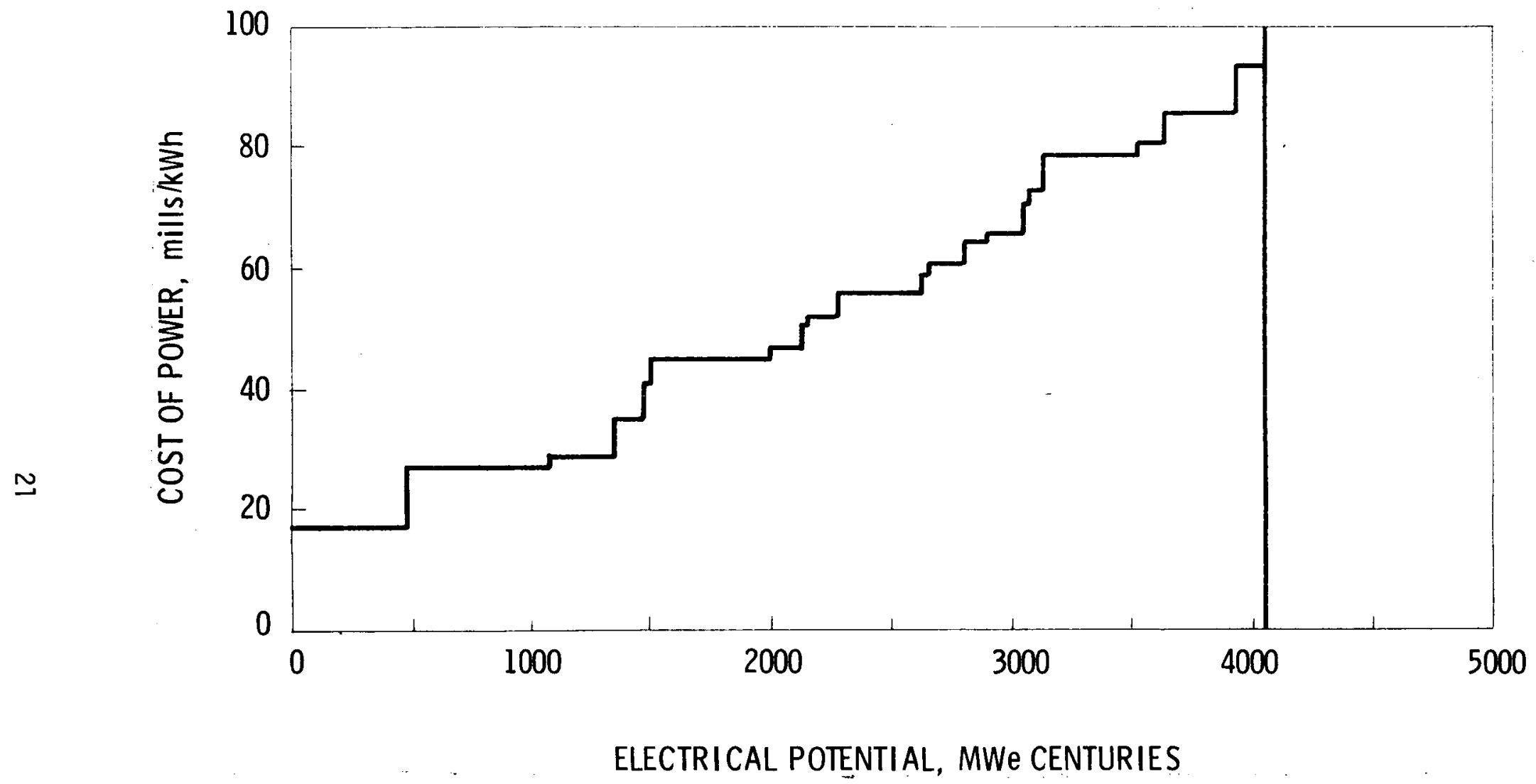

FIGURE 11. Supply Curve for Direct-Contact Heat Exchanger Program (Conventional Shell-and-Tube Exchangers) 


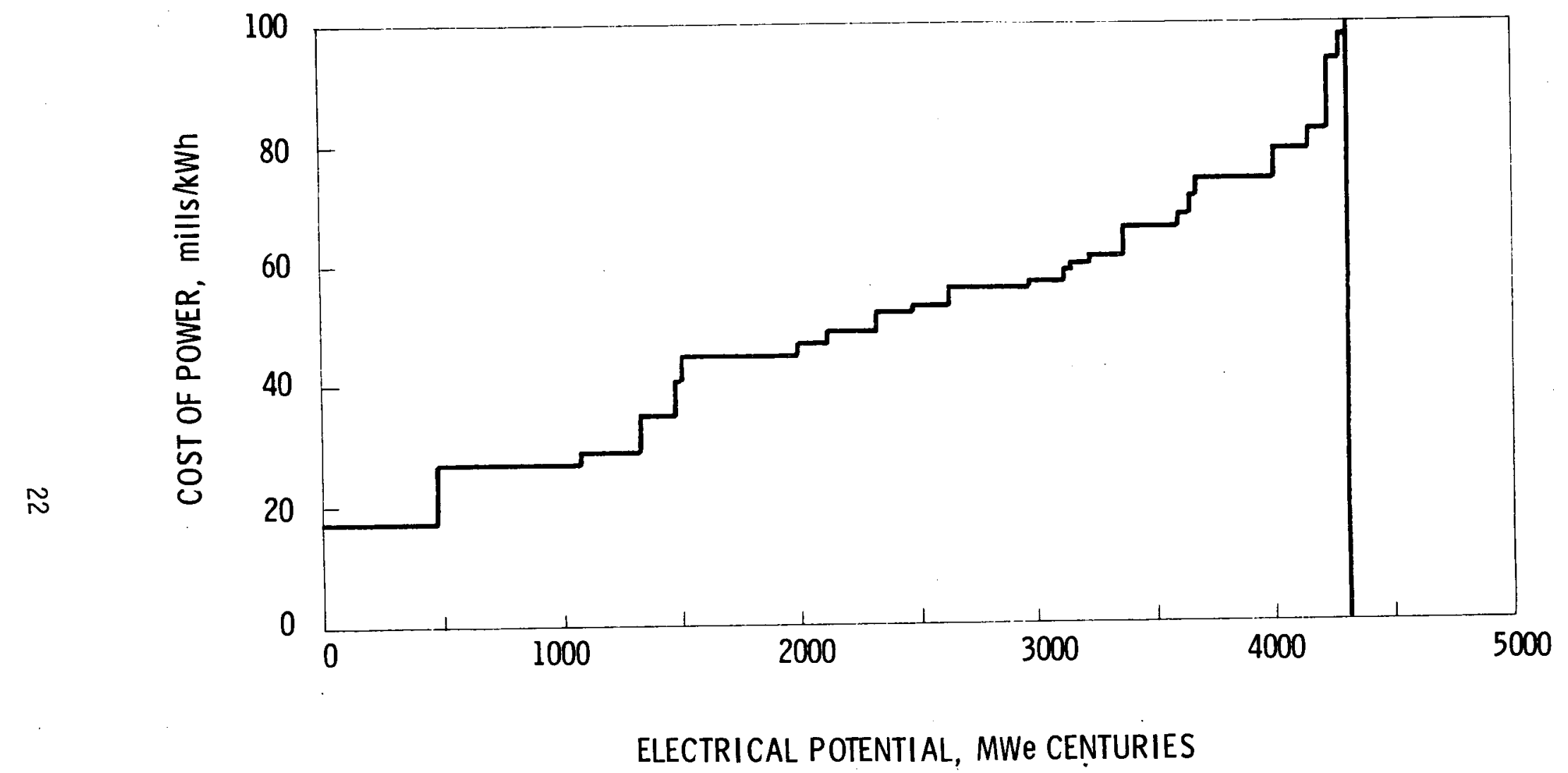

FIGURE 12. Supply Curve for Direct-Contact Heat Exchanger Program (Direct-Contact Exchangers) 


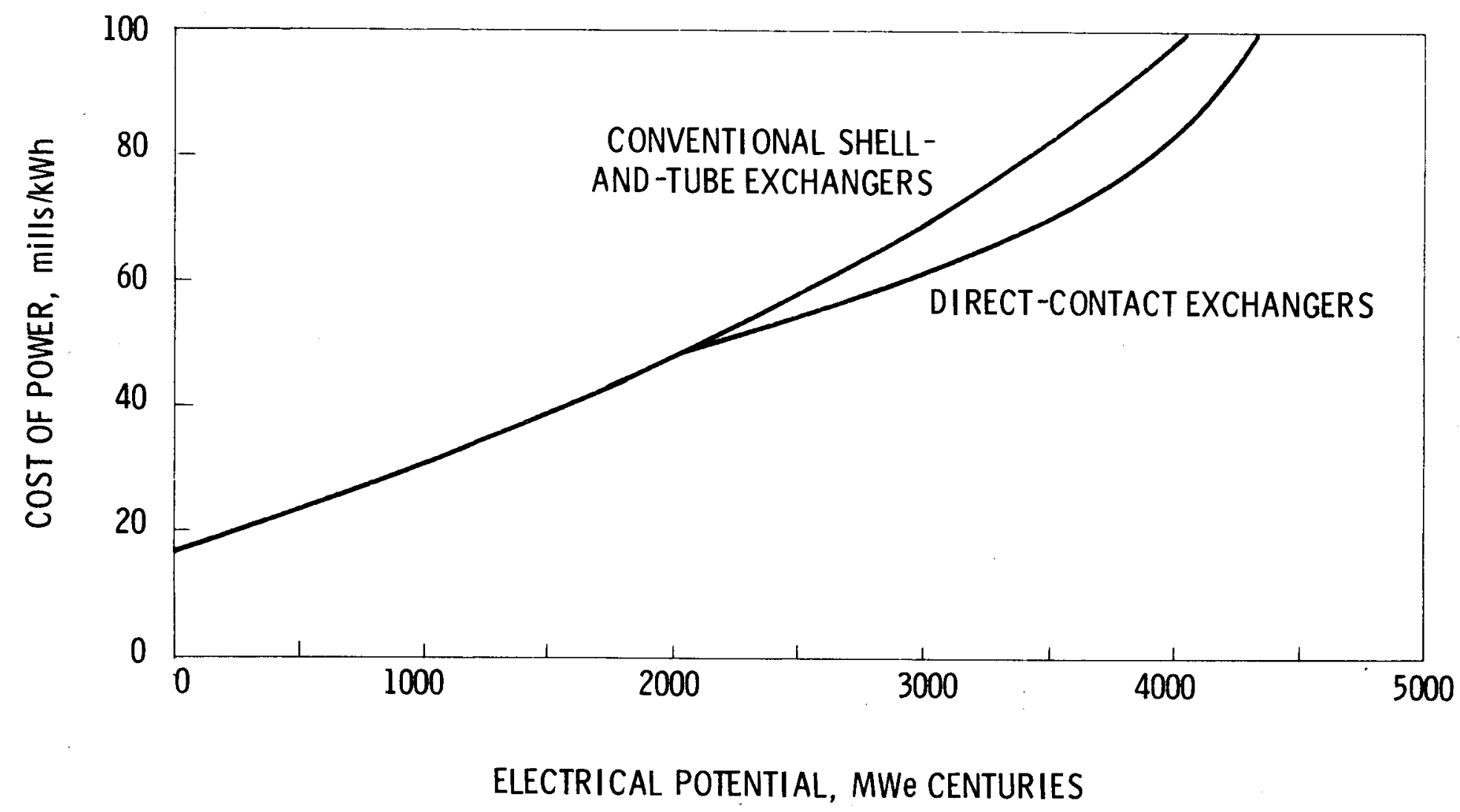

FIGURE 13. Supply Curves for Direct-Contact Heat Exchanger Program 
PROGRAM: DOWNHOLE PUMPS

OBJECTIVES: The purpose of this program is to develop a downhole pump with the following characteristics:

$\begin{array}{ll}\text { Maximum Temperature Limit } & 180^{\circ} \mathrm{C} \\ \text { Maximum Flow Rate } & 2000 \mathrm{GPM} \\ \text { Life } & 5 \text { Years }\end{array}$

We used these data to model the possible results of the research program. According to the DGE estimate, this technology, which we will refer to as advanced downhole pumps, is expected to be available within the next year or two.

To determine the impact of the program on the supply of geothermal energy, we had to establish reference conditions to represent the current state-of-the-art. Based on information in the literature $(7,8)$, we used the following assumptions for conventional downhole pumps:
Maximum Temperature Limit
$180^{\circ} \mathrm{C}$
Maximum Flow Rate
880 GPM
Life
9 Months

Based on vendor data obtained in a telephone conversation with Harold Samford of Peerless Pump in Montebello, California, we assumed a cost of $\$ 125,000$ per pump. We used this cost for both conventional and advanced downhole pumps, since it lies within the range of published cost estimates for advanced downhole pumps $(9)$.

RESULTS: $\quad$ Figure 14 represents the current situation, which means using conventional downhole pumps. Figure 15 represents achievement of the objective of developing and using advanced downhole pumps. In Figure 16, we have plotted smooth curves to represent the two cases previously shown as step functions. As Figure 16 indicates, the impact of advanced downhole pumps would be twofold: (1) the cost of power from resources with subsurface temperatures $<180^{\circ} \mathrm{C}$ 
would decrease dramatically, and (2) the supply of geothermal electrical potential available at or below a cost of $100 \mathrm{mills} / \mathrm{kWh}$ would increase from 4,050 MWe centuries to 4,300 MWe centuries.

There would be no impact on the resources with subsurface temperatures $>180^{\circ} \mathrm{C}$, since this is the assumed temperature limit of advanced downhole pumps. Also, the impact is greater for the higher-cost (lower-quality) resources because reservoir costs account for a higher proportion of the costs for these resources. In other words, the lower the brine temperature, the more wells you need for a 50 MWe plant; and the more wells you need, the greater the differential cost between using conventional and advanced downhole pumps.

Assuming that the entire 2,800 MWe centuries of geothermal binary electrical potential shown in Figure 16 is developed, an average cost reduction of $13.50 \mathrm{mills} / \mathrm{kWh}$ amounts to a savings of about $\$ 23$ billion (not discounted). The portion of the curve between 1,500 MWe centuries and 4,300 MWe centuries is assumed to be exploited with the binary cycle. This portion amounts to 2,800 MWe centuries as mentioned above. 


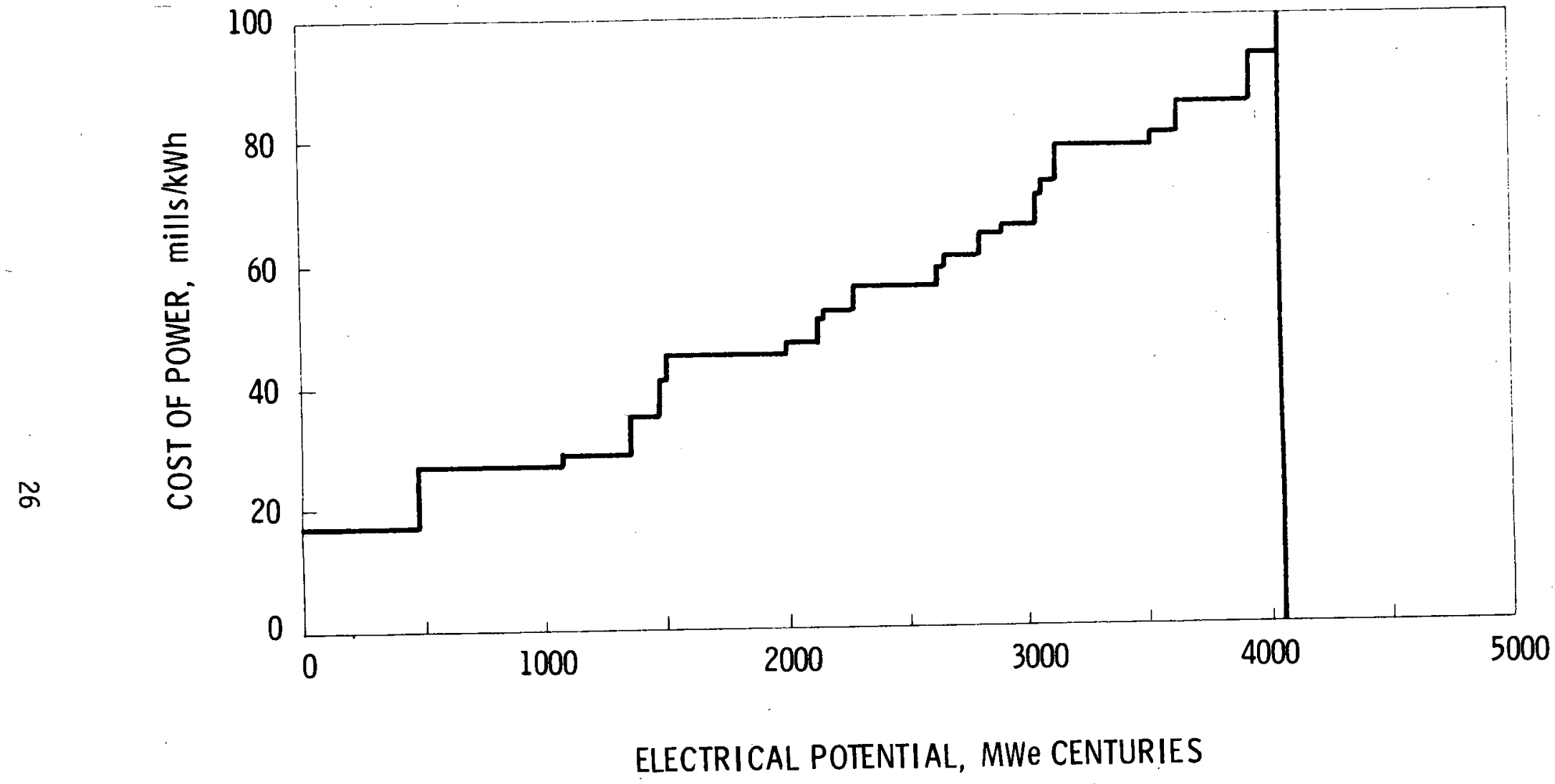

FIGURE 14. Supply Curve for Downhole Pump Program (Conventional Pumps) 


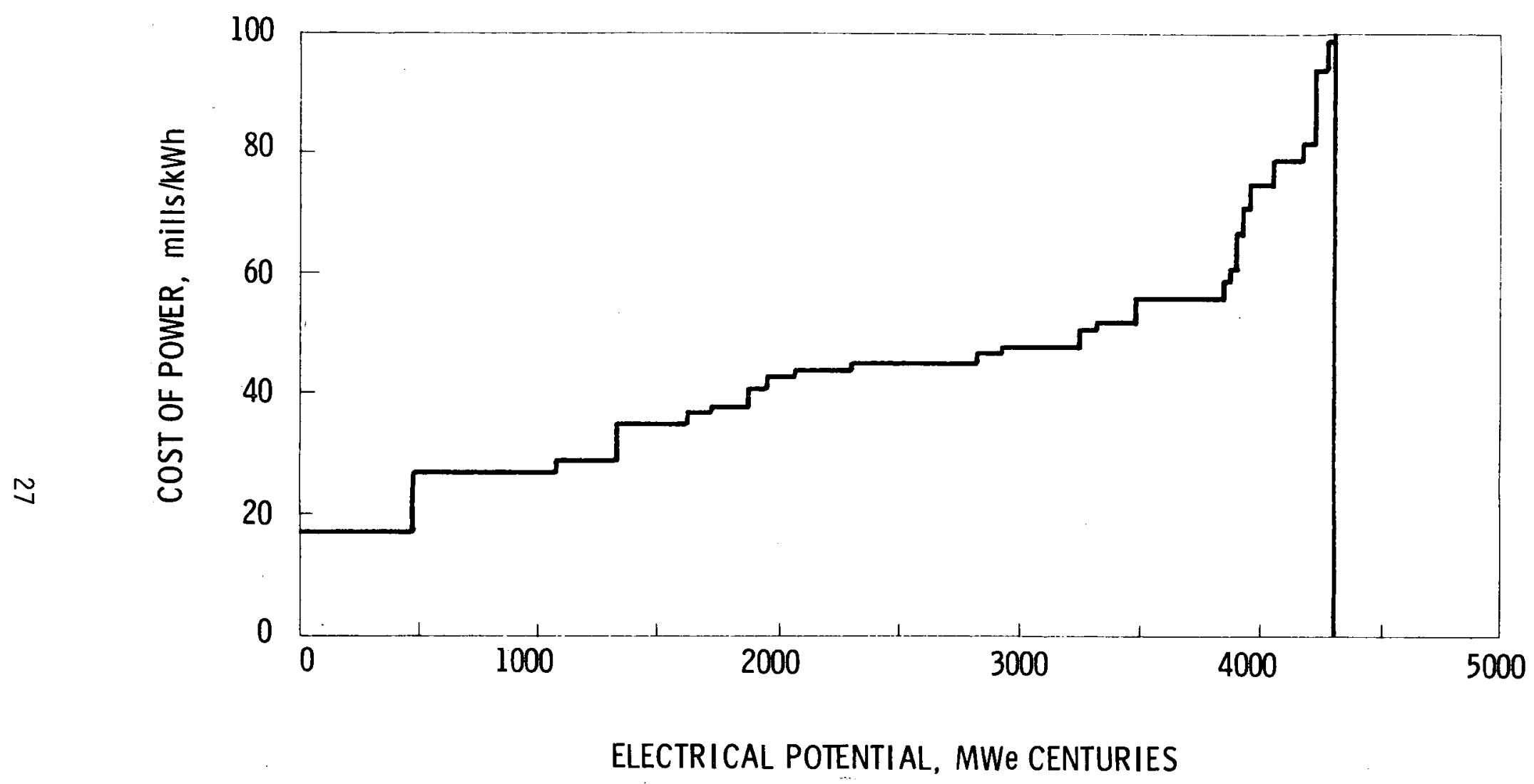

FIGURE 15. Supply Curve for Downhole Pump Program (Advanced Pumps) 


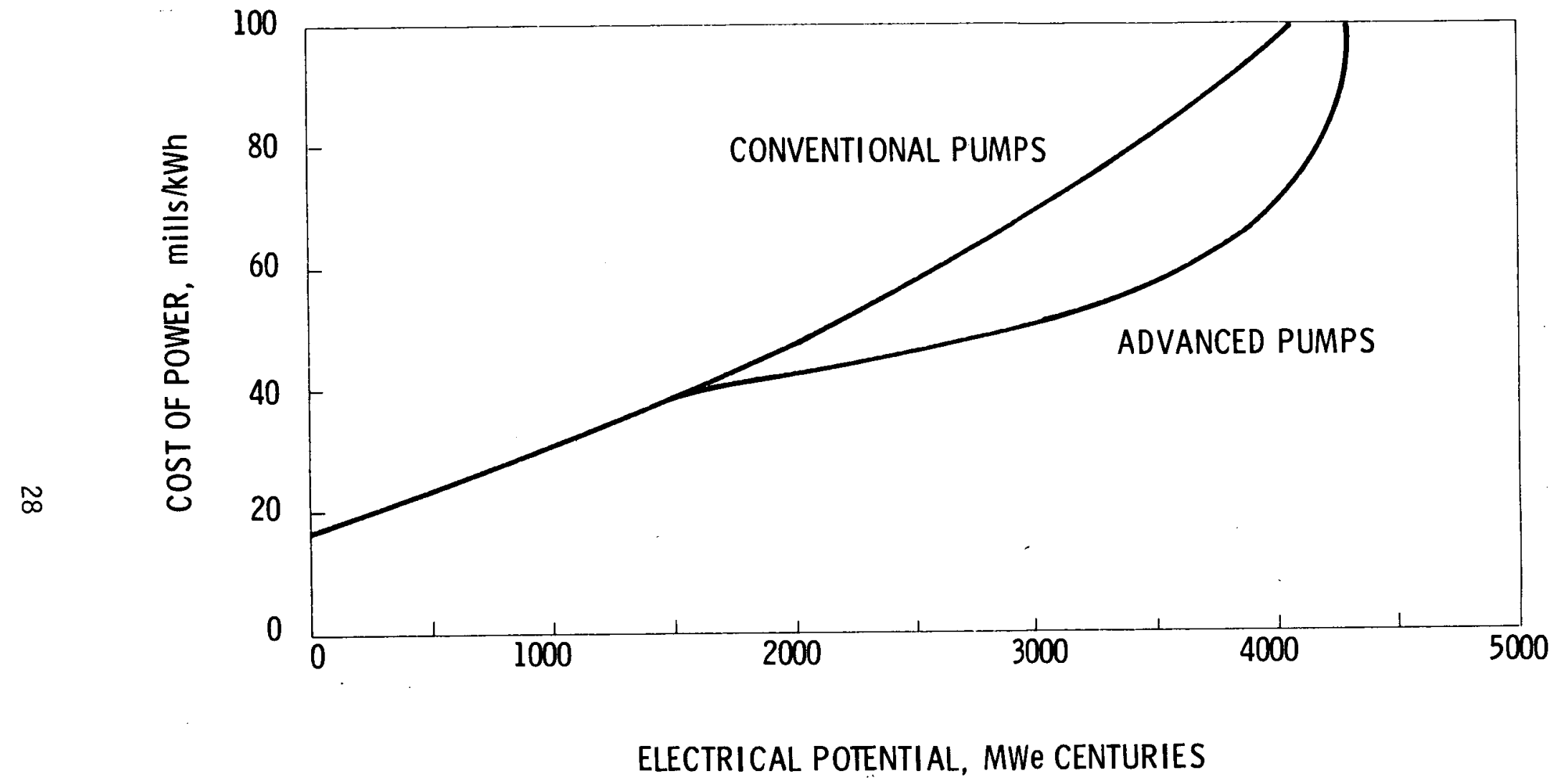

FIGURE 16. Supply Curves for Downhole Pump Program 
PROGRAM:

OBJECTIVE: The purpose of this program is to develop a fluted-tube condenser for the binary cycle which would result in a high film coefficient for heat transfer. This new design could reduce the required condenser area by a factor of 2 . However, the fluted-tube condenser capital cost per square foot should be slightly higher than that of conventional condensers because of more expensive tubes and a higher pressure drop. We assumed that the capital cost per square foot is $10 \%$ higher than the conventional cost used in the GEOCOST model. But since the area is only $50 \%$ of the conventional area, the total cost of a fluted-tube condenser is $55 \%$ of the cost of a conventional condenser. We used this $45 \%$ capital cost savings to model the potential impact of the program.

RESULTS: $\quad$ Figure 17 represents the current situation, which means using conventional condensers. Figure 18 represents achievement of the objective of developing and using fluted-tube condensers. In Figure 19, we have plotted smooth curves to represent the two cases previously shown as step functions. As Figure 19 shows, the impact of fluted-tube condensers would be to reduce the cost of power by $0.70-0.87 \mathrm{mil1} / \mathrm{kWh}$, depending on resource quality. Over the entire 1,850 MWe centuries of geothermal binary electrical potential shown in Figure 19, a $0.70-0.87 \mathrm{mill} / \mathrm{kWh}$ reduction in the cost of power amounts to a savings of between $\$ 0.79$ and $\$ 0.99$ billion (not discounted).

The portion of the curve between 2,200 MWe centuries and 4,050 MWe centuries is assumed to be exploited with the binary cycle. This portion amounts to 1,850 MWe centuries as mentioned above. 


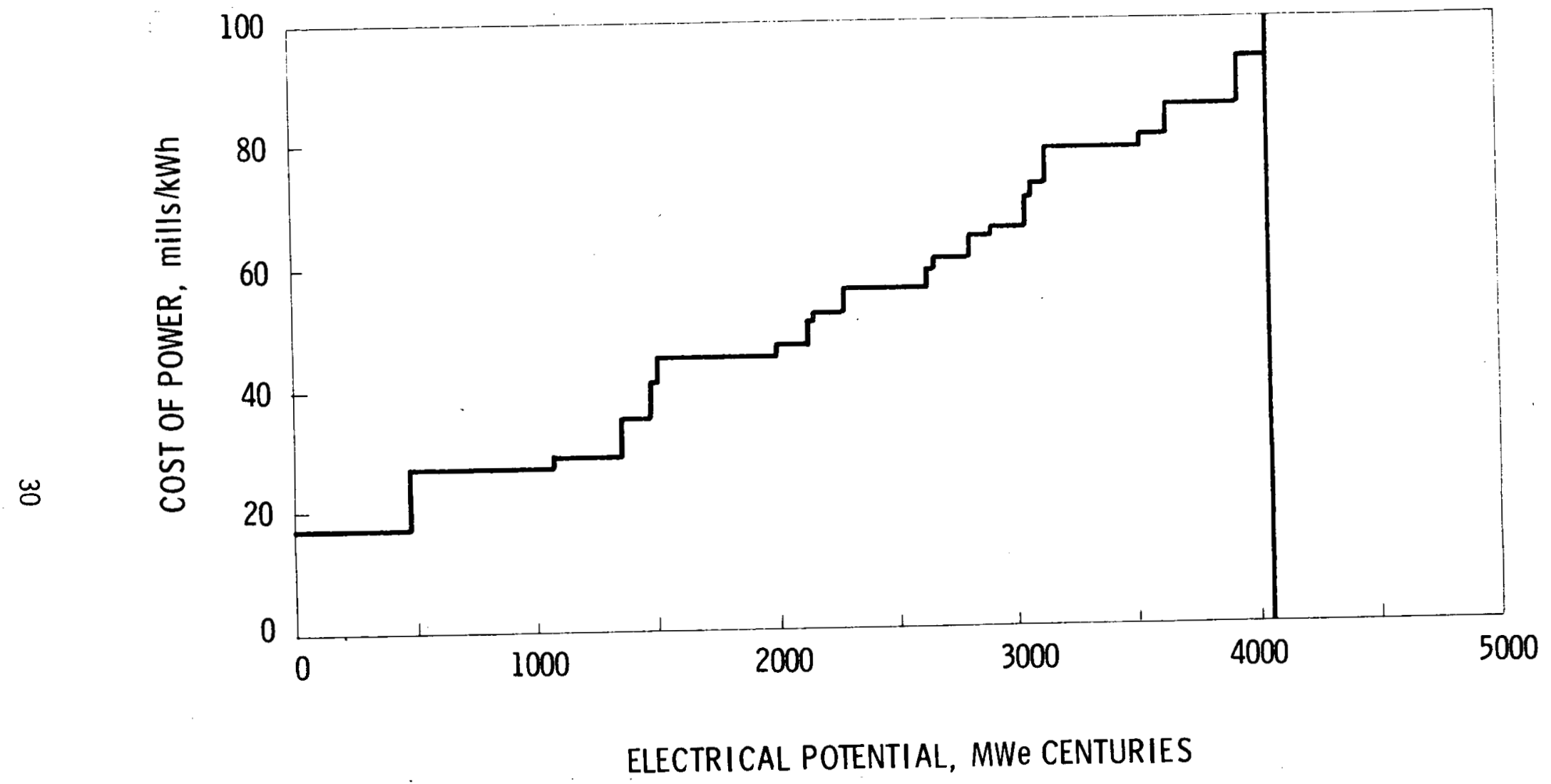

FIGURE 17. Supply Curve for Fluted-Tube Condenser Program (Conventional Condensers) 


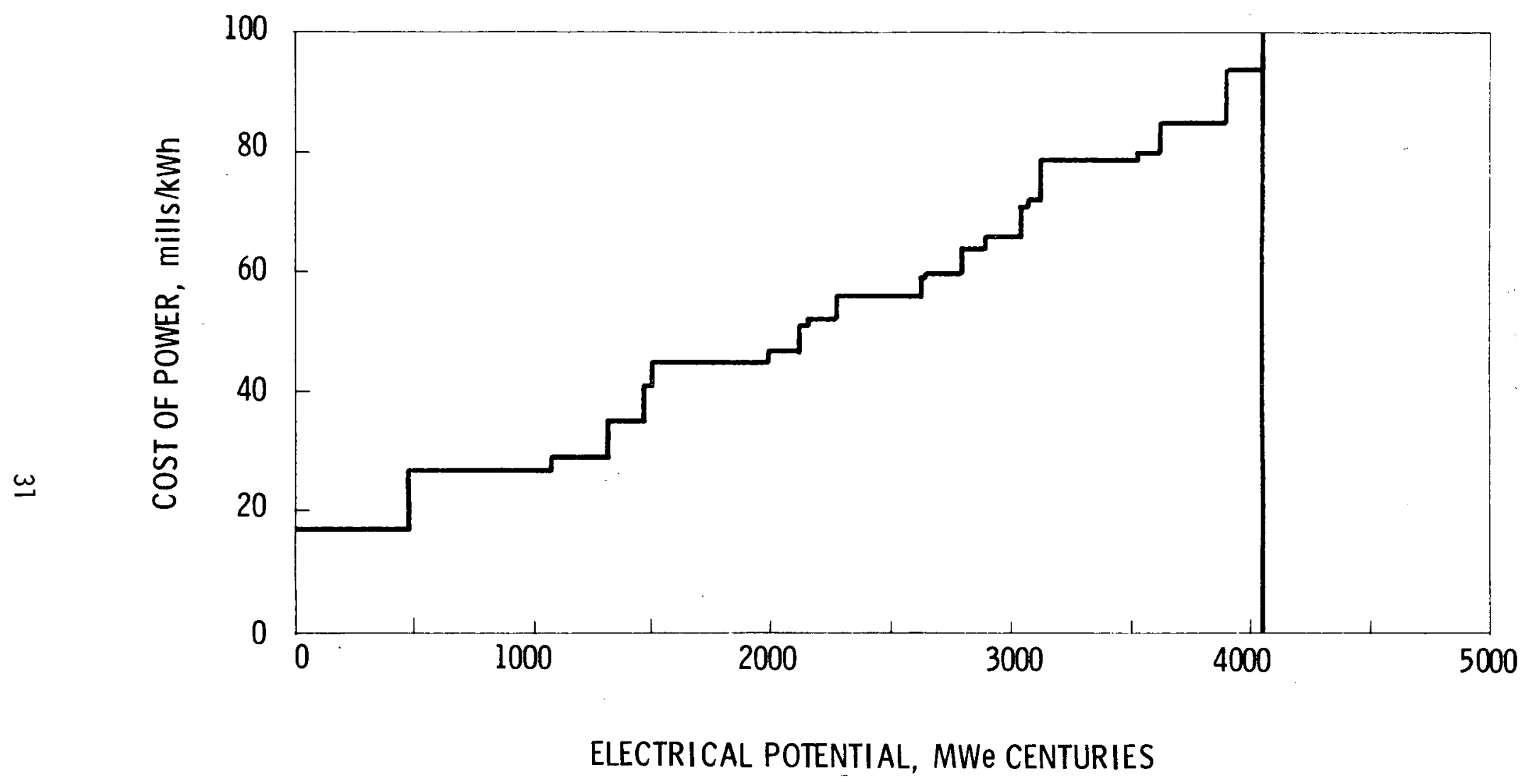

FIGURE 18. Supply Curve for Fluted-Tuke Condenser Program (Fluted-Tube Condensers) 


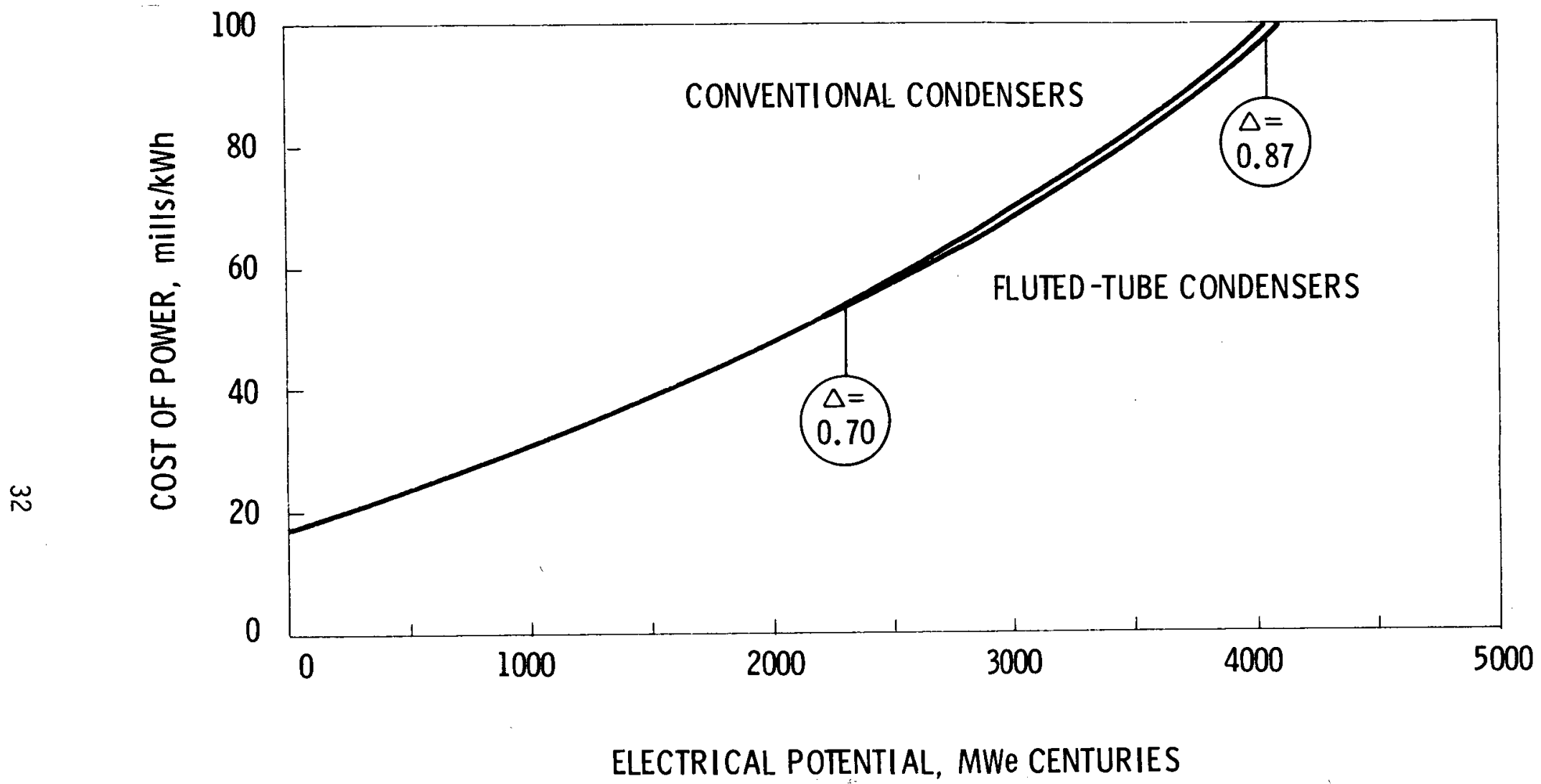

FIGURE 19. Supply Curves for Fluted-Tube Condenser Program 
PROGRAM: RESERVOIR ENGINEERING - RESERVOIR VERIFICATION

OBJECTIVES: Currently 15 to 20 wells are required to prove a resource for a 50 MWe geothermal power plant. In addition, it takes several months of testing to verify each well to the satisfaction of potential investors and to gather data to verify reservoir models. The near-term objective (by 1985) is to reduce by one-half the number of wells required to prove a resource, which will also reduce by one-half the time required between the start of drilling and the initiation of plant construction. The long-term objective (by 2000) is to reduce the number of wells needed to prove a resource for a 50 Mwe plant to three to five wells, thereby resulting in minimal time required for reservoir verification so production drilling can occur concurrently with plant construction. Figure 20 is a bar graph that reflects the timing of these activities.

RESULTS: The Base Case represents the current situation, with a 6-month testing period for the production wells prior to power plant construction. The 1985 Case represents the ability to prove a resource with only half as many production wells as are currently required for this purpose. The 2000 Case represents the ability to prove a resource with only 3 to 5 wells.

In Figure 24, we have plotted smooth curves to represent the three cases previously shown as step functions. The GEOCOST results show that by the year 2000, the cost of power at The Geysers can be lowered by $1 \mathrm{mill} / \mathrm{kWh}$ and the cost of power generated by a lower-quality resource (subsurface temperature $=145^{\circ} \mathrm{C}$ ) can be lowered by 6 mills/ kWh. Assuming that the entire 4,050 MWe centuries of geothermal electrical potential shown in Figure 24 is developed at an average savings of $3.5 \mathrm{mills} / \mathrm{kWh}$, the reduced cost of power by the year 2000 would amount to $\$ 8.7$ billion (not discounted). 


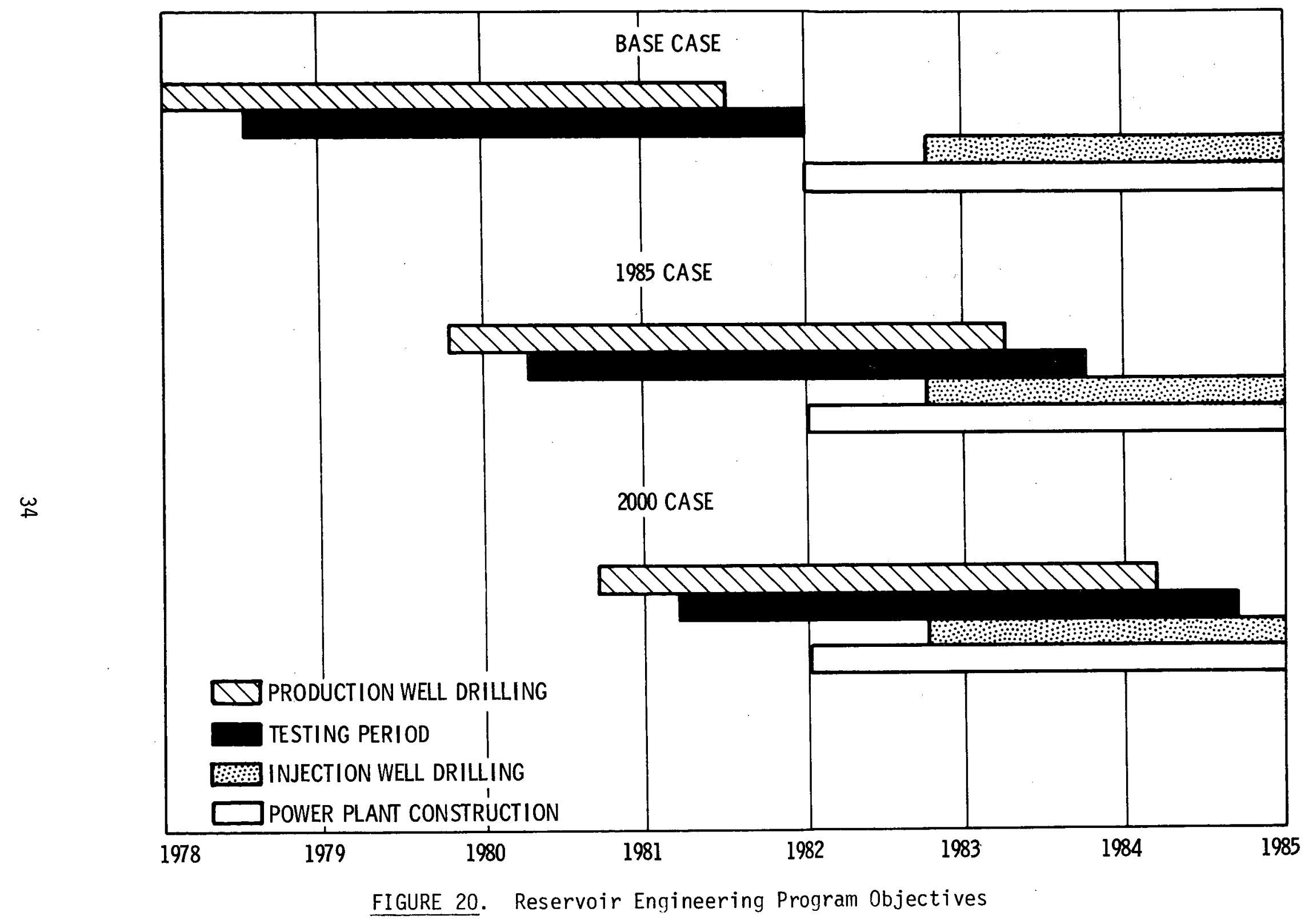




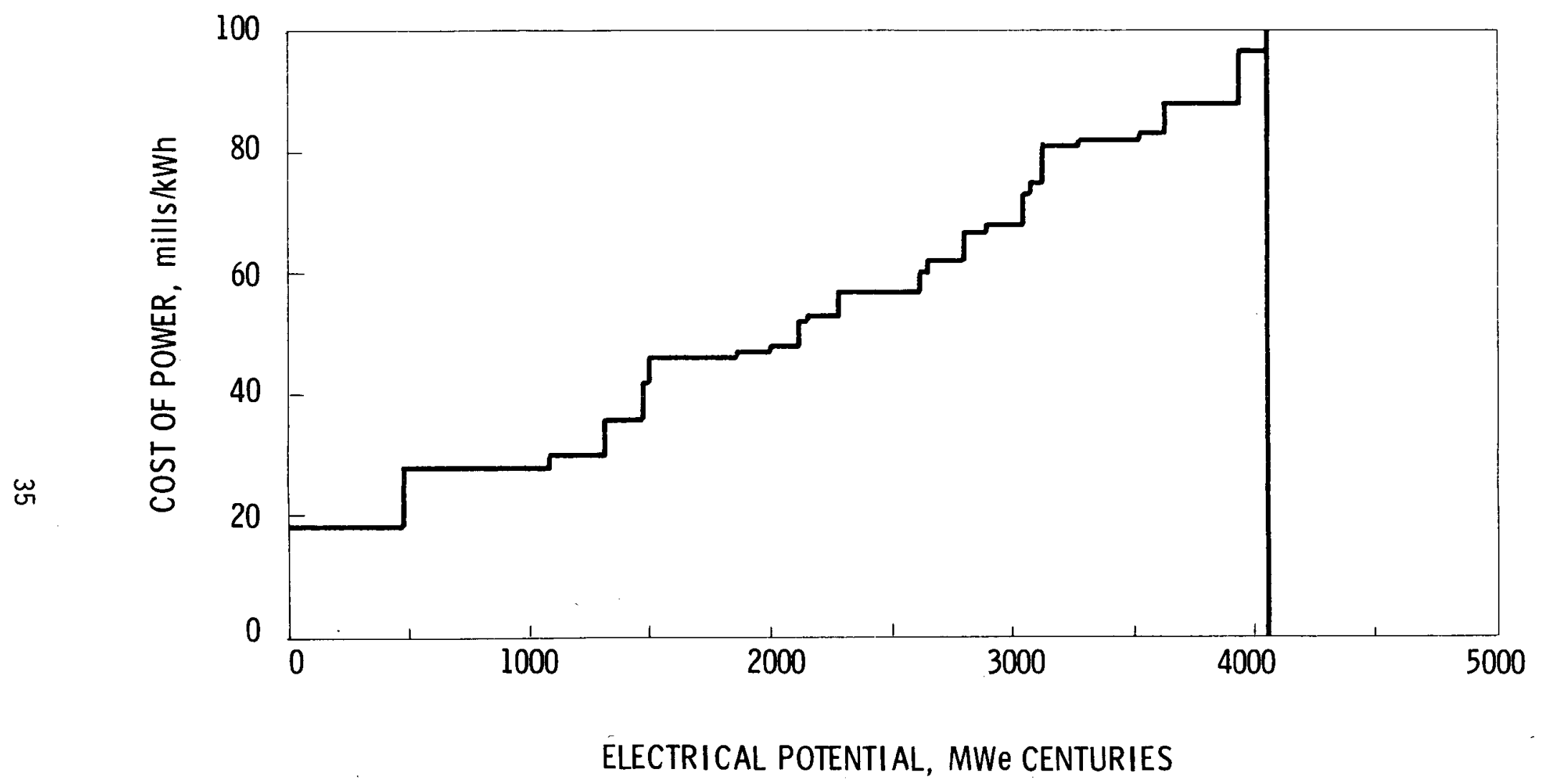

FIGURE 21. Supply Curve for Reservoir Engineering Program (Base Case) 


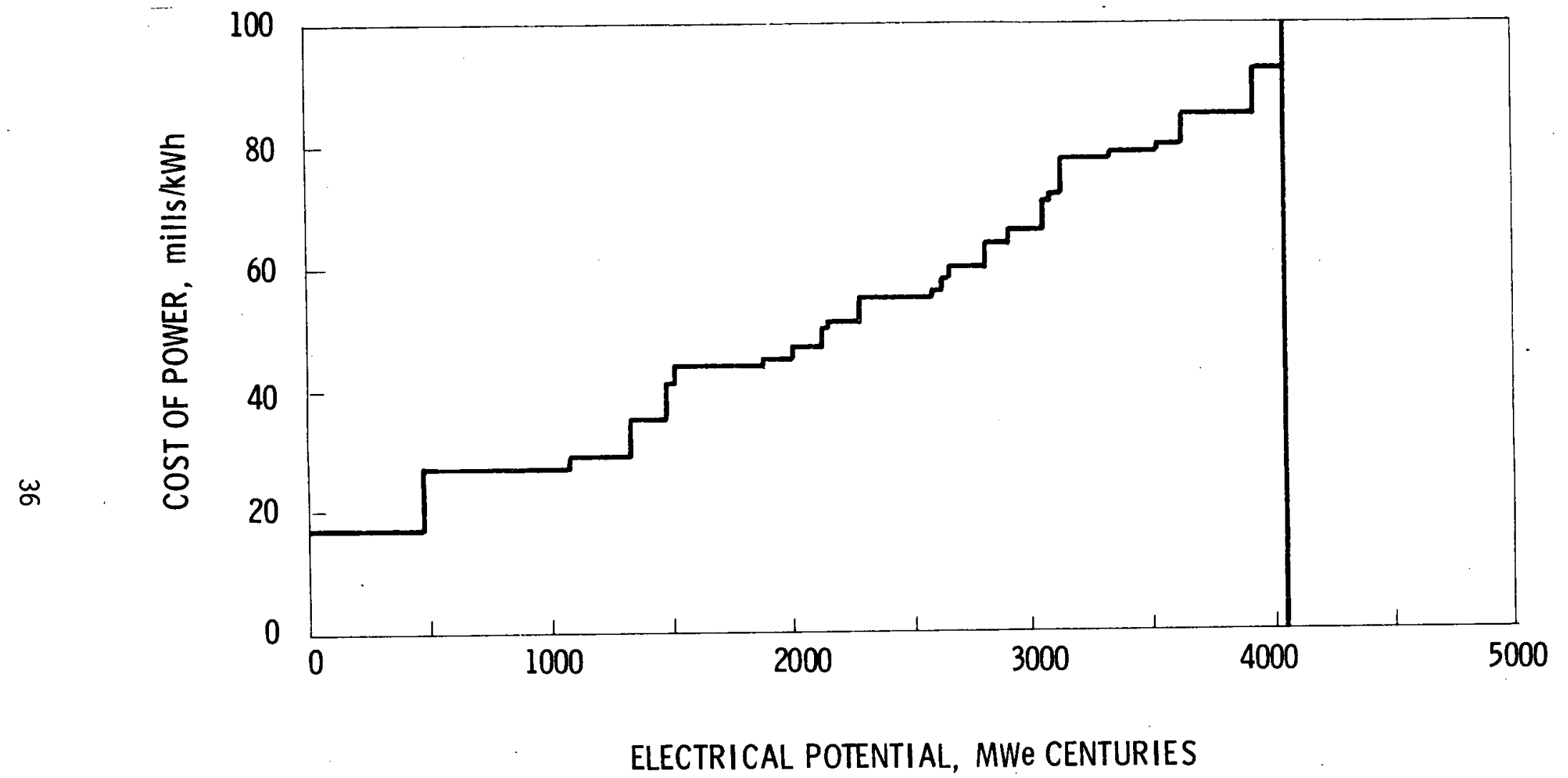

FIGURE 22. Supply Curve for Reservoir Engineering Program (1985 Case) 


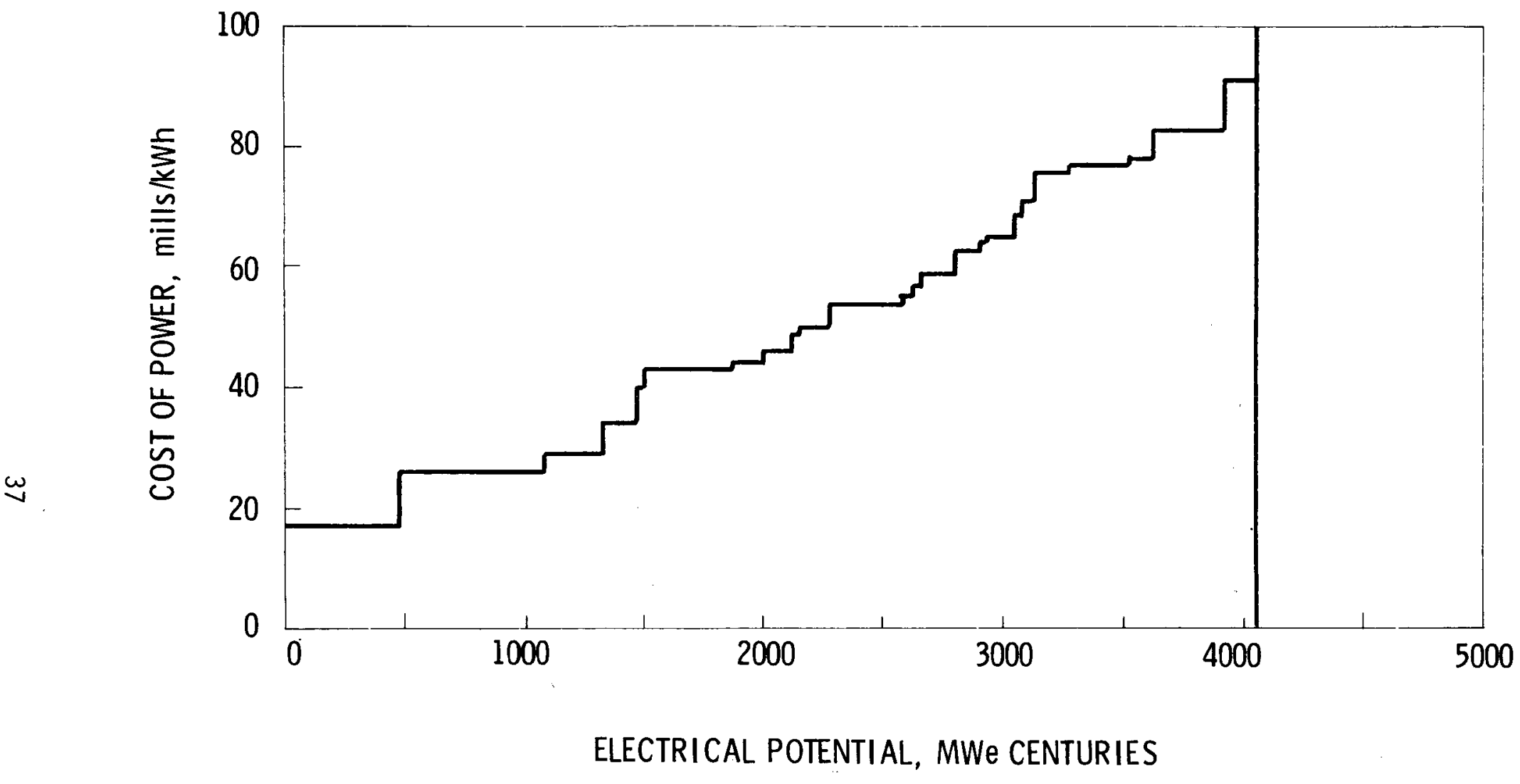

FIGURE 23. Supply Curve for Reservoir Engineering Program (2000 Case) 


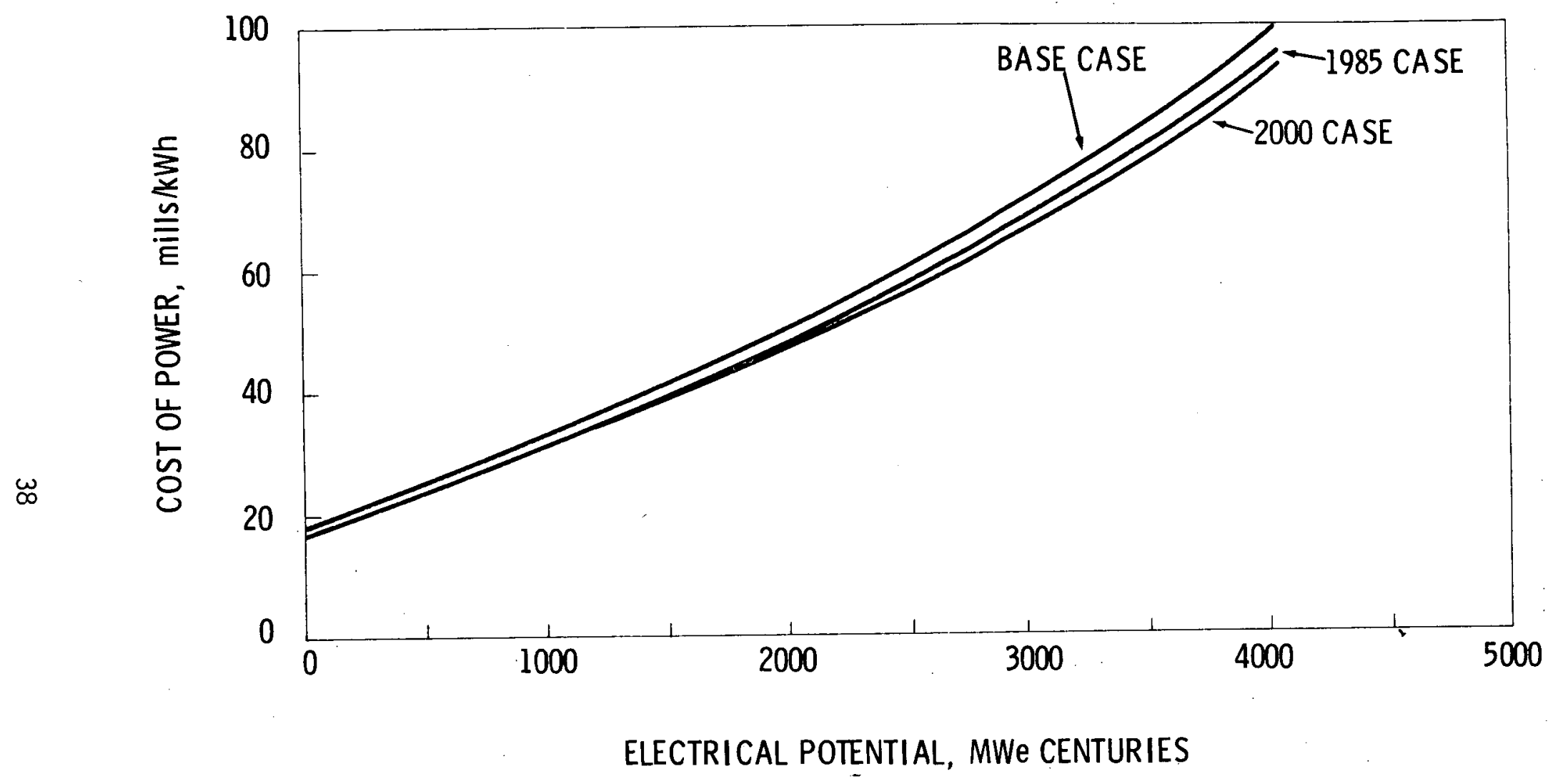

FIGURE 24. Supply Curves for Reservoir Engineering Program 
PROGRAM: $\quad$ INJECTION WELL STIMULATION

OBJECTIVE: The objective of this program is to extend injection well life by $50 \%$ through routine maintenance, at a minimum cost of $\$ 50,000$ per wel1. Here we are assuming that currently the life of an injection well is 3-6 years. The probability of needing to stimulate a well, the probability of success, the cost of stimulation, and the life of an injection well are all site-specific parameters. However, for our purposes we used the following representative values to model the possible results of this research program:

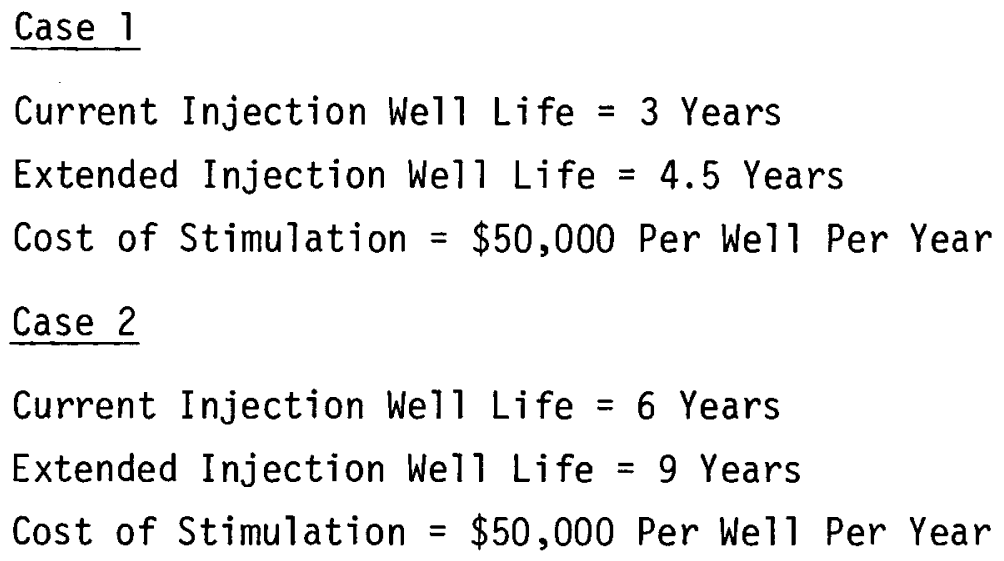

These cases bracket the assumed range for current well life.

RESULTS: $\quad$ Figure 25 represents the current situation if injection well 1 ife is 3 years. Figure 26 represents achievement of the objective of increasing the well life to 4.5 years at an annual maintenance cost of $\$ 50,000$ per wel1. If, on the other hand, the current injection well life is 6 years, then the situation is represented by Figure 28 . Similarly, Figure 29 portrays the results of increasing the well life to 9 years at an annual maintenance cost of $\$ 50,000$ per well. In Figures 27 and 30 we have plotted smooth curves to represent the cases previously shown as step functions. As Figure 27 indicates, the impact of extending injection well 1 ife from 3 years to 4.5 years would be to lower the cost of power by $0-4 \mathrm{mills} / \mathrm{kWh}$, depending upon the resource temperature. Figure 30 shows that the impact of extending injection well life from 6 to 9 years would be to lower the cost of power by about $1 \mathrm{mill} / \mathrm{kWh}$. 
Comparison of Figures 27 and 30 shows that the supply curves in Figure 27 diverge more than those in Figure 30 do. The explanation for this difference lies in the values used for well lifetimes:

Well Life, Years

4.5

6

9
Fraction of Wells Replaced Each Year

$$
\left.\begin{array}{rl}
1 / 3 & =0.33 \\
1 / 4.5 & =0.22 \\
1 / 6 & =0.17 \\
1 / 9 & =0.11
\end{array}\right\} \Delta=0.11
$$

When the well life is increased from 3 years to 4.5 years, the number of injection wells that must be replaced each year is decreased by 11 percent. But when the well life is increased from 6 to 9 years, the number of replacement wells is decreased by only 6 percent. Since the percentage improvement decreases, the potential cost savings are lower and, thus, the supply curves are closer together in Figure 30 than in Figure 27 . In other words, this program will have a greater impact on the long-term supply curve if the current injection well life is actually on the low end of the assumed range.

Assuming that the entire 3,650 MWe centuries of geothermal electrical potential shown in Figure 27 is developed, the lowered cost of power would amount to a savings of about $\$ 4.5$ billion (not discounted). If the entire 3,925 MWe centuries shown in Figure 30 is developed, the savings would be about $\$ 1.2$ billion (not discounted). 


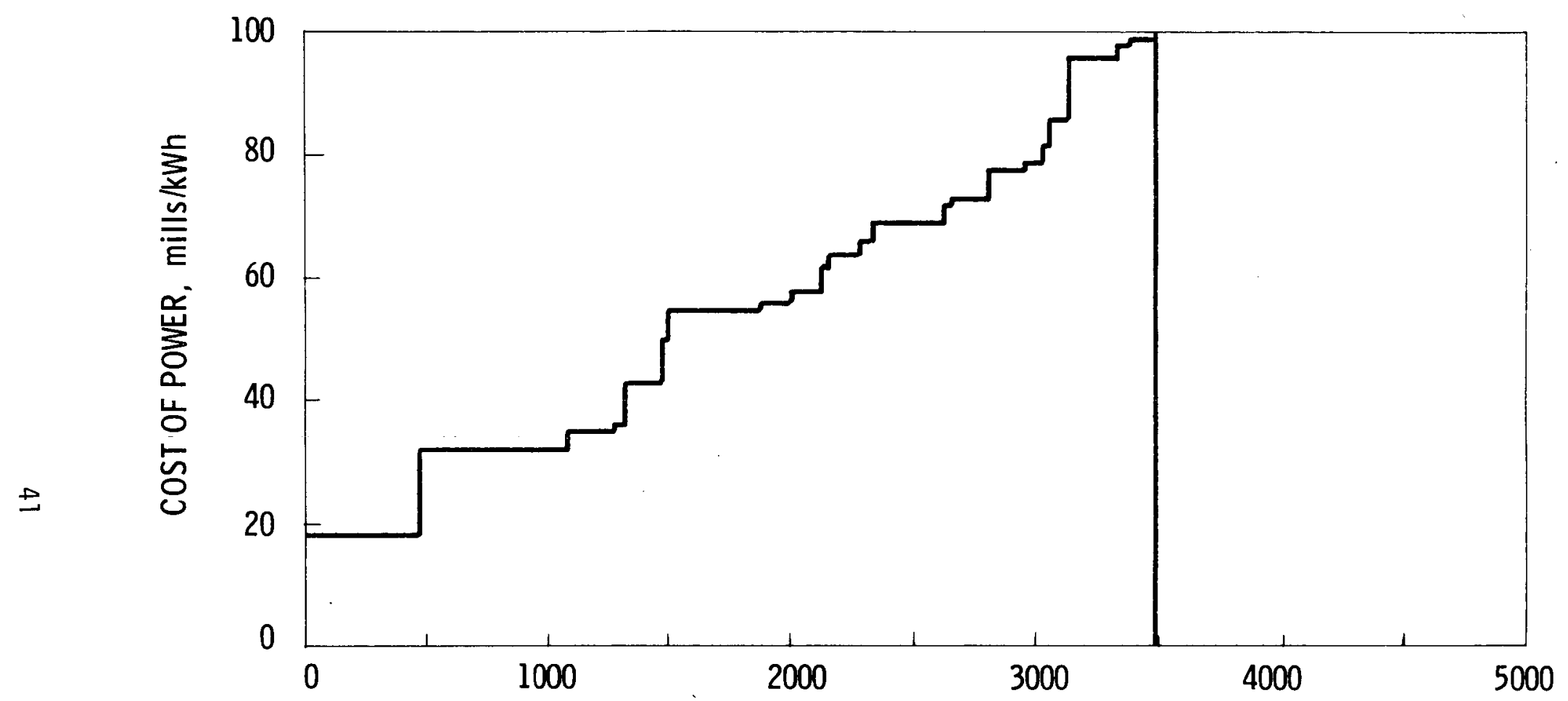

ELECTRICAL POTENTIAL, MWe CENTURIES

FIGURE 25. Supply Curve for Injection We1l Stimulation Program (3-Year Injection Uell Life) 


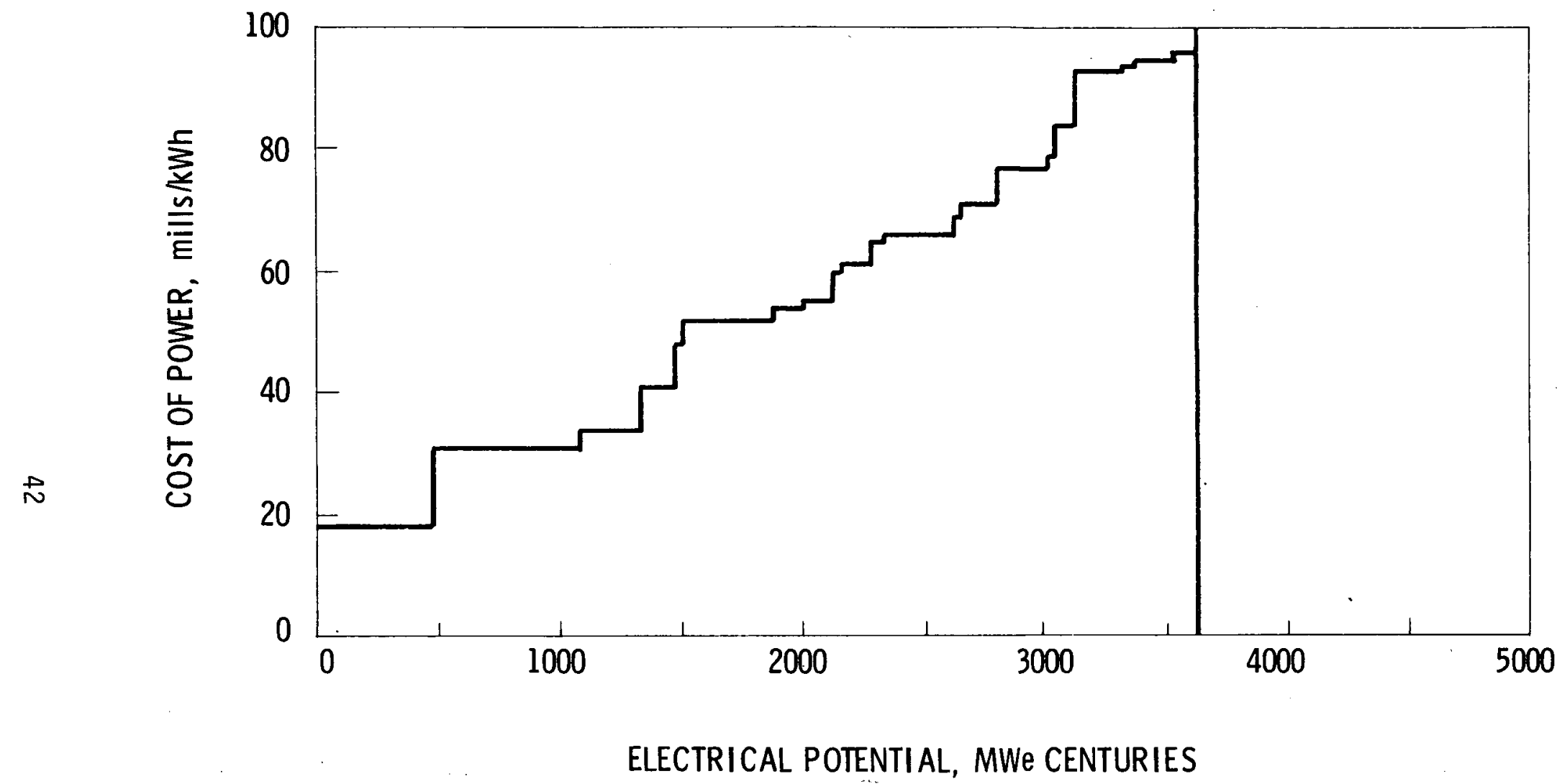

FIáURE 26. Supply Curve for Injection Well Stimulation Program (4.5-Year Injection Well Life) 


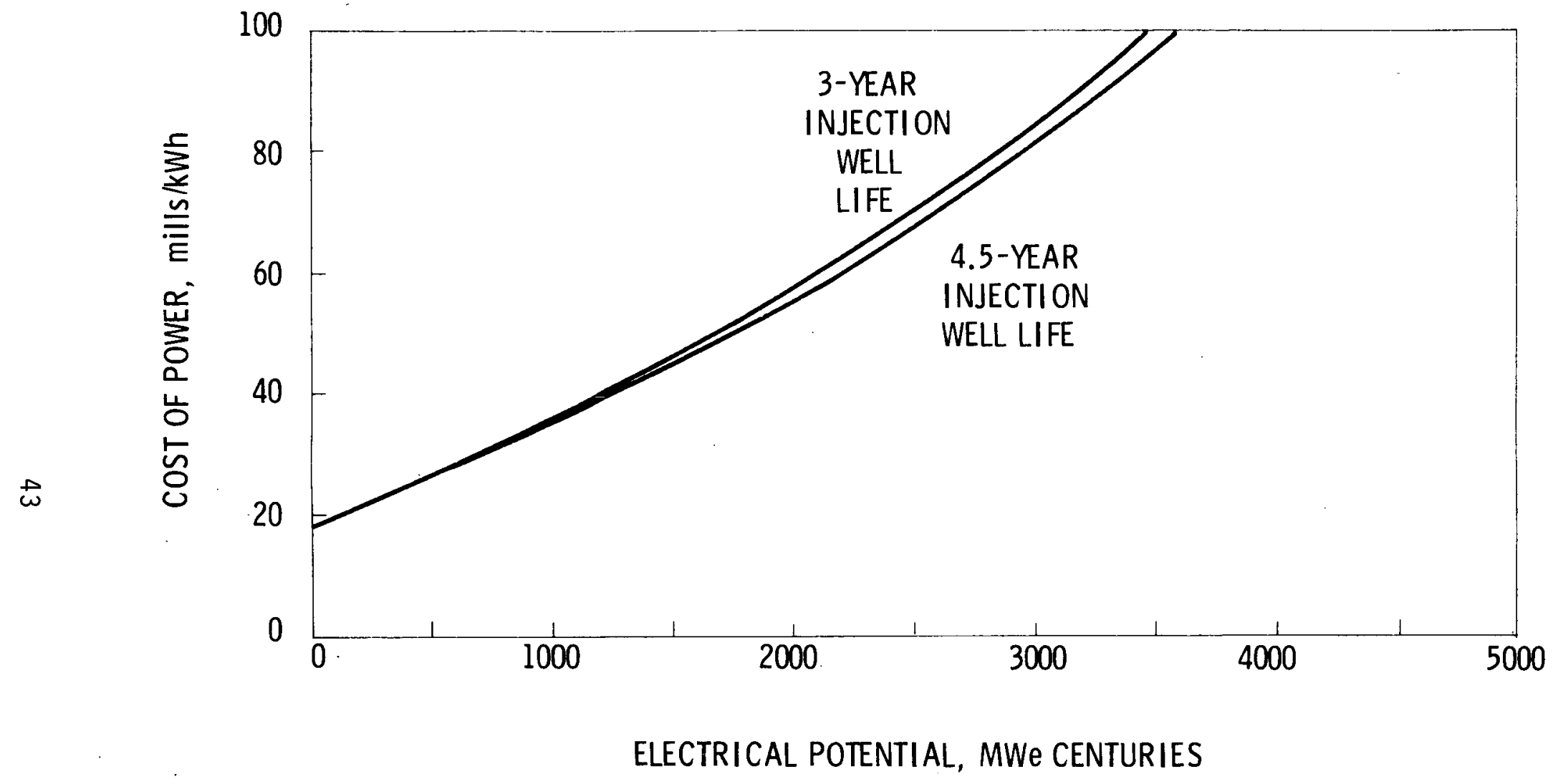

FIGURE 27. Supply Curves for Injection Well Stimulation Program 


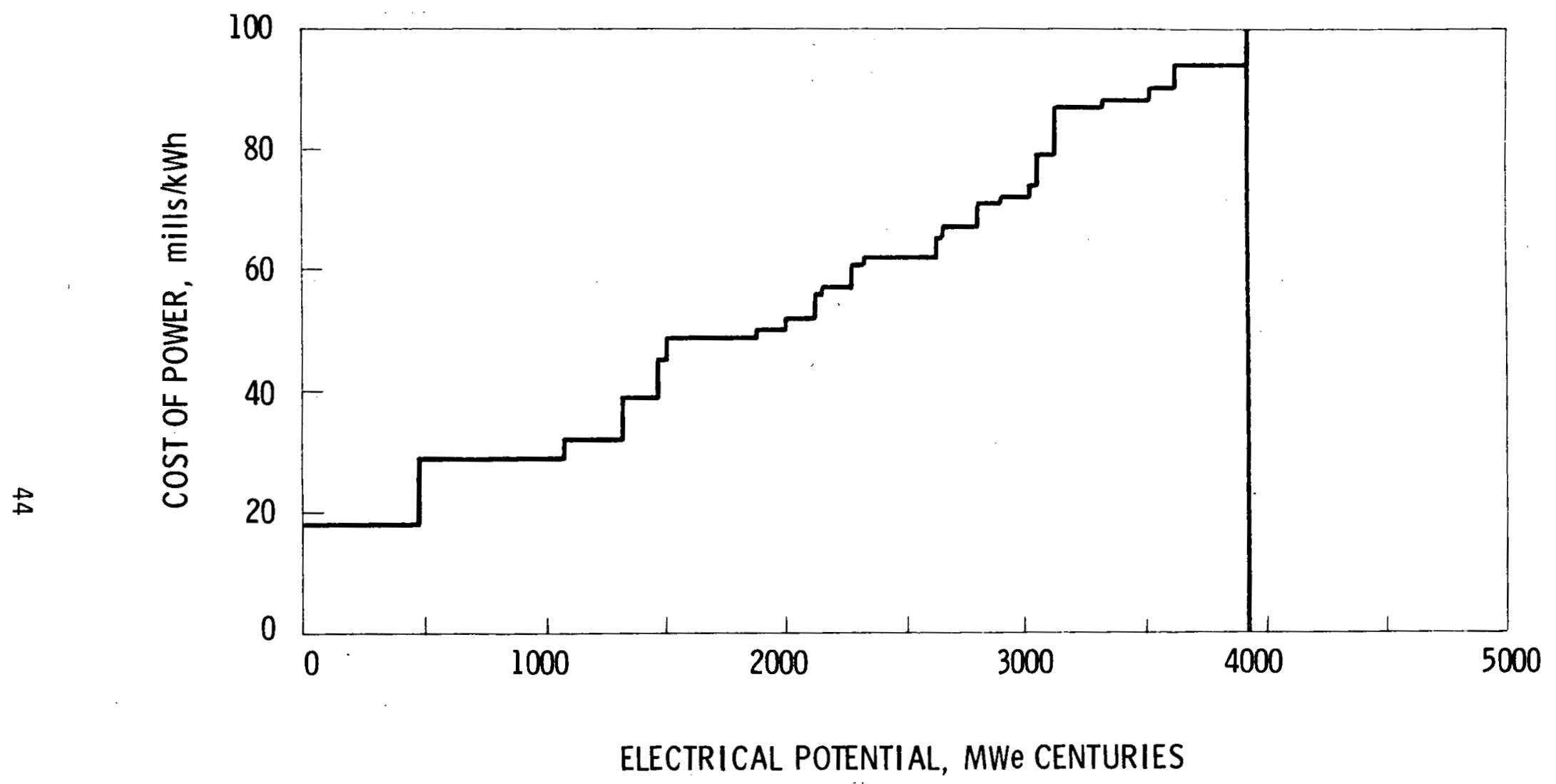

FIGURE 28. Supply Curve for Injection Well Stimulation Program (6-Year Injection Well Life) 


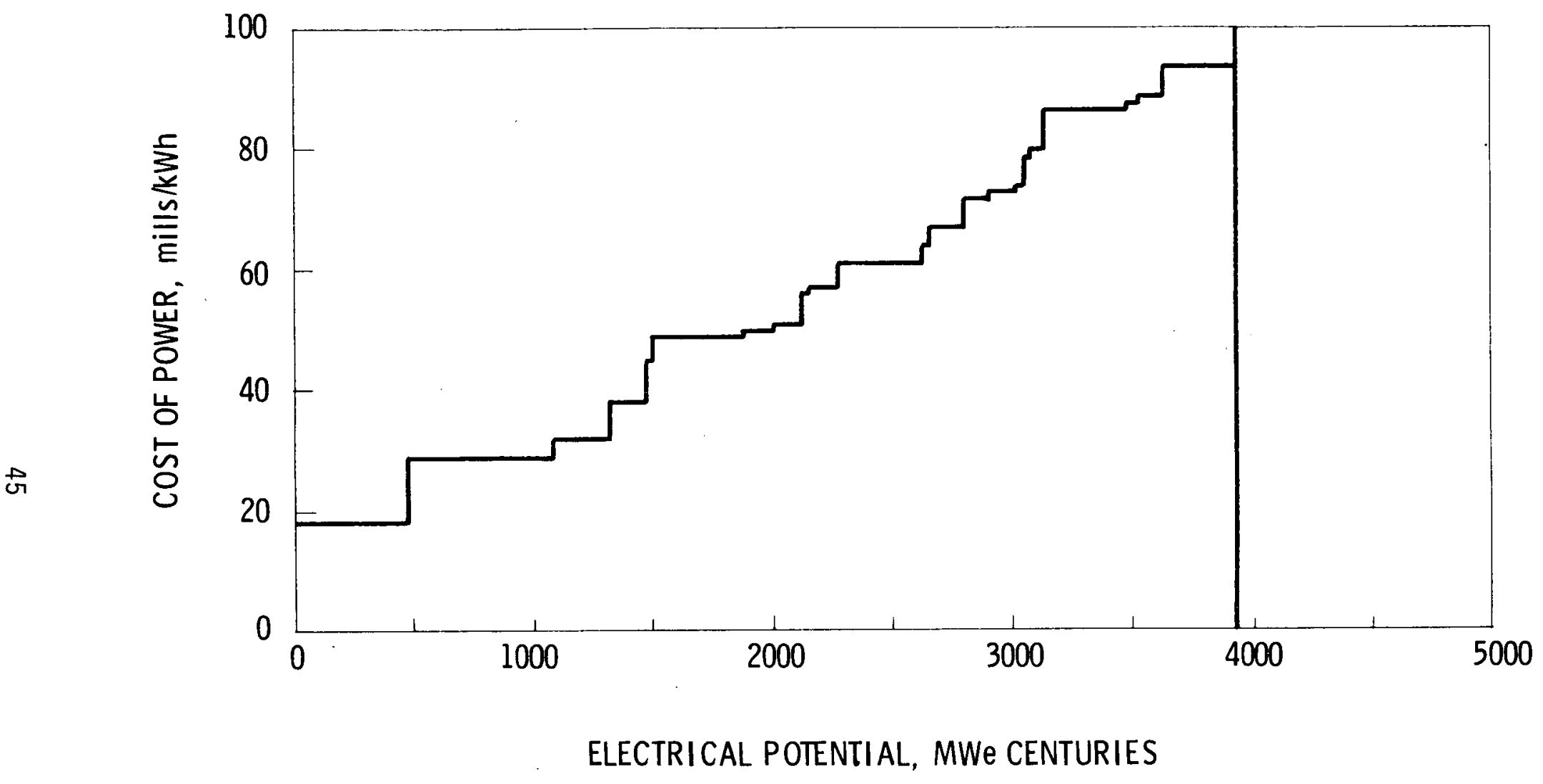

FIGURE 29. Supply Curve for Injection Well Stimulation Program (9-Year Injection Well Life) 


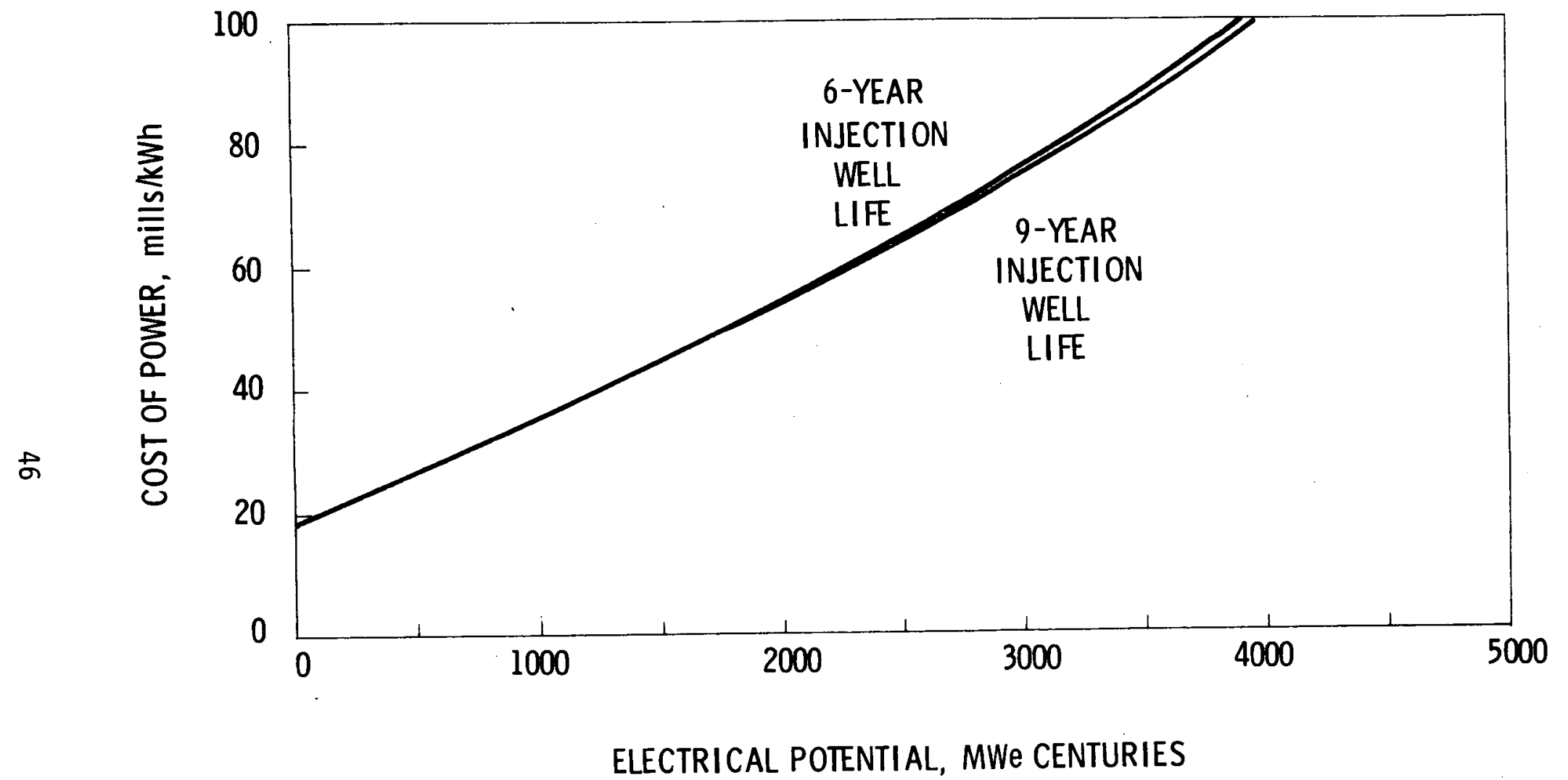

FIGURE 30. Supply Curves for Injection Well Stimulation Program 
PROGRAM:

POLYMER CONCRETE

OBJECTIVE: The objective of this program is to develop a polymer concrete for lining piping and pressure vessels in geothermal power plants. Because polymer concrete doesn't pit or corrode, its use as an alternate material to carbon steel is expected to result in plant capital cost savings and plant operating cost savings. The Burns and Roe economic assessment $(10)$ of this program proved very useful in this analysis.

Burns and Roe reviewed the Bechtel conceptual designs (11) for 50 Mlle geothermal power plants at Heber and Niland and identified areas where polymer concrete could replace the carbon steel vessels and piping specified by Bechtel. The Burns and Roe report concluded that the following cost savings were possible for the Heber flashed steam plant design:

- $80 \%$ reduction in the capital cost of the steam separators;

- $40 \%$ reduction in the capital cost of the supply and injection piping; and

- $29 \%$ reduction in the capital cost of the power plant piping.

In addition, the report concluded that the load factor of the plant could be increased (from the $70 \%$ assumed by Bechtel) to $74 \%$. We used these estimated cost savings and this improvement in the load factor to model the possible results of this research program. (For binary plants, we omitted the $29 \%$ reduction in the cost of the power plant piping, since we have no data on the technical or economic feasibility of using polymer concrete in conjunction with organic working fluids.)

We realize that the more corrosive the brine is, the greater the potential cost savings with the use of polymer concrete. However, we did not include the effect of brine chemistry in our analysis.

RESULTS: $\quad$ Figure 31 (Reference Case) represents the current situation, which means using carbon steel piping and steam separators. Figure 32 represents achievement of the objective of developing and using a poly- 
mer concrete to line the piping and separators, and thus reducing the plant capital and operating costs.

In Figure 33, we have plotted smooth curves to represent the two cases previously shown as step functions. As Figure 33 indicates, the impact of the plant cost savings resulting from the use of polymer concrete would be to lower the cost of power by $0-3 \mathrm{mills} / \mathrm{kWh}$, depending upon the resource temperature. The mean cost savings is $1.5 \mathrm{mills} / \mathrm{kWh}$, which would lead to a savings of $\$ 3.73$ bilion (not discounted) if the entire 4,050 MWe centuries of geothermal electrical potential shown in Figure 33 were developed. 


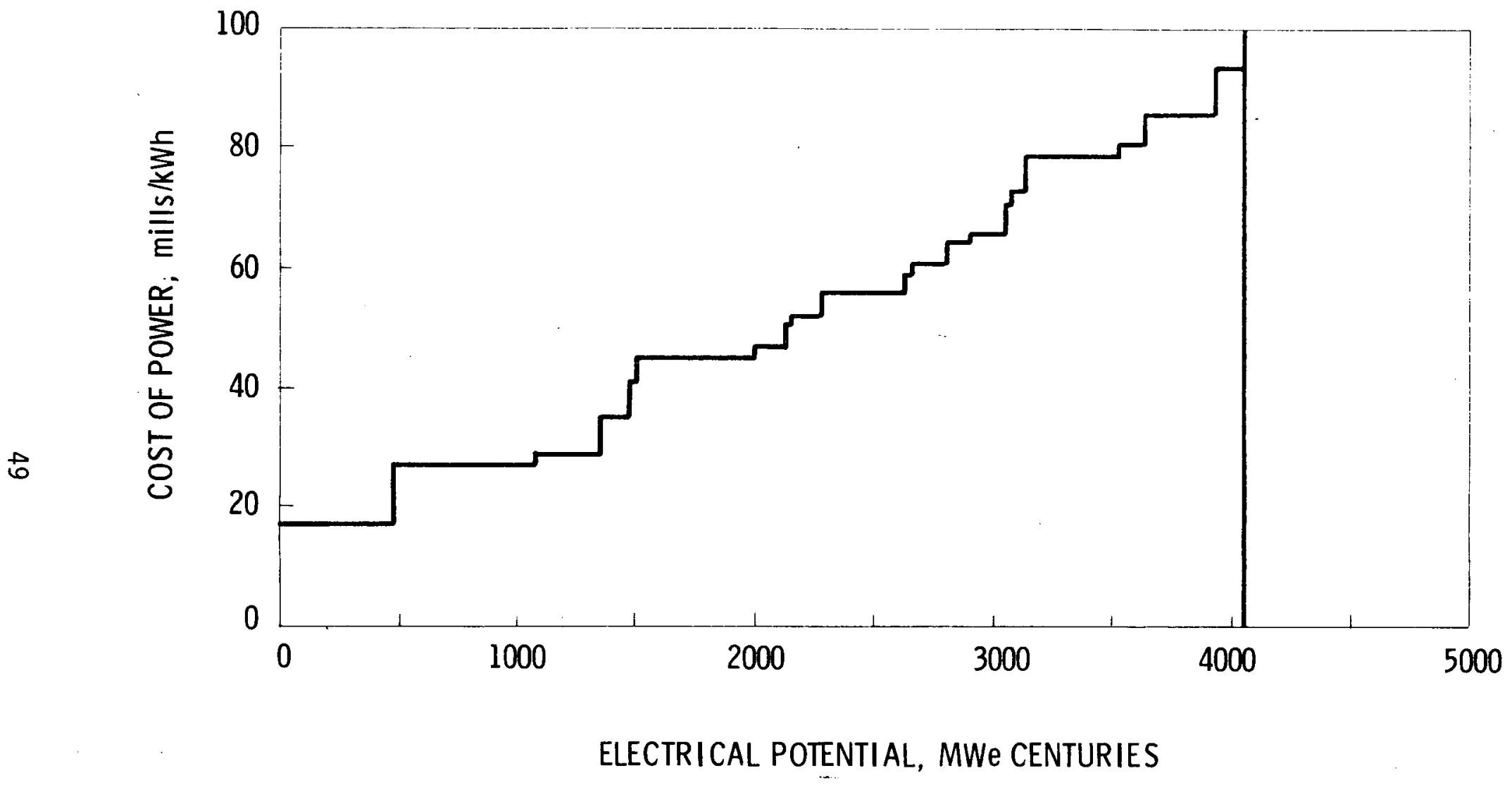

FIGURE 31. Supply Curve for Polymer Concrete Program (Reference Case) 


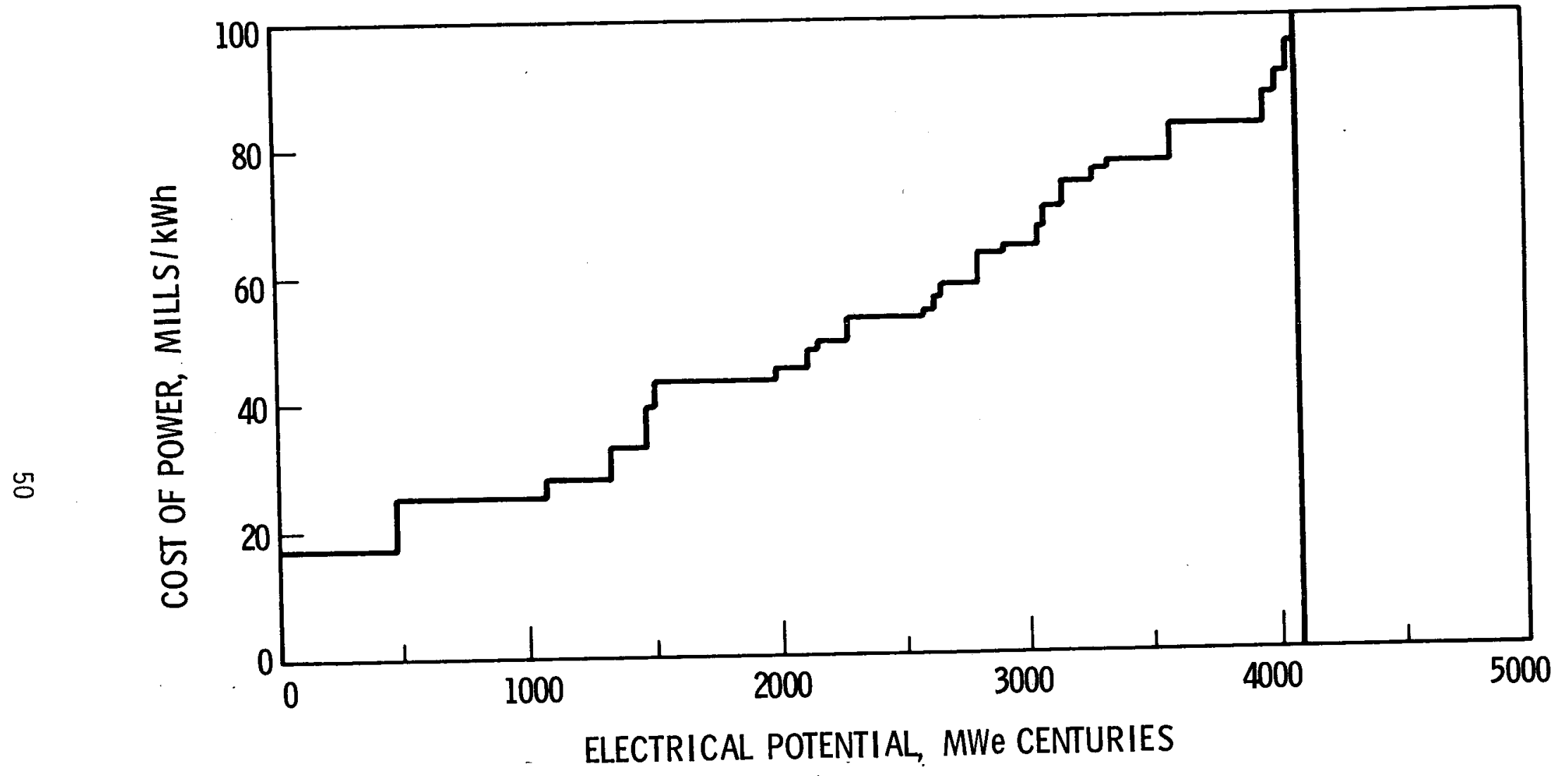

FIGURE 32. Supply Curve for Polymer Concrete Program (Polymer Concrete) 


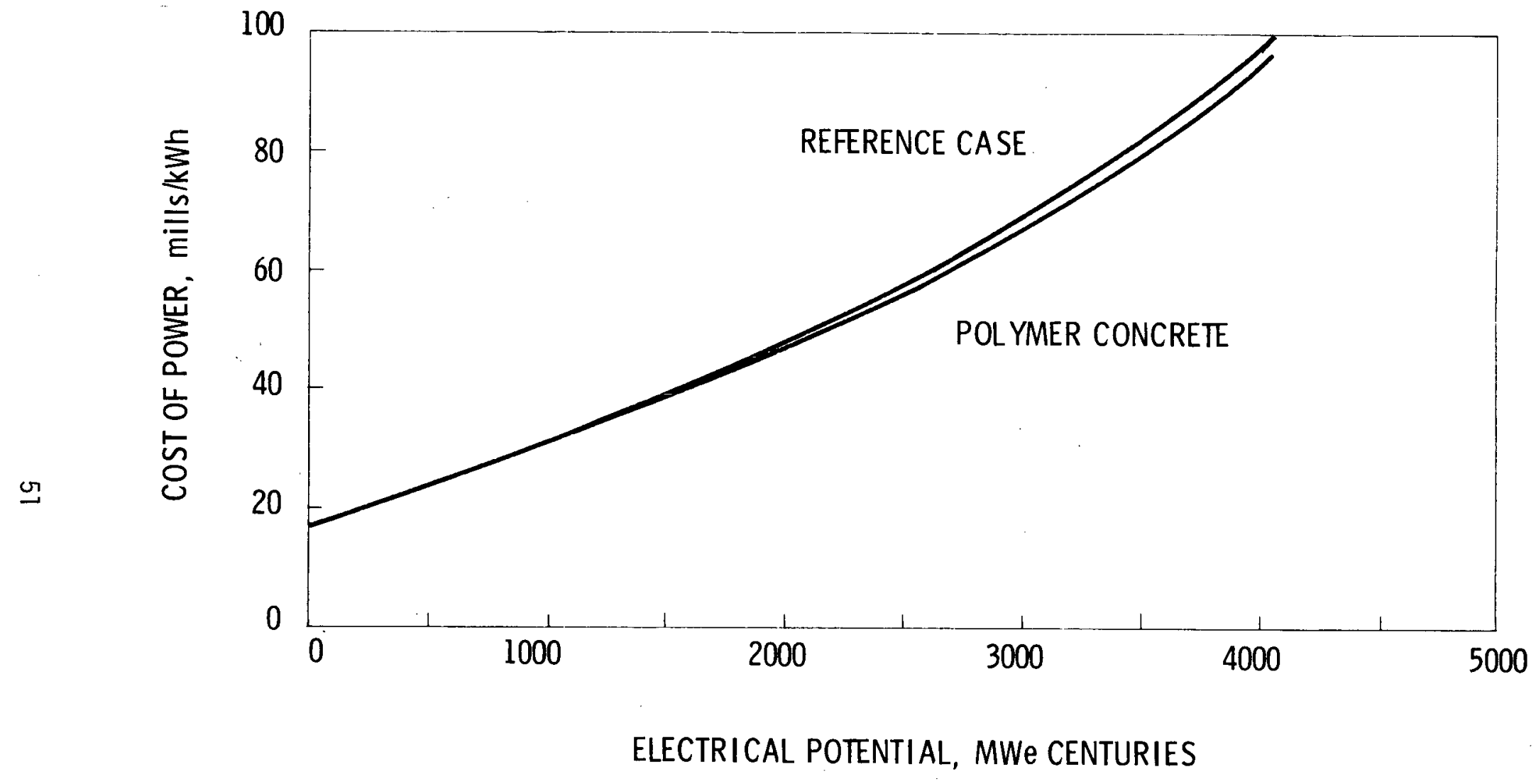

FIGURE 33. Supply Curves for Polymer Concrete Program 
OBJECTIVES: The objective of this program is to develop electrical and electrochemical probes that can measure the chemical environment of geothermal brine and steam under the high-pressure, high-temperature conditions of a geothermal well and associated piping. Downhole and inline probes will be developed to measure $\mathrm{CO}_{2}$, $\mathrm{pH}$, oxidation-reduction potential, conductivity, corrosivity, sulfide ion concentration, heat transport, and scale thickness. A reference electrode will also be developed. The probe package will have three practical effects:

(1) Prediction and control of corrosion,

(2) Prediction and control of scale deposition, and

(3) Prediction and control of pollution.

The cost of the complete probe package has been estimated to be $\$ 3700$. One package will be placed in each production well and one in each injection well. Also, spare equipment is needed in those spots where scaling is expected to occur. Thus, we also included costs for two wellhead steam separators per production well for the steam cycle, and two heat exchangers for the binary cycle.

There are two expected impacts from successful completion of this program:

(1) An increase in power plant load factor of $8-12 \%$ and

(2) A $75 \%$ reduction in operating and maintenance cost.

RESULTS: $\quad$ Figure 34 represents the current situation, i.e., a load factor of 0.70 and existing operating and maintenance costs. (Figure 34 is the same near-term supply curve presented in Figure 1.) Figure 35 represents a $75 \%$ reduction in $0 \& M$ costs and an $8 \%$ increase in load factor (up to 0.76 ). Figure 36 represents a $75 \%$ reduction in $0 \& M$ costs and a $12 \%$ increase in load factor (up to 0.78 ).

In Figure 37 we have plotted smooth curves to represent the three cases previously shown as step functions. As Figure 37 shows, the increase in load factor from 0.70 to 0.76 coupled with the reduced 0\&M costs will lower the cost of power by 3-10 mills/kWh, depending 
upon the resource temperature. At a mean cost reduction of 6.5 mills/ $\mathrm{kWh}$, this corresponds to an undiscounted savings of $\$ 17.5$ billion. The increase in load factor from 0.70 to 0.73 coupled with the reduced 0\&M costs will. lower the cost of power by $3-12 \mathrm{mill} / \mathrm{s} / \mathrm{kh}$, which at a mean cost reduction of $7.5 \mathrm{mills} / \mathrm{kWh}$ would correspond to a savings of $\$ 20$ billion (not discounted). 


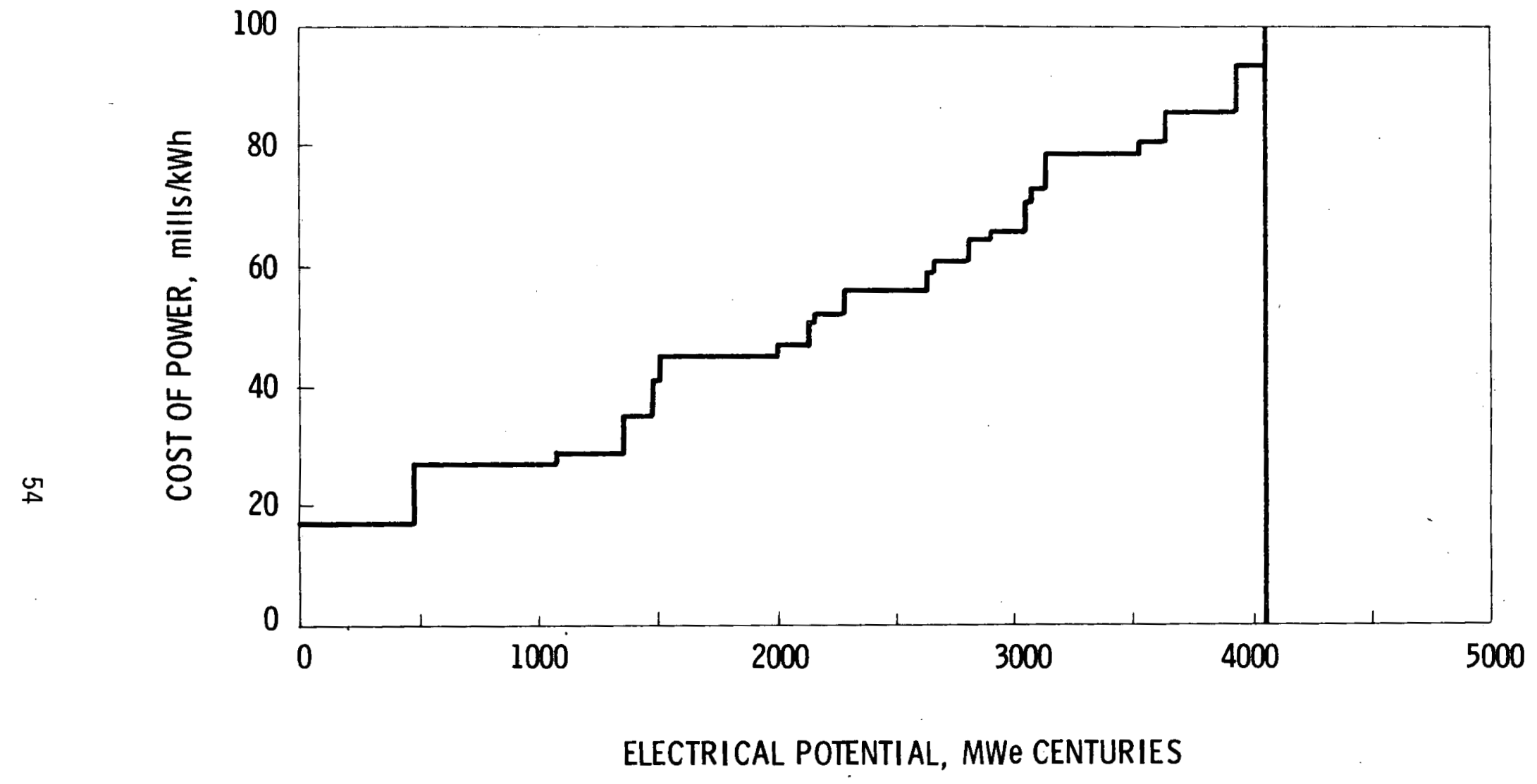

FIGURE 34. Supply Curve for Sampling and Monitoring Instrumentation and Control Equipment (Load Factor $=0,70)$ 


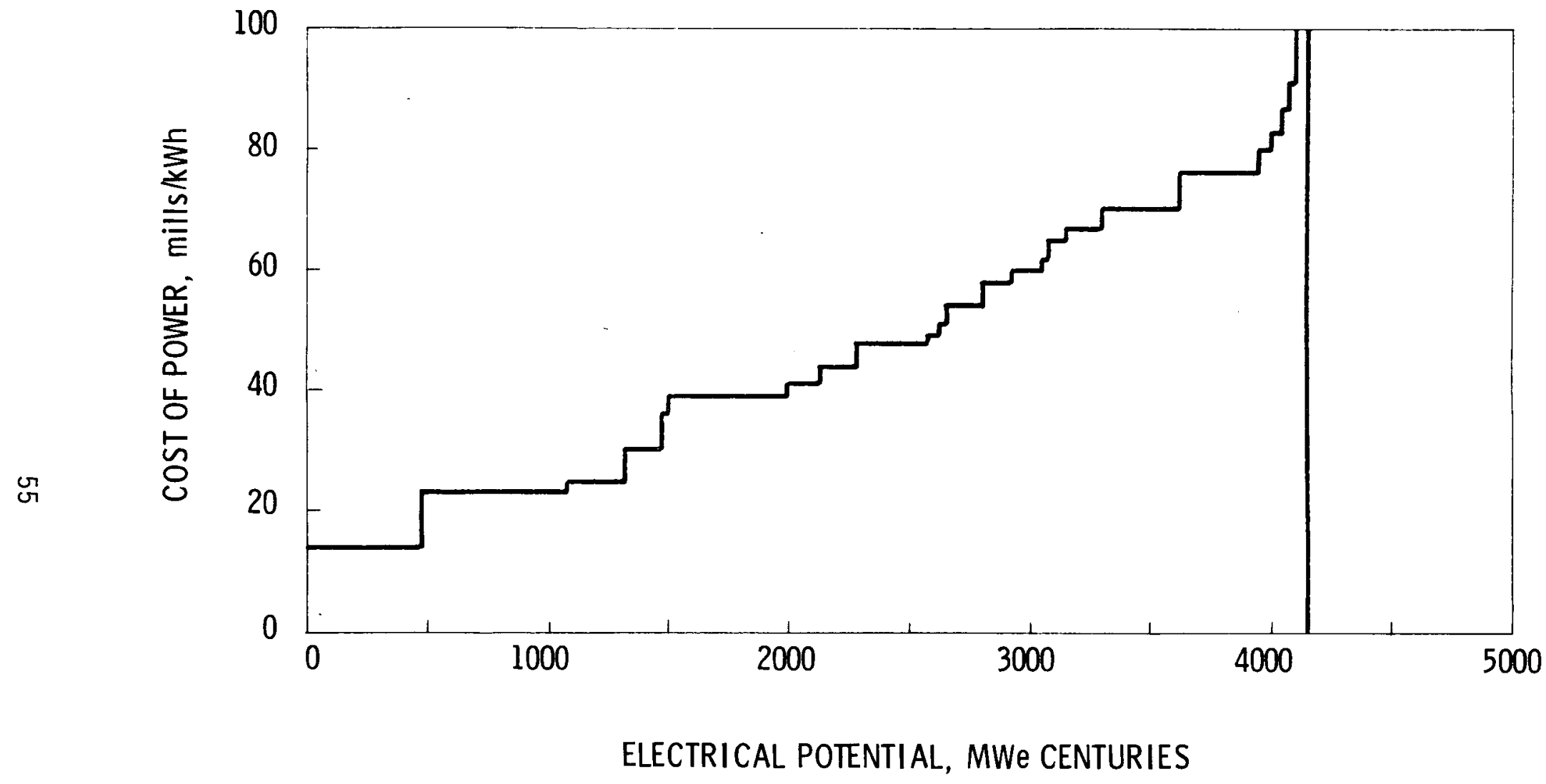

FIGURE 35. Supply Curve for Sampling and Monitoring Instrumentation and Control Equipment (Load Factor $=0.76)$ 


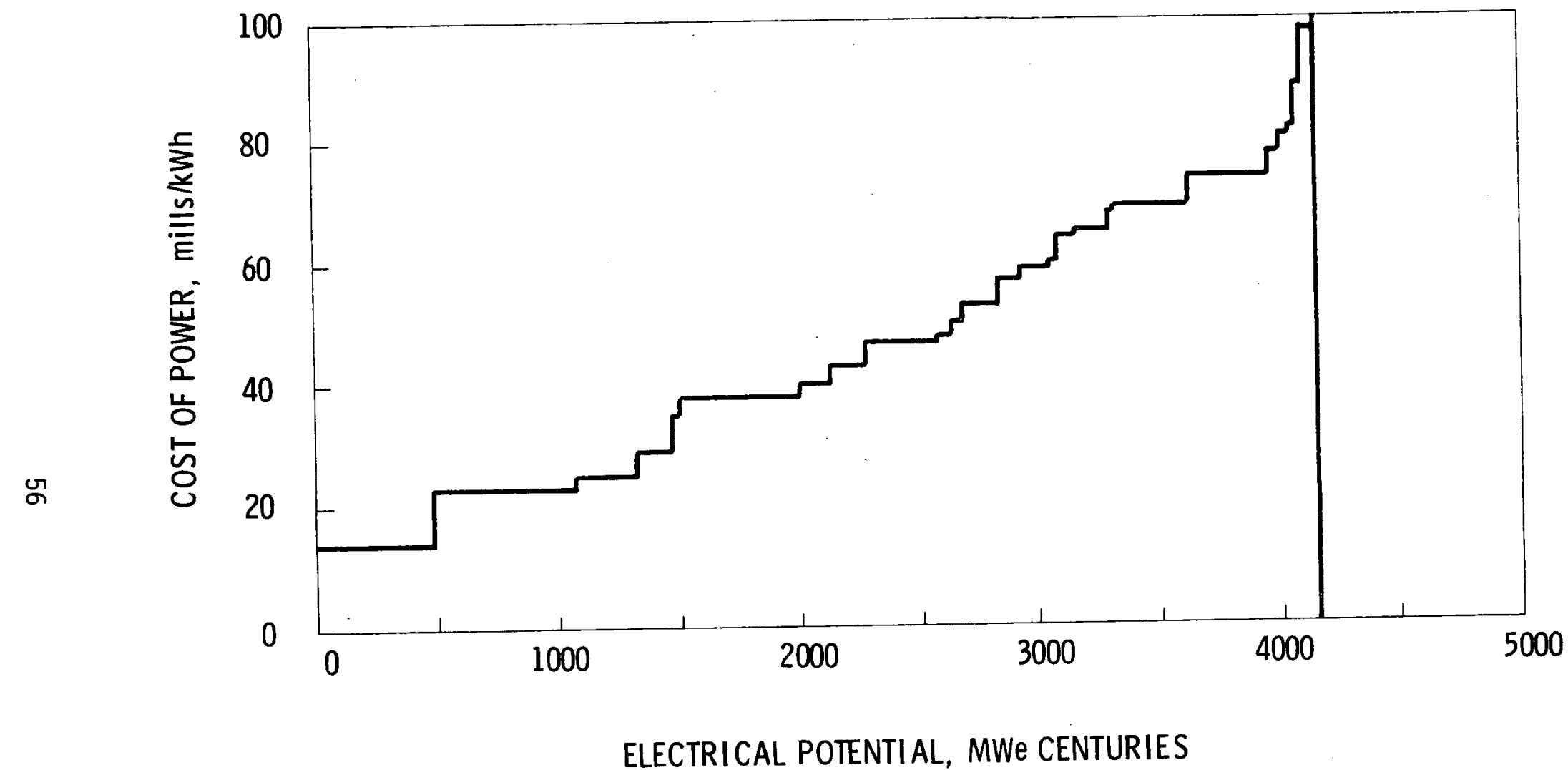

FIGURE 36. Supply Curve for Sampling and Monitoring Instrumentation and Control Equipment (Load Factor $=0.78$ ) 


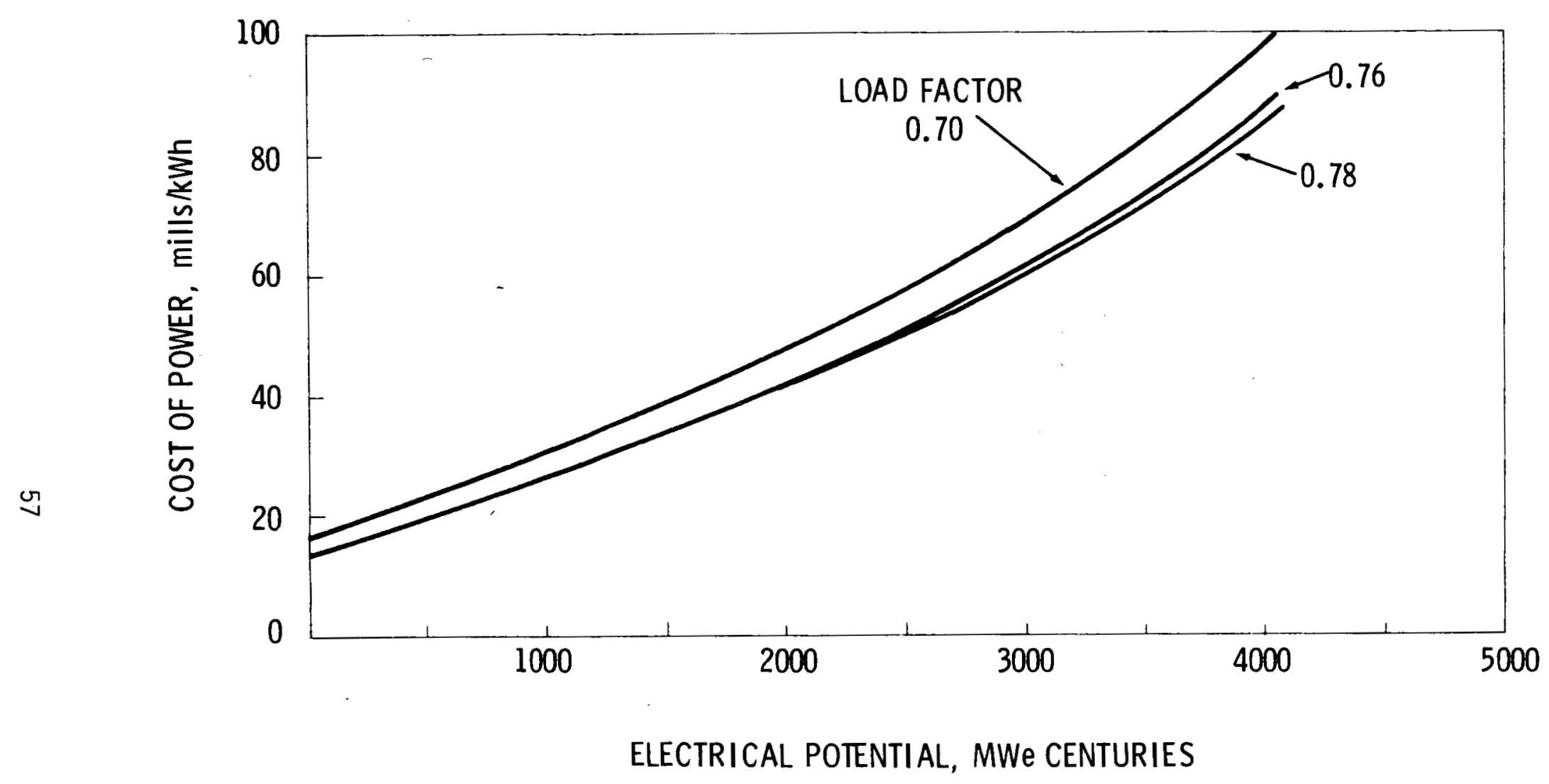

FIGURE 37. Supply Curves for Sampling and Monitoring Instrumentation and Control Equipment 
PROGRAM: GEOTHERMAL WELL CEMENTS

OBJECTIVES: To develop new cements for geothermal wells that will not break up in a $200^{\circ} \mathrm{C}+$ environment. This achievement could extend production wel1 1 ife by $30 \%$ for resources with temperatures above $200^{\circ} \mathrm{C}$. To model the results of this program, we assumed that production well life is currently 15 years on the average, and that this program could increase the well life to 19.5 years. We also doubled the cost of well cement currently used in the GEOCOST drilling model to represent the new, improved cement.

RESULTS: $\quad$ Figure 38 represents the current situation (the near-term supply curve, with a 15-year well life). Figure 39 represents the case where well 7 ife is 19.5 years and well cement cost is doubled. Figure 40 shows the smooth curves we drew based on the two step curves just discussed. As Figure 40 indicates, this program can lower the cost of power by 0.29-1.07 mills/ $/ \mathrm{kWh}$, depending upon the resource temperature. At a mean cost reduction of $0.7 \mathrm{mills} / \mathrm{kWh}$ this would correspond to a savings of $\$ 1.3$ billion (not discounted) in power production costs. 


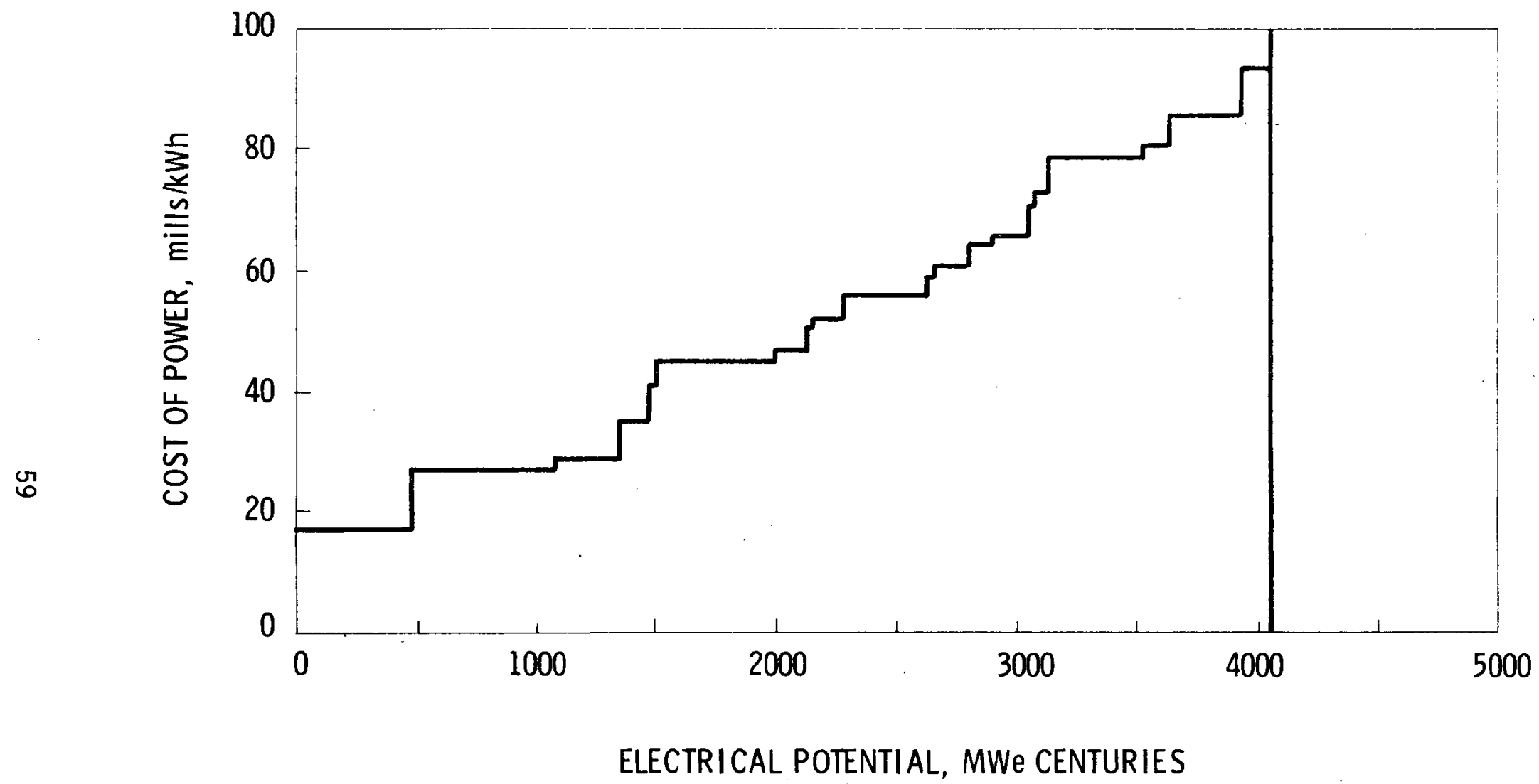

FIGURE 38. Supply Curve for Geothermal Well Cements Program (Existing Cement) 


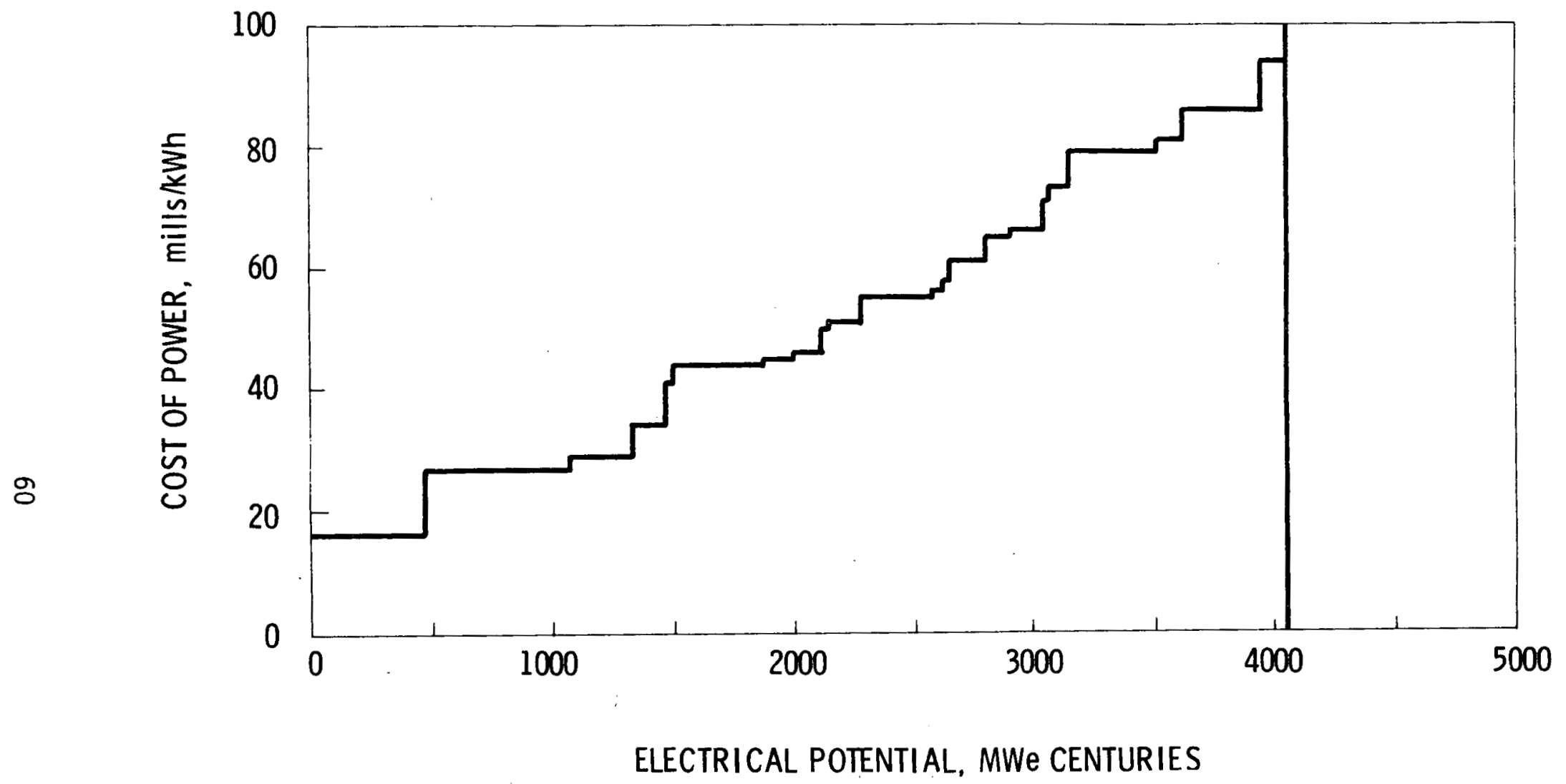

FIGURE 39. Supply Curve for Geothermal We11 Cements Program (New Cement) 


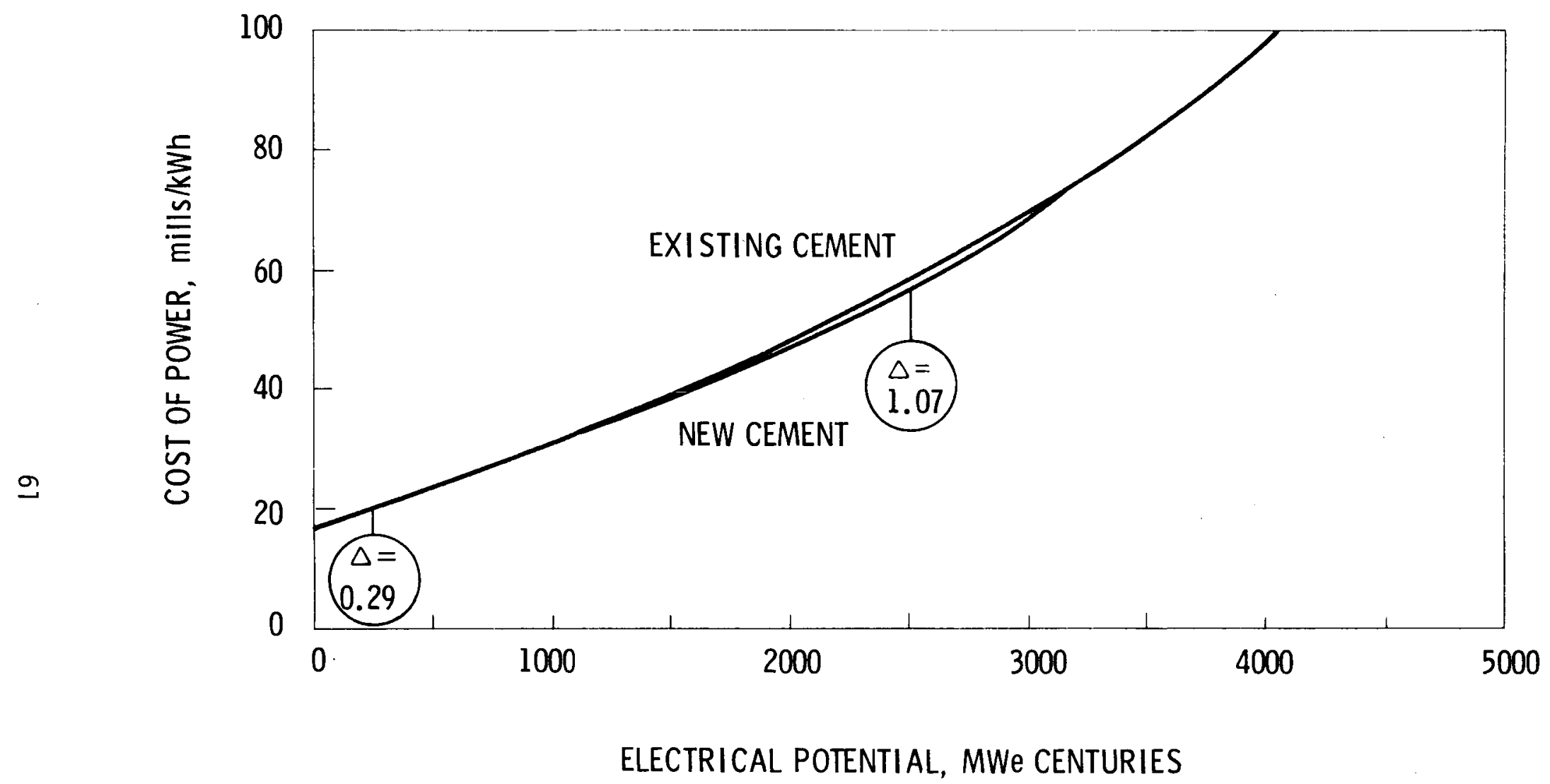

FIGURE 40. Supply Curves for Geothermal Well Cements Program 
PROGRAM: $\quad$ CERAMIC OR CEMENT CASINGS

OBJECTIVES: The objective of this program is to develop ceramic or cement casings to replace the steel casings currently used in geothermal wells. This achievement could reduce casing costs by $20 \%$.

RESULTS: $\quad$ Figure 41 shows the current situation, which means steel casing in the wells. Figure 42 shows the results when ceramic or cement casings are used, resulting in a $20 \%$ reduction in casing costs. Figure 43 shows smooth curves based on the two step curves. As indicated, the use of ceramic or cement casings could lower the cost of power by up to $1 \mathrm{mill} / \mathrm{kWh}$ for all of the resources, which amounts to a savings of about $\$ 1.24$ billion (not discounted). 


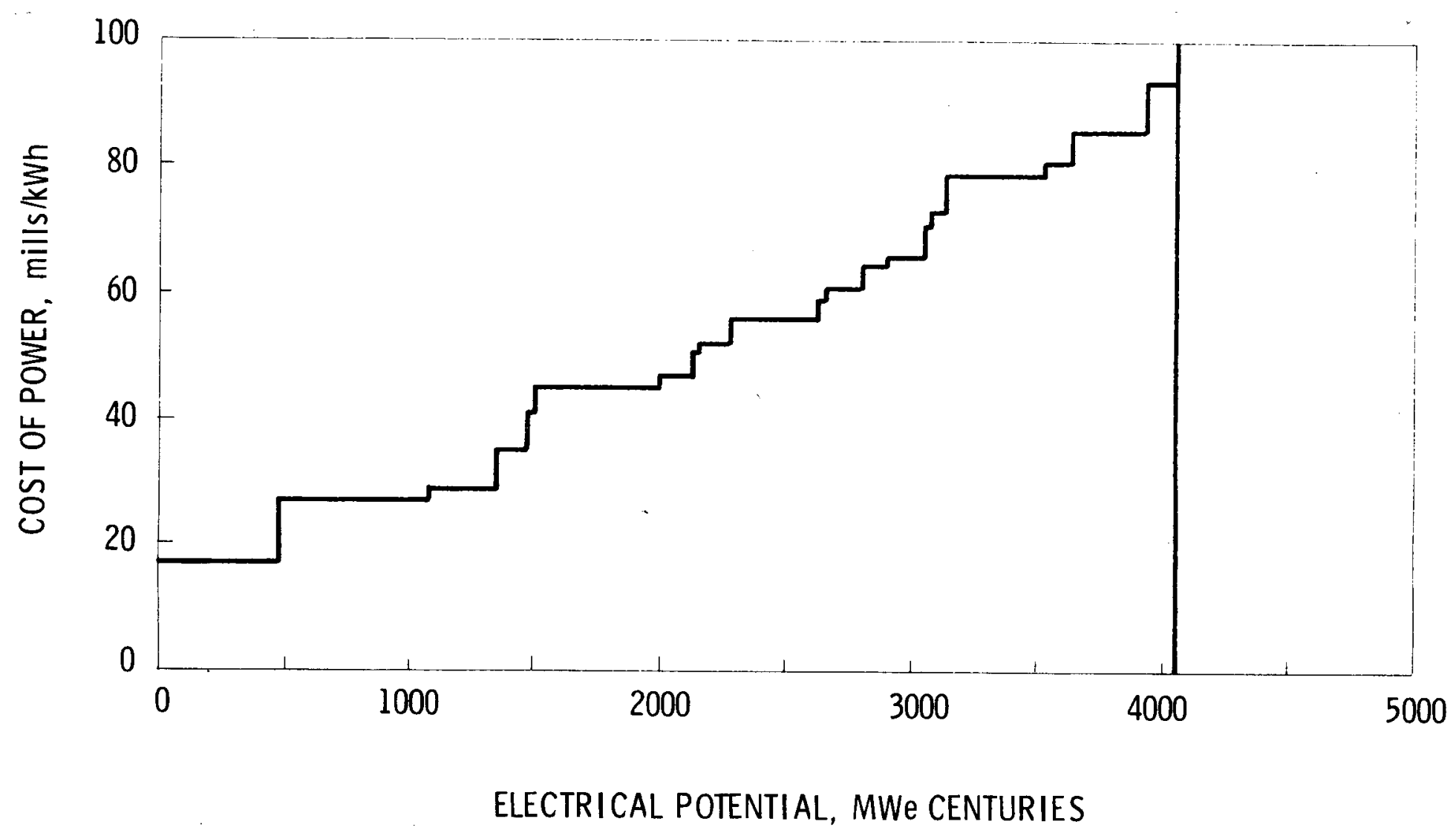

FIGURE 41. Supply Curve for Ceramic or Cement Casings Program (Steel Casing) 


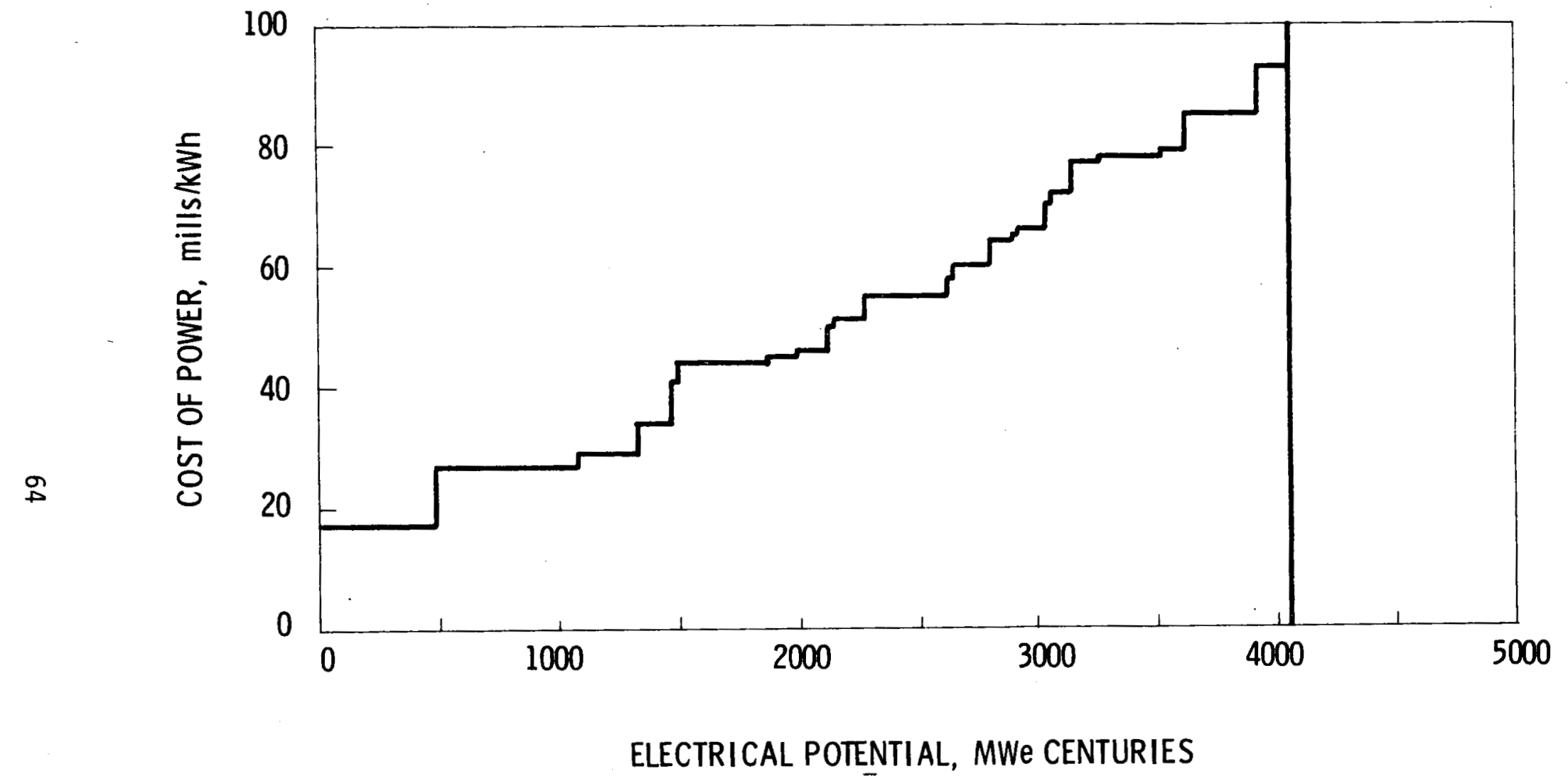

FIGURE 42. Supply Curve for Ceramic or Cement Casings Program (Ceramic or Cement Casing) 


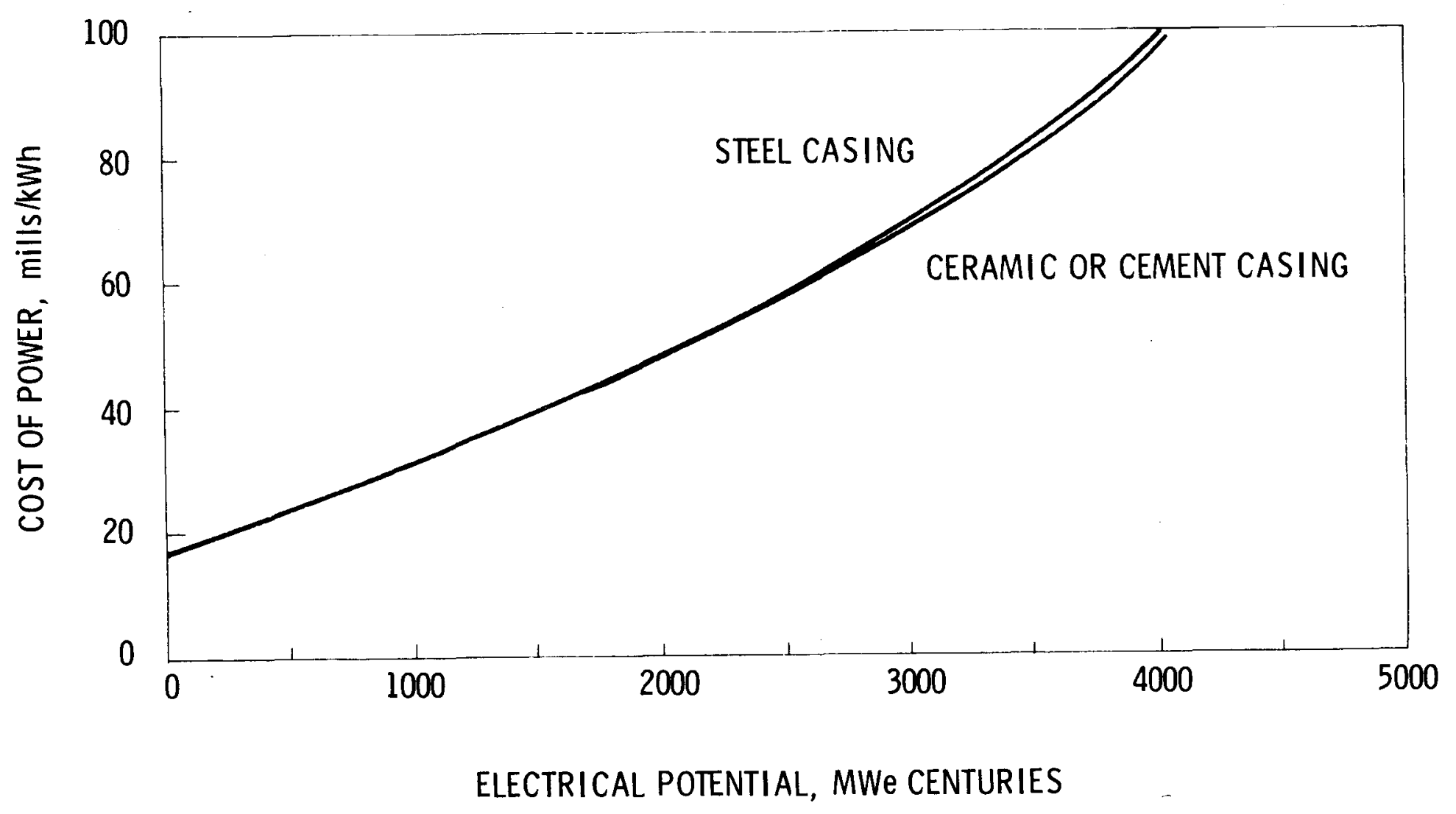

FIGURE 43. Supply Curves for Ceramic or Cement Casings Program 


\section{COMBINED IMPACTS OF ALL PROGRAMS}

Now that we have examined the impacts of the various R\&D programs one by one, we need to assess the combined impacts of all of them. Each program that we looked at showed a positive cost reduction in the neighborhood of $\$ 1$ billion or more (not discounted). Thus, we would expect that all of them taken together will exhibit a huge impact. Table 5 shows the timing assumed for the successful achievement of the various programs that were analyzed.

By 1982 we should achieve a $25 \%$ reduction in drilling costs, and we should have developed advanced downhole pumps, fluted-tube condensers, and new geothermal well cements that can withstand high-temperature environments. By 1985 we should achieve a 50\% reduction in drilling costs; we should have developed direct-contact heat exchangers, polymer concrete lining for vessels and pipes, downhole and inline probes, and ceramic or cement casing; and we should achieve a $50 \%$ reduction in the number of wells needed to prove a resource, a $50 \%$ increase in injection well life, and a $50 \%$ success ratio for exploration wells. By the year 2000 we should be at the point where only 3-5 wells are needed to prove a resource.

Figure 44 again shows the near-term supply curve, which represents the current state-of-the-art in electric applications of hydrothermal resources. Figure 45 shows the suppiy curve for the combined impacts of all programs expected to be successful by 1982. Figure 46 shows the supply curve for the combined impacts of all programs expected to be successful by 1985, which, of course, includes those objectives that are achieved in 1982 as we11. (We did not include the supply curve for the year 2000 since it was nearly identical to Figure 46, the 1985 curve.)

Figure 47 shows the smooth supply curves used to represent the step curves shown previously. As we expected, the impacts are extremely large. By 1982 we should see the cost of power drop by 2-30 mills/kWh, depending upon resource temperature. This amounts to an undiscounted cost reduction of between $\$ 5$ billion and $\$ 80$ billion. By 1985 we should see a reduction of 6-47 $\mathrm{mi} 11 \mathrm{~s} / \mathrm{kWh}$, or an undiscounted cost reduction of between $\$ 20$ billion and $\$ 158$ billion.

Another way to assess the situation is to return to our earlier benchmarks of 25-30 mi11s/kWh for new nuclear or coal plants. Figure 47 shows that currently about 900 MWe centuries of geothermal is competitive with $30 \mathrm{mill} / \mathrm{kWh}$ conventional power. However, by 1982 the amount is increased to about 1700 MWe centuries, and by 1985 it is up to 2800 MWe centuries. (This 2800 MWe centuries corresponds to about 9,330 MWe or 187 geothermal plants of 50 MWe each.) Again, this potential market penetra- 
TABLE 5. Timing for Technology Improvements

1982

$25 \%$ reduction in drilling costs

Advanced downhole pumps

Fluted-tube condensers

New geotherma 1 well cements

$\underline{1985}$

$50 \%$ reduction in drilling costs

Direct-contact heat exchangers

Polymer concrete lining for vessels and pipes

Downhole and inline probes

Ceramic or cement casing

$50 \%$ reduction in number of wells needed to prove a resource

$50 \%$ increase in injection well 1 ife

$50 \%$ success ratio for exploration wells

$\underline{2000}$

Oniy 3-5 wells needed to prove a resource 


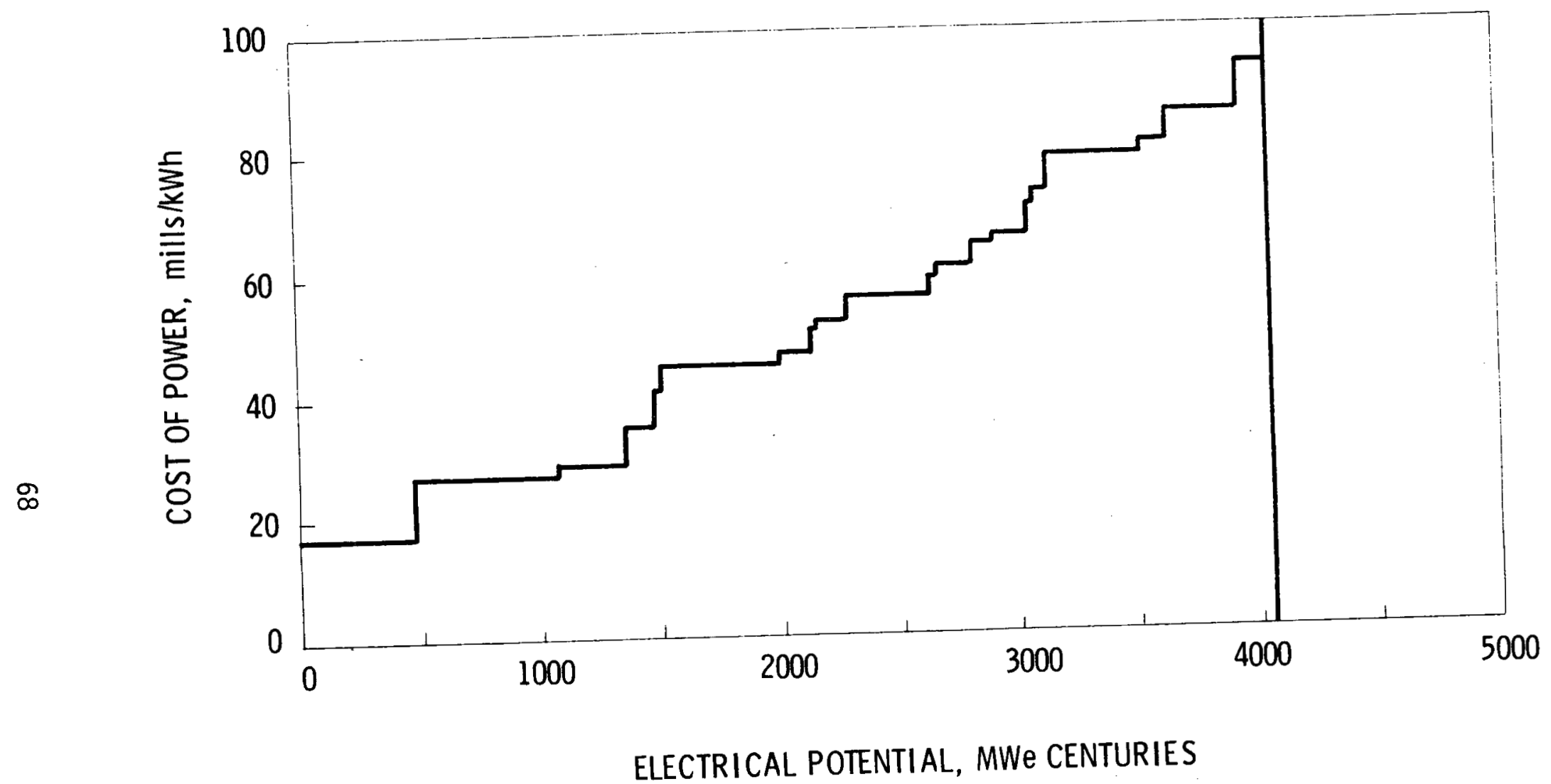

FIGURE 44. Near-Term Supply Curve for Electric Applications of Hydrothermal Resources 


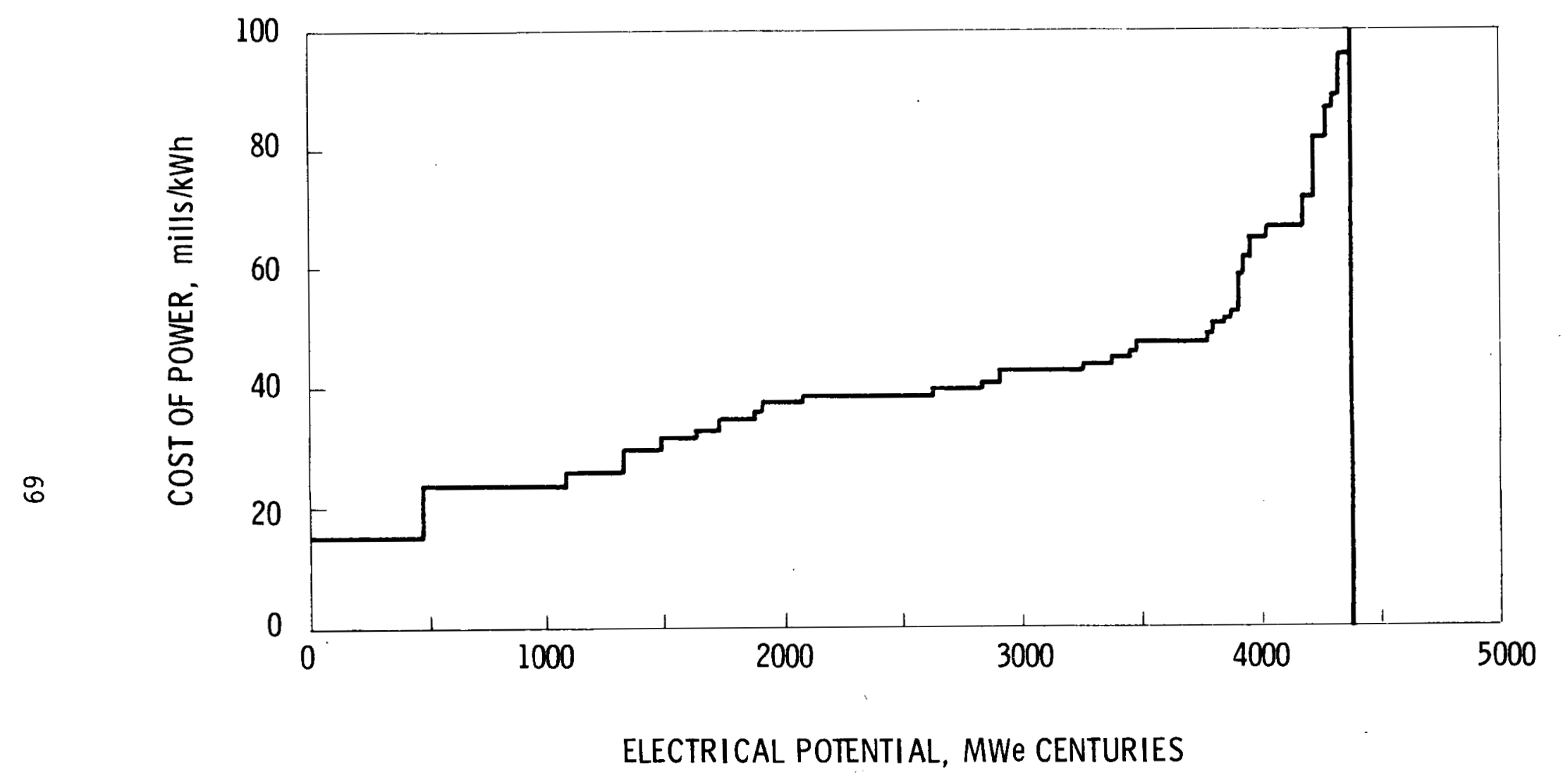

FIGURE 45. Supply Curve for Combined Impacts of A11 Programs (1982) 


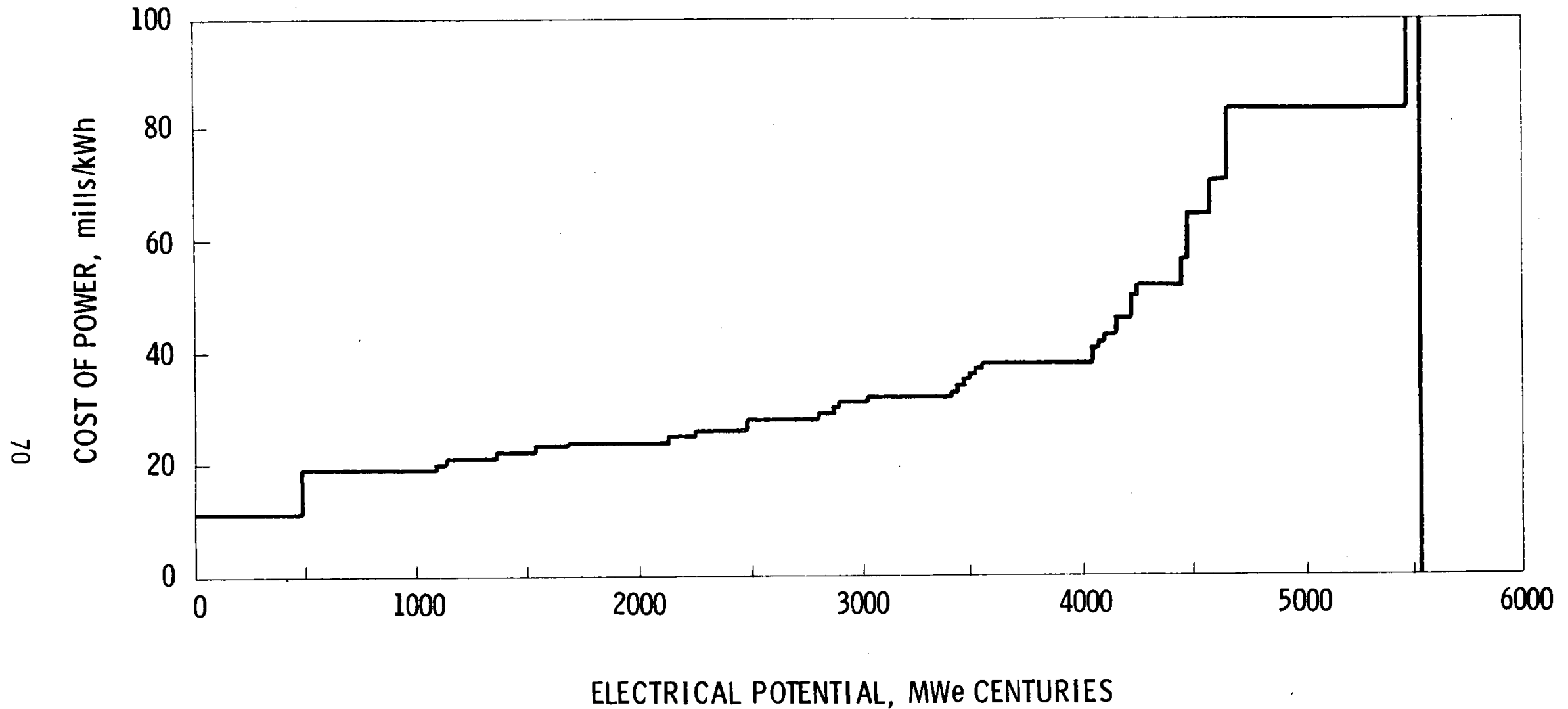

FIGURE 46. Supply Curve for Combined Impacts of A11 Programs (1985) 


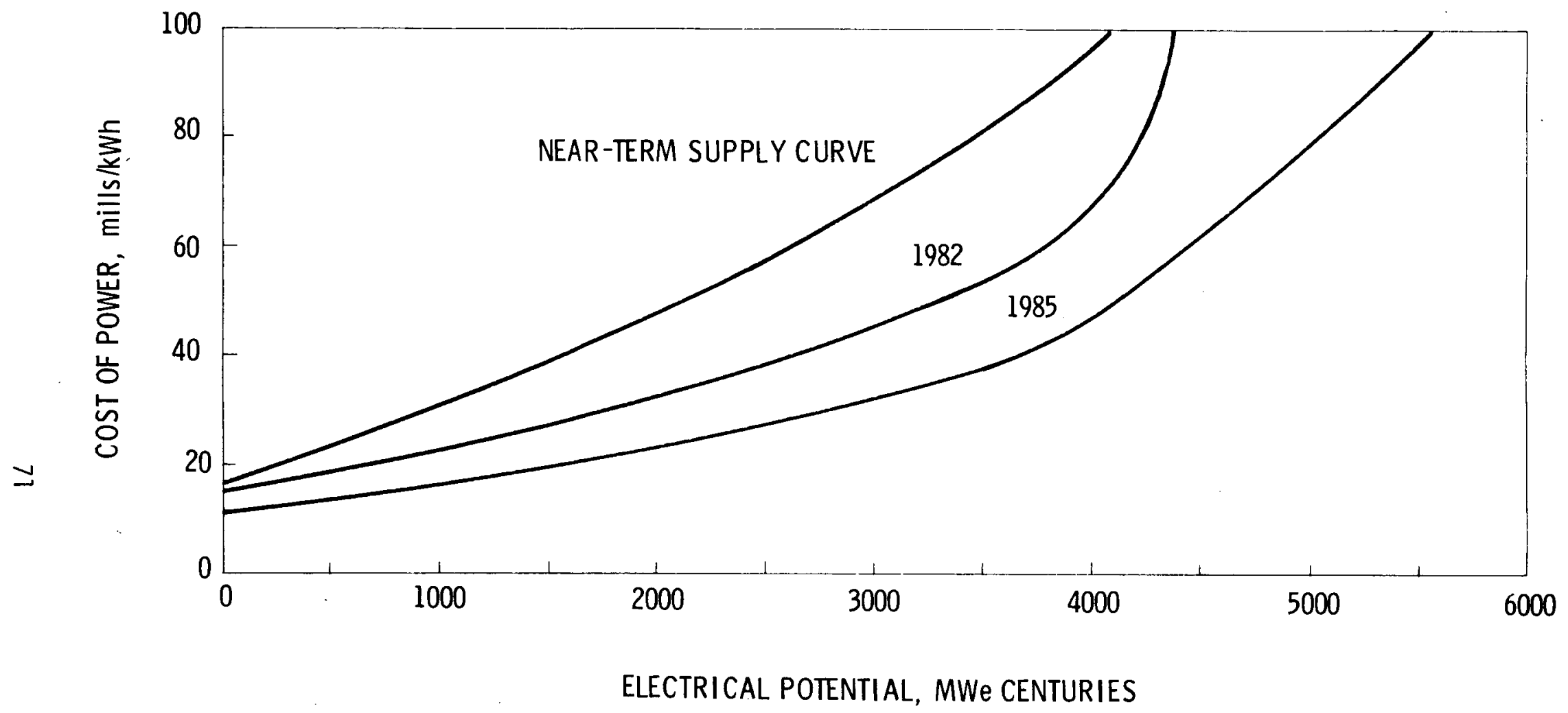

FIGURE 47. Supply Curves for Combined Impacts of A11 Programs 
tion pertains to identified resources only; if some of the inferred resources are discovered, the potential penetration is much larger. Clearly, the technology improvements being pursued by DGE would not only lower the cost of power at specific sites, but they would substantially increase the competitiveness of all of the hydrothermal resources. The shifting of the near-term supply curve downward and to the right is very dramatic. However, even with these dramatic improvements, substantial amounts of hydrothermal resources would remain uncompetitive; additional technology improvements, increases in the costs of conventional energy sources, and tax subsidies would be required to make these resources competitive. 


\section{STEAM CYCLE TECHNOLOGIES}

As explained previously, our supply curves are based on the use of a steam cycle for all resources with subsurface temperatures greater than $175^{\circ} \mathrm{C}$. We assumed that current state-of-the-art technology consists of flashing in the well bore and steam separation at the wellhead. The wel Thead separator temperature is defined to be the average of the subsurface temperature and the turbine exhaust temperature $\left(124^{\circ} \mathrm{F}\right)$. The separator temperatures used for the various resource temperatures are shown in Table 6.

TABLE 6. Wel lhead Separator Temperatures and Steam Contents

\begin{tabular}{ccc}
$\begin{array}{c}\text { Subsurface } \\
\text { Temperature, } \\
{ }^{\circ} \mathrm{C}\end{array}$ & $\begin{array}{c}\text { Separator }(a) \\
\text { Temperature, } \\
{ }^{\circ} \mathrm{C}\end{array}$ & $\begin{array}{c}\text { Steam } \\
\text { Content, } \\
\text { Wt.\% }\end{array}$ \\
\cline { 2 - 3 } 275 & 163 & 25.2 \\
265 & 158 & 23.6 \\
255 & 153 & 22.0 \\
230 & 141 & 18.6 \\
225 & 138 & 17.9 \\
220 & 136 & 17.3 \\
215 & 133 & 16.6 \\
205 & 128 & 15.4 \\
200 & 126 & 14.9 \\
190 & 121 & 13.7 \\
180 & 116 & 12.6
\end{tabular}

(a) Separator Temperature $=(\mathrm{ST}+\mathrm{TET}) / 2$, where $S T$ = subsurface temperature $T E T=$ turbine exhaust temperature $=124^{\circ} \mathrm{F}=51^{\circ} \mathrm{C}$ 
We also analyzed two alternate technologies for steam plants:

(1) Steam separation at the wellhead, transmission of the steam phase and the water phase to the plant in separate pipes, flashing of the water phase at the plant, and sending both the separated steam and the flashed steam to the turbine. This technology is planned for Ahuachapan, El Salvador for 1980.

(2) Use of advanced downhole pumps in the wells, transmission of pressurized water to the plant, and 2-stage flashing at the plant.

The results of these analyses are shown in Table 7 and Table 8, for two different resource temperatures.

TABLE 7. Comparison of Three Steam Cycle Technologies for a $275^{\circ} \mathrm{C}$ Resource

Technology

Wellhead Separator

Wellhead Separator and Flash at Plant

2-Stage Flash at Plant
Cost of Power, Mills/kWh

31

29

25

TABLE 8. Comparison of Three Steam Cycle Technologies for a $180^{\circ} \mathrm{C}$ Resource

Technology

Wellhead Separator

Wellhead Separator and Flash at Plant

2-Stage Flash at Plant
Cost of Power, Mills/kWh

54

The use of 2-stage flashing at the plant rather than steam separation at the wellhead will reduce the cost of power generated from a $275^{\circ} \mathrm{C}$ resource by $19 \%$. It will reduce the cost of power generated from a $180^{\circ} \mathrm{C}$ resource by $48 \%$. This technology would require advanced downhole pumps to prevent flashing in the wells. The large cost reductions that would accrue are ample incentives to encourage the development of advanced downhole pumps. 


\section{CONCLUSIONS}

Certain R\&D programs analyzed in this report show much larger impacts on the near-term supply curve for geothermal electrical potential than others do. However, this does not imply that those programs with lesser impacts should be sacrificed. It is not possible to know with certainty which of the programs will actually be successfully completed within the expected time periods. Each program has some probability of success and some probability of failure, so it is best to increase the overall probability of success by pursuing as many options as possible, as long as each option yields a positive cost savings.

If all of the objectives discussed in this report are achieved, then the amount of geothermal electric power that is competitive with nuclear and coal will triple by 1985. This would be an impressive accomplishment for DOE in their goal of commercialization of the hydrothermal resources. 


\section{ACKNOWLEDGMENTS}

The authors gratefully acknowledge the programming contributions of Harlan Huber and the assistance of Marcel Ballinger in preparing many of the supply curves. 
1. L. L. Fassbender and C. H. Bloomster, Near-Term Geothermal Energy Supply Curves and the Impacts of Technology. PNL-2753, Battelle, Pacific Northwest Laboratory, Richland, WA 99352, September 1978.

2. C. H. Bloomster, et al., GEOCOST: A Computer Program for Geothermal cost Analysis. BNWL-1888, Battelle, Pacific Northwest Laboratory, Richland, WA 99352, February 1975.

3. L. J. P. Muffier, Assessment of Geothermal Resources of the United States-1978. U.S. Geological Survey Circular 790, February 1979.

4. C. H. Bloomster and C. A. Knutsen, The Economics of Geothermal Electricity Generation from Hydrothermal Resources. BNWL-1989, Battelle, Pacific Northwest Laboratories, Richland, WA.

5. C. H. Bloomster and R. L. Engel, The Potential Benefits of Geothermal Electrical Production from Hydrothermal Resources BNWL-2001, Battelle, Pacific Northwest Laboratory, Richland, WA, June 1976.

6. D. E. White and D. L. Williams, Assessment of Geothermal Resources of the United States - 1975. U.S. Geological Survey Circular 726, 1975.

7. Status Report - Geothermal Program Definition Project - Part II: Geothermal Energy Deve Topment Status. 1200-205, Jet Propulsion Laboratory, Pasadena, CA, Apri1 4, 1975.

8. Program Definition for the Development of Geothermal Energy. 5040-6, Jet Propulsion Laboratory, Pasadena, CA, August 29, 1975.

9. C. H. Bloomster and C. A. Knutsen, Downhole Pump Benefit Cost Analysis, Battelle, Pacific Northwest Laboratory, Richland, $M A$, letter and report to Inja Paik, October 8, 1976.

10. Economic Assessment of Polymer Concrete Usage in Geothermal Power Plants, BNL 50777, Burns \& Roe Industrial Services Corporation, Paramus, New Jersey, November 1977.

11. Conceptual Design of Commercial 50 MNe (net) Geothermal Power Plants at Heber and Niland, California, SAN-1124-1, Bechtel Corporation, San Francisco, CA, October 1976. 
PNL-3072

UC $-66 i$

\section{DISTRIBUTION}

iNo. of

Copies

No. of

Copies

OFFSITE

OFFSITE

DOE Chicago Patent Group

Department of Energy

Argonne, IL 60439

A. A. Churm

10 Resource Applications

Department of Energy

Washington, D.C. 20545

Dr. Fred Abel

453 DOE Technical Information

Center

ONSITE

Japan Geothermal Energy

Association

Yurakucho Denki Building

1-7-1 Yuraku-Cho Chiyoda-Ku

Tokyo, Japan

Pete Sherwood

WESTEC Services, Inc.

3211 Fifth Avenue

San Diego, CA 92103

Jim Johnson

Westinghouse Electric Corp. Hendy Avenue, Mailstop Bldg. 71-37

Sunnyvale, CA 94088

W. Ogle

Energy Systems, Inc.

4510 International Airport

Road

Anchorage, AK 99502

Vasel Roberts

Electric Power Research

Institute

$3412 \mathrm{Hillview}$ Avenue

Palo Alto, CA 94304

Elliott Zais

7915 N. W. Siskin Drive

Corvallis, OR 97330

Syd Willard

Energy Resources

Conservation \& Development

Commission

1111 Howe Avenue

Sacramento, CA 95825

DOE Richland Operations Office

H. E. Ransom

Pacific Northwest Laboratory

M. Y. Ballinger

C. H. Bloomster (30)

J. B. Burnham

J. W. Currie

D. E. Deonigi

L. L. Fassbender (30)

H. D. Huber

S. A. Weakley

K. D. Wells

L. D. Williams

T. L. Willke

Economics Library (3)

Technical Information (5)

Publishing Coordination (2) 